Nancy Kazumi Taniguchi

\title{
Reconstituição paleoceanográfica e inferências \\ paleoclimáticas na margem equatorial Brasileira no \\ Holoceno Médio e Tardio
}

Dissertação apresentada ao Instituto Oceanográfico da Universidade de São Paulo, como parte dos requisitos para obtenção do título de Mestre em Ciências, área de Oceanografia Geológica.

Orientadora:

Prof. Dra. Silvia Helena de Mello e Sousa

São Paulo 


\section{Universidade de São Paulo \\ Instituto Oceanográfico}

Reconstituição paleoceanográfica e inferências paleoclimáticas na margem equatorial Brasileira no Holoceno Médio e Tardio

(versão corrigida)

\section{Nancy Kazumi Taniguchi}

Dissertação apresentada ao Instituto Oceanográfico da Universidade de São Paulo, como parte dos requisitos para obtenção do título de Mestre em Ciências, área de Oceanografia Geológica.

Julgada em ___ I__

$\operatorname{Prof}(\mathrm{a}) \cdot \operatorname{Dr}(\mathrm{a})$.

Conceito

$\operatorname{Prof}(\mathrm{a}) . \operatorname{Dr}(\mathrm{a})$

Conceito

$\operatorname{Prof}(a) . \operatorname{Dr}(a)$.

Conceito 


\section{Sumário}

Resumo xiii

$\begin{array}{ll}\text { Abstract } & \text { xiv }\end{array}$

1 Introdução 1

1.1 Foraminíferos plantônicos .................. 6

1.2 Razão $\mathrm{Mg} / \mathrm{Ca}$ em foraminíferos planctônicos . . . . . . . . . . . . 8

1.3 Isótopos estáveis de oxigênio e carbono . . . . . . . . . . . . . . 10

1.4 Carbonato de cálcio $\left(\mathrm{CaCO}_{3}\right) \ldots \ldots \ldots \ldots$

1.5 Elementos inorgânicos em sedimento . . . . . . . . . . . . 13

1.6 Granulometria e sortable silt . . . . . . . . . . . . . . . . 15

2 Objetivos 17

3 Área de estudo $\quad 18$

3.1 Condições oceanográficas atuais . . . . . . . . . . . . . . 18

3.2 Bacia de drenagem do rio Parnaíba . . . . . . . . . . . . . . . . . 24

3.3 Clima da região nordeste brasileira durante o Holoceno . . . . . . . . . . 31

3.4 Flutuações do nível relativo do mar na região nordeste brasileira durante o Holoceno .......................... 33

4 Materiais e Métodos $\quad 36$

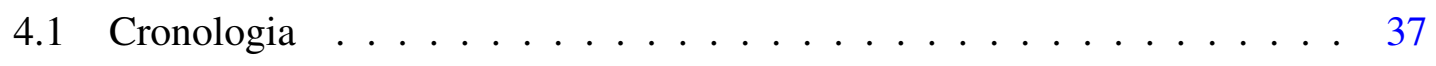

4.2 Análise sedimentológica . . . . . . . . . . . . . . . . 37

4.3 Análises geoquímicas . . . . . . . . . . . . . . . . . 38

4.3.1 Conteúdo de carbonato de cálcio $\left(\mathrm{CaCO}_{3}\right) \ldots \ldots$. . . . . . . 38

4.3.2 Elementos inorgânicos no sedimento - Fe, Ti e Ca . . . . . . . . 38

4.3.3 Determinação da razão $\mathrm{Mg} / \mathrm{Ca}$ e isótopos estáveis de oxigênio em foraminíferos planctônicos . . . . . . . . . . . . 39 
4.3.4 Estimativa da temperatura (TSM) e salinidade da superfície do $\operatorname{mar}(\mathrm{SSM}) \ldots \ldots \ldots \ldots \ldots \ldots$

5 Resultados $\quad 43$

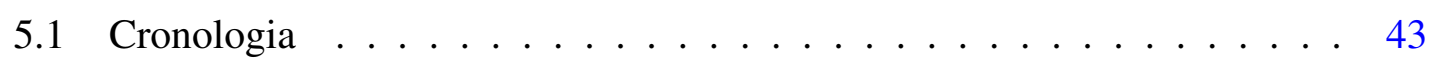

5.2 Análise sedimentológica . . . . . . . . . . . . . . 45

5.3 Análises geoquímicas . . . . . . . . . . . . . . . . . . . 47

5.3.1 Conteúdo de $\mathrm{CaCO}_{3}(\%) \ldots \ldots \ldots 47$

5.3.2 Elementos inorgânicos no sedimento - Ti, Fe e Ca . . . . . . . . 48

5.3.3 Razão elementar $\mathrm{Mg} / \mathrm{Ca}$ e $\mathrm{Al} / \mathrm{Ca}$ em foraminíferos planctônicos . 49

5.3.4 Razão $\mathrm{Mg} / \mathrm{Ca}$, isótopos estáveis de oxigênio em foraminíferos planctônicos, TSM e SSM . . . . . . . . . . . 50

5.3.5 $\delta^{18} \mathrm{O}$ e $\delta^{13} \mathrm{C}$ dos morfotipos Globigerinoides ruber (s.1.) e Globigerinoides ruber (s.s.) . . . . . . . . . . . . 52

6 Discussão $\quad 54$

6.1 Comparação dos resultados de elementos químicos a partir de XRF e digestão total . . . . . . . . . . . . . . . . . . . 54

6.2 Comparação entre sinais isotópicos dos morfotipos G. ruber (s.1.) e G. ruber (s.s.) ............................. 55

6.3 Discussão no contexto Paleoceanográfico e Paleoclimático . . . . . . . . 56

6.4 Holoceno Médio . . . . . . . . . . . . . . . . . . . . . . 59

6.4.1 Primeiro período ( 8100 anos cal A.P. até 5000 anos cal. A.P.) . 59

6.5 Holoceno Médio - Tardio . . . . . . . . . . . . . . . . . . . 63

6.5.1 Segundo período ( 5000 anos cal A.P. até 2500 anos cal. A.P.) 63

6.6 Holoceno Tardio . . . . . . . . . . . . . . . . . . . . 68

6.6.1 Terceiro período (2500 anos cal A.P. até o presente) . . . . . . . . 68

6.7 Propriedades hidrográficas de superfície do mar: temperatura e salinidade, durante os últimos 5000 anos . . . . . . . . . . . . . . . 70 
Referências

74 


\section{Lista de Figuras}

1 Foto ilustrativa dos dois morfotipos da espécie Globigerinoides ruber (white).

1-4: Globigerinoides ruber s.s.; e 5-9: Globigerinoides ruber s.1... Adaptado de Wang (2000). . . . . . . . . . . . . . . . . . 8

2 Relação entre tamanho de partícula de sedimentos finos com velocidade de corrente estabelecido por Ledbetter's (1986) apud McCave (2008) para Vema Channel no Atlântico Sul. Gráfico adaptado de McCave (2008). . . . . . . . . . . . 16

3 Área de estudo e posição geográfica do testemunho GeoB 16204-2. (A) Localização do testemunho GeoB 16204-2 em vermelho $(\bullet)$, na latitude $1^{\circ} 59.75 ’ S$ e longitude $42^{\circ} 20.30$ 'W. (B) Desenho esquemático das correntes de superfície da região tropical do Atlântico, configuração característica do período entre Julho e Setembro quando a Contracorrente Norte Equatorial (CCNE) flui em direção à leste. As demais correntes são: Corrente Sul Equatorial (CSE), Corrente do Brasil (CB), Corrente Norte do Brasil (CNB), Corrente Norte Equatorial (CNE). Figura adaptada de Philander (2001). . . . . . . . . . . . . . . . . . . 20

4 Diagrama T-S para a latitude $2.125^{\circ} \mathrm{S}$ e longitude $42.125^{\circ} \mathrm{W}$, dados provenientes do World Ocean Atlas 2013 (Levitus et al 2013). As massas d'água presentes nos primeiros 1500 m são: Água Tropical (AT), Água Central do Atlântico Sul (ACAS) e Água Intermediária Antártica (AIA) . . . . . . . . . . . . . . 22

5 Média referente ao período de 1955 a 2012 de temperatura e salinidade da superfície do mar para os meses entre Janeiro a Março e Julho a Setembro provenientes do World Ocean Atlas 2013, Levitus et al. (2013). . . . . . . . . . . . 23

6 Localização da Bacia do Parnaíba, adaptado de Caderno da Região Hidrográfica do Parnaíba, Ministério do Meio Ambiente, Secretaria de Recursos Hídricos Brasília: MMA (2006). . . . . . . . . . . . . . . . . . . . . 24

$7 \quad$ Imagem de satélite do delta do Parnaíba, adaptado de Szczygielski et al (2014) 25 
8 Painéis à esquerda: precipitação média de longo prazo em escala de cinza, valores extraídos de "Prediction Center de Prediction Center Merged Analysis of Precipitation" (CMAP) e vetores médios do campo de vento, em $925 \mathrm{hPa}$, para os períodos de (a) Janeiro e (b) Julho. Painéis à direita: precipitação média de longo prazo em escala de cinza e isolinhas do campo de pressão atmosférica em 300 hPa para (c) Janeiro e (d) Julho. Adaptado de Garreaud et al. (2009). . . . . 26

9 Circulação atmosférica esquemático em baixa e alta troposfera. ANE: alíseos de nordeste, ASE: alíseos de sudeste, ZCIT: Zona de Convergência Intertropical, ZCAS: Zona de Convergência do Atlântico Sul, JBN: jato de baixos níveis, FF: frente fria, FQ: frente quente, AB: Alto da Bolívia, CNE: cavado do nordeste, B: baixa pressão, BC: baixa do Chaco, JS: Jato subtropical e JP: jato polar. AB e o CNE são sistemas que se configuram no verão e desaparecem no inverno. Adaptado de Reboita et al. (2010). . . . . . . . . . . . . . . . . . 28

10 Médias climatológicas mensais normalizadas referente ao período de 1961 1990, provenientes do INMET. Os parâmetros climáticos apresentados são: temperatura do ar, pressão atmosférica, evaporação, insolação, precipitação para as cidades de Parnaíba e Teresina, estado do Piauí. . . . . . . . . . . . . . . . . 29

11 Deslocamento meridional da ZCIT sobre o oceano Atlântico, na longitude de 30W, adaptado de Nobre e Shukla (1996) . . . . . . . . . . . . . . . . 30

12 Curvas das flutuações do nível relativo do mar plotadas em idade calibrada e elevação em metros acima do nível do mar referente a região costeira do Rio Grande do Norte, nordeste brasileiro. A) Em linha continua, curva de variação do nível relativo do mar para o litoral de Salvador-BA proposto por Suguio et al.(1985) e, em cinza, curva proposta para o litoral do Rio Grande do Norte por Bezerra et al.(2003). B) Curva de variação do nível relativo do mar para o litoral do Rio Grande do Norte proposto por Caldas et al.(2006) . . . . . . . . . . . . 35

13 Cronologia do testemunho GeoB 16204-2: relação entre idade e profundidade baseado em 8 datações radiométricas distribuídas ao longo do testemunho. . . . . 44 
14 Distribuição das frações areia (\%), silte (\%) e argila (\%), nos últimos 8100 anos no testemunho GeoB 16204-2. . . . . . . . . . . . . . . . . 45

15 Distribuição dos tamanhos das partículas (Particle size distribution - PSD), frequência em \% para cada classe de $\phi$, nos últimos 8100 anos no testemunho GeoB 16204-

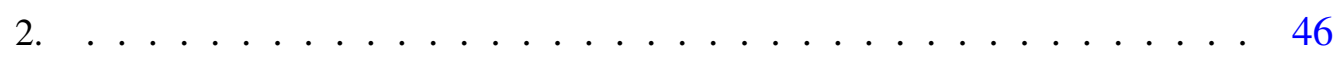

16 Distribuição dos valores de sortable silt $(\phi)$ para os para os últimos 8100 anos no testemunho GeoB 16204-2. . . . . . . . . . . . . . . . 47

17 Distribuição dos valores de conteúdo de $\mathrm{CaCO}_{3}$ (\%) ao longo dos últimos 8100 anos no testemunho GeoB 16204-2 . . . . . . . . . . . . . . . . . 48

18 Distribuição dos valores das razões $\mathrm{Ti} / \mathrm{Ca}$ e $\mathrm{Fe} / \mathrm{Ca}$ ao longo dos últimos 8100 anos no testemunho GeoB 16204-2, obtidos pelos métodos de XRF e digestão total. . . . . . . . . . . . . . . . . . . 49

19 Dados obtidos de correlação simples entre as razões $\mathrm{Mg} / \mathrm{Ca}$ e $\mathrm{Al} / \mathrm{Ca}$ obtidas nas carapaças dos foraminíferos planctônicos do testemunho GeoB 16204-2 . . . 50

20 Resultados das análises geoquímicas obtidos em indivíduos de foraminíferos planctônicos da espécie G. ruber white para os últimos 5000 anos no testemunho GeoB 16204-2. (I) Resultados obtidos de Mg/Ca e TSM, (II) Resultados obtidos de $\delta^{18} \mathrm{O}_{\text {G.ruber }}$, (III) Resultados de $\delta^{18} \mathrm{O}_{\text {seawater }}$ e SSM. . . . . . . . . . . . . 51

21 Distribuição do $\delta^{18}$ para os morfotipos G. ruber (s.l.) e G. ruber (s.s) ao longo do testemunho GeoB16204-2. . . . . . . . . . . . . . . . 53

22 Relação entre $\delta^{18} \mathrm{O}$ e $\delta^{13} \mathrm{C}$ dos morfotipos G. ruber (s.l.) e G. ruber (s.s) do testemunho GeoB16204-2. . . . . . . . . . . . . . . 53

23 (a) Distribuição de sortable silt, (b) Distribuição do conteúdo de $\mathrm{CaCO}_{3}$, (c) Distribuição da razão Ti/Ca em ppm representados pelo símbolo "o", (d) Distribuição da razão Ti/Ca em cps representados por "•", (e) $\delta^{18} \mathrm{O}$ de espeleotemas do Rio Grande do Norte adaptado de Cruz et al. (2009), (f) Insolação de verão no mês de Fevereiro em $10^{\circ} \mathrm{S}$ adaptado de Cruz et al. (2009) . . . . . . . . . . . 58 
24 Distribuição da média do sortable silt nos testemunho (a) GeoB 16204-2 analisado no presente trabalho, Atlântico Sul, e testemunhos do Atlântico Norte:(b) MD08-3183Cq adaptado de Kissel et al. (2013), (c) MD99-2251 adaptado de Hoogakker et al. (2011). . . . . . . . . . . . . . . . . . . . 61

25 Comparação do aporte continental entre as Bacia do Cariaco, Bacia do Parnaíba e Bacia de Santos. (a) Ti (\%) da Bacia do Cariaco, Atlântico Norte adaptado de Haug et al. (2001), "•"se refere ao Ti/Ca obtido por digestão total e --"se refere ao Ti/Ca obtido por XRF, (b) Ti/Ca do testemunho GeoB 16204-2 analisado no presente trabalho, Atlântico Sul, (c) Ti/Ca da Bacia de Santos, Atlântico Sul, adaptado de Pivel (2010). . . . . . . . . . . . . . . . . . . 67 


\section{Lista de Tabelas}

1 Datações radiométricas e idades calibradas obtidas para o testemunho GeoB 16204-2. . . . . . . . . . . . . . . . . 44

2 Resultados dos isótopos estáveis para G. ruber (s.l.) e G. ruber (s.s). . . . 52 


\section{Agradecimentos}

Primeiramente agradeço a Deus pela graça concedida, pela presença e pelo amor em todos os momentos.

À minha família, em especial minha Mãe (Matsuko Kitaura), meu Ditian (Tsutomu Kitaura), Hiroshi Taniguchi, Daniela Dondo e tio Beto (Alberto Saiki), pelo apoio e amor incondicional.

À Profa. Dra Silvia Helena de Mello e Sousa pela orientação, dedicação, confiança, paciência, disponibilidade, amizade e todas as oportunidades de aperfeiçoamento profissional e pessoal. Obrigada por estar sempre acompanhando de perto todas as atividades realizadas.

Ao Prof. Dr. Cristiano Mazur Chiessi pelas datações além de intermediar e facilitar meu período na Universidade de Bremen. Agradeço todas observações que contribuíram muito para este trabalho e para meu processo de aprendizagem.

Ao Prof. Dr. Stefan Mulitza e Dr. Henning Kunhert por me receberem tão cordialmente e pacientemente para realização das análises geoquímicas no Departamento de Geociências da Universidade de Bremen. Foi um período de grande aprendizado e enriquecimento profissional e pessoal essa estadia de 3 meses em Bremen.

Ao Prof. Dr. Rubens Cesar Lopes Figueira pelas análises de elementos inorgânicos realizadas no Laboratório de Química Inorgânica (LAQIMAR). Agradeço a paciência, a disposição em ajudar, ensinar e pela amizade de reconsiderar momentos de "explosão", no âmbito físico e pessoal em laboratório, rsrsrsrs.

À Profa. Dra. Márcia Caruso Bícego pelas análises orgânicas realizadas no Laboratório de Química Orgânica Marinha (LABQOM) e pelo apoio de sempre.

Ao Bsc. Edilson de Oliveira Faria pela análise granulométrica realizada no Laboratório de Sedimentologia do IOUSP, pela amizade e companhia.

À Profa. Dra. María Alejandra Gómez Pivel e Bsc. Lucas Makowski Bariani pela disponibilização dos dados de Ti/Ca do testemunho KF02.

Aos professores Dra. Olga Tiemi Sato, Dr. Paulo Polito, Dra. Isabel Montoya- 
Montes, Dr. Rui Taborda e Dra. Sueli Susana de Godoi pela amizade, apoio, disposição em ajudar e incentivo em todos os momentos.

À todos os professores do programa de pós-graduação que contribuíram para minha formação acadêmica e desenvolvimento do presente trabalho.

Agradeço ao Marcio Katsumi Yamashita pela concessão do template do LaTeX, pelo suporte técnico, pela amizade, pelo companheirismo que mesmo sendo físico e "robótico" mostrou seu lado artístico (kkkkkkk) e acima de tudo um Amigo para todas as horas, incluindo momentos de desespero (hihihi)... Obrigada Marcioooo!!!

Aos meus amigos do IO: Tiago Biló (meu carona e companheiro de Santo André), André Paloczy (Mestre), Filipe Galiforni, Renato Oliveira (Rocha), Natasha Hoff, Hanna Vale, Gilberto Watanabe, Patrícia Baldasso (Patola), Carolina Miyoshi, Dante (Pinguim), Marouan, Marcio Borges, Sebastian, Carine e todos que tornaram esse período um pouco mais leve e descontraído com risadas memoráveis, cafés, viagens, discussões e muito mais.

Ao pessoal do Laboratório de Bioindicadores Ambientais: Cintia Yamashita, Naira Yamamoto, Renata Hanae Nagai, Thaisa Marques, Carla Ito, Patrícia Ribeiro, Rafael Menezes, Ana Silvia, Edilson de Oliveira, Adriana Perreti pelo prazer de ter convivido esse tempo com vocês. Agradeço os cafés, as risadas, os desabafos, as festinhas, a companhia e muito mais. Agradeço especialmente a Cintia, Naira, Thaisa e Renata por sempre estarem disponíveis para me ajudar, ouvir e aconselhar em todos os momentos. Obrigada meninas!

Aos meus amigos da vida, Catia Sumie Shimatai Sazaki, Marcelo Saito, Bruno Sazaki Saito, Felipe Hideki Sazaki Saito, Daniele Fernanda Silva, Enrico Sala, Camila Nabeshima, Camila Imamura, Fabiana Aika Kitaura, Marcos Junji Kitaura, Ivo Koga, Raphael Did, Rodrigo Portilho, Karen Sayuri Moriya, Sergio Akiyama Jr., Marcio Julio, Fabio Lopes de Sousa e tantos outros, que podem não estar nesta lista, mas não menos importantes. Obrigada pela amizade, carinho, apoio, que mesmo não tão próximos no dia a dia, o tempo e a distância não apagaram a essência da nossa amizade.

Ao pessoal do LAQIMAR: Paulo Alves, Alexandre Salaroli, Bianca Kim, Carol, 
Elvis e ao pessoal do LABQOM: Silvio Sazaki, Amanda Spera, Ana Cecília Barbosa pelas conversas, dicas, auxílios, cafés.

Ao pessoal da biblioteca: Sandra, Cidinha, Claudinha, Neuci, Wagner;

Ao pessoal da secretaria da pós-graduação: Ana Paula, Silvana, Letícia, Daniel;

Ao pessoal do administrativo do IOUSP e a TODOS da família IO que direta e indiretamente contribuíram e tornaram esse momento possível .

À Lavanderia Gaúcha que é o carro chefe da família desde 1950.

Ao Programa de Pós-Graduação do Instituto Oceanográfico e à FAPESP (2013/10676-1 e BEPE 2013/26951-1) pelo apoio financeiro através de bolsa de estudo durante o mestrado.

À TODOS, meu sincero agradecimento.

Nancy Kazumi Taniguchi 
daqui a pouco a página vira, o cenário muda, novos ventos, nova brisa, novos ares, novos mares. (autor desconhecido) 


\section{Resumo}

Análises sedimentológicas e geoquímicas realizadas no registro sedimentar GeoB $16204-2\left(01^{\circ} 9.75^{\prime} \mathrm{S}, 42^{\circ} 20.30^{\prime} \mathrm{O}, 1210 \mathrm{~m}\right.$ de profundidade) permitiram reconhecer três períodos com diferentes configurações paleoceanográficas e paleoclimáticas ao longo dos últimos 8100 anos para margem equatorial brasileira. O primeiro período $(8100-5000$ anos cal A.P.) foi caracterizado por condições hidrodinâmicas mais intensas, menor influência marinha e maior aporte continental, constatados por menores valores de sortable silt, maior porcentagem da fração areia, menores conteúdos de $\mathrm{CaCO}_{3}$ e maiores valores das razões de Ti/Ca e Fe/Ca. O segundo período (5000 - 2500 anos cal A.P.) apresentou maiores flutuações na intensidade das correntes de fundo e diminuição do aporte continental indicados por variações do sortable silt, moda não definida na distribuição dos tamanhos das partículas (PSD) e tendência decrescente das razões Ti/Ca e Fe/Ca. O terceiro período (2500 anos cal A.P. - presente), prevaleceram condições hidrodinâmicas menos intensas e menor aporte continental sinalizados por moda do PSD próximo a 7 $\phi$ e menores valores das razões Fe/Ca e Ti/Ca. Ao longo dos 8100 anos ocorreu uma desintensificação da Corrente Norte do Brasil, provavelmente associado a um enfraquecimento da circulação de revolvimento meridional do Atlântico (AMOC) e também à migração em direção sul da Zona de Convergência Intertropical (ZCIT). A migração da ZCIT além de influenciar as correntes oceânicas também contribuiu para mudanças das configurações atmosféricas favorecendo condições mais secas na região de estudo durante o Holoceno Tardio. Estimativas de temperatura e salinidade da superfície do mar revelam pouca variação nos últimos 5000 anos, com valores próximos aos da média climatológicos atuais, $26,4^{\circ} \mathrm{C}$ e 36,5 .

Keywords: Holoceno, temperatura e salinidade da superfície do mar, aporte continental, Margem brasileira equatorial, Oceano Atlântico, paleoceanografia, paleoclima, Corrente Norte do Brasil 


\section{Abstract}

Sedimentological and geochemical analyzes on sedimentary record GeoB 16204$2\left(01^{\circ} 9.75^{\prime} \mathrm{S}, 42^{\circ} 20.30^{\prime} \mathrm{W}, 1210 \mathrm{~m}, 1210 \mathrm{~m}\right.$ depth) allowed to recognize three periods with different paleoceanographic and paleoclimatic settings over the last 8100 years for the Brazilian equatorial margin. The first period (8100 - 5000 cal yr BP) was characterized by more intense hydrodynamic conditions, lower marine influence and greater continental contribution, evidenced by lower values of sortable silt, higher percentage of sand fraction, lower $\mathrm{CaCO} 3$ content and higher values of the $\mathrm{Ti} / \mathrm{Ca}$ and $\mathrm{Fe} / \mathrm{Ca}$ ratios. The second period (5000 - $2500 \mathrm{cal}$ yr BP) showed greater fluctuations in the intensity of bottom currents and decreased continental contribution indicated by variations of sortable silt, poorly defined mode in the particle size distribution (PSD) and decrease trend of the Ti/Ca and Fe/Ca ratios. The third period (2500 cal yr BP - present) was dominated by less intense hydrodynamic conditions and less continental contribution indicated by for mode PSD about $7 \phi$ and lower values of $\mathrm{Fe} / \mathrm{Ca}$ and $\mathrm{Ti} / \mathrm{Ca}$ ratios. Over the 8100 years there has been a weakening of North Brazilian Current, probably associated with a weakening of the Atlantic Meridional Overturning Circulation (AMOC) and also the southward migration of the Intertropical Convergence Zone (ITCZ). Besides influencing ocean currents the migration of the ITCZ also contributed to changes atmospheric conditions, favoring drier conditions in the study area during the Late Holocene. Sea surface temperature ans salinity show little change in the last 5000 years, with values close to the current climatological average, $26.4^{\circ} \mathrm{C}$ and 36.5 .

Keywords: Holocene, sea surface temperature and salinity, terrigenous input, Brazilian equatorial margin, Atlantic Ocean, paleoceanography, paleoclimate, North Brazil Current 


\section{Introdução}

A Paleoceanografia compreende uma área da ciência que investiga a história dos oceanos que inclui formação e evolução das bacias oceânicas, estudo das correntes, massas d'água, produtividade biológica entre outros. Essa ciência tem como meta compreender a influência dos processos oceânicos nas mudanças climáticas globais, a partir da estratigrafia do sedimento marinho, notadamente os sedimentos de mar profundo. Utilizase de vários métodos de estudo, que estão inseridos nas ciências biológicas, químicas e físicas, além de aplicar técnicas estatísticas modernas para tratamento e interpretação dos dados. Provavelmente, o resultado mais importante na Paleoceanografia é a reconstituição das condições ambientais e climáticas do passado em escalas de tempo variadas e com diversos níveis de precisão (WEFER et al., 1999).

Na reconstituição da história dos oceanos, é de grande importância as informações que estão preservadas nos sedimentos, quer seja na forma de associações de microfósseis, matéria orgânica, composição elementar e isotópica de conchas e outros componentes de sedimentos (WEFER et al., 1999).

Estudos sobre a composição elementar dos sedimentos marinhos podem proporcionar uma ampla gama de informações tais como fonte e/ou origem dos sedimentos, direção, modo do transporte sedimentar além de condições hidrográficas do mar. A composição e proporção elementar dos sedimentos marinhos de uma determinada região são resultantes de um conjunto de fatores dentre eles configurações geomorfológicas, espessura da coluna d'água, tipo de fundo oceânico, entre outros, e são resposta de complexos processos físicos, químicos, biológicos e geológicos. Portanto, os depósitos sedimentares são importantes registros das condições ambientais e dos processos oceanográficos, tanto do presente como do passado (CALVERT e PEDERSEN, 2007; TESSLER e MAHIQUES, 2000).

Os depósitos sedimentares estão relacionados às condições ambientais e oceanográficas no momento de sua deposição e são considerados importantes registros dessas condições, em diferentes escalas de tempo, tanto do presente como do passado. (CALVERT e PEDERSEN, 2007; TESSLER e MAHIQUES, 2000). 
Os oceanos, por apresentarem elevada capacidade de armazenamento térmico e dinâmicas de correntes, afetam de diversas maneiras os ambientes adjacentes através de processos como fluxos, de energia e massa, entre oceano e atmosfera. Processos como troca de calor, momento e massa, ocorrentes na interface entre oceano e atmosfera são de fundamental importância na geração e manutenção das circulações oceânicas e atmosféricas. Oceano e atmosfera constituem um sistema acoplado e desempenham papéis importantes como agentes na redistribuição do calor e consequentemente na manutenção do clima do planeta. Resultados dos múltiplos processos são evidenciados principalmente por variações do nível do mar bem como no volume de gelo global (BARRON e SEIDOV, 2001; GODFREY et al., 2001).

A principal fonte de energia que impulsiona oceanos e atmosfera é a radiação solar, e devido à incidência desigual na superfície do planeta, causada pela esfericidade e inclinação do eixo da Terra, proporciona o estabelecimento de um gradiente meridional da temperatura. A radiação incidente por unidade de área decresce em direção aos pólos, uma vez que nas altas latitudes uma mesma radiação incidente atinge uma área maior do que se incidisse numa região equatorial. Assim, regiões de baixas latitudes são mais aquecidas e tipicamente mais quentes que regiões de altas latitudes ou polares, tipicamente mais frias (GODFREY et al., 2001; BROWN et al., 1989).

A reconstituição de condições ambientais de tempos pretéritos é importante para a compreensão da variabilidade climática global e essencial para o fornecimento de previsões de mudanças climáticas futuras. As variáveis reconstituídas, em geral, são utilizadas como parâmetro de contorno em modelos de simulação e que podem favorecer o fornecimento de previsões climáticas mais precisas (CALVERT e PEDERSEN, 2007).

Estudos, como os de Hippler et al. (2006) e Henderson (2002), assumem que a temperatura da superfície do mar (TSM) é o parâmetro mais importante para a compreensão da dinâmica climática da Terra, pois equivale ao limite de contorno inferior da circulação atmosférica gerando ventos e influenciando condições meteorológicas, taxas de evaporação, precipitação e atuando no ciclo da água. Estudos como Lu (2005) ressalta a importância da região tropical do Atlântico como fator determinante das condições de 
temperaturas atmosféricas além da TSM influenciar o posicionamento da Zona de Convergência Intertropical (ZCIT) e afetar na intensidade do regime de monções africano que controla a aridez e precipitação no Brasil e Sahel (SCHEFUSS et al., 2003).

Valores de TSM são obtidos por medidas diretas através do uso de instrumentos como termômetros, batitermógrafos descartáveis (XBT), sensores de CondutividadeTemperatura-Profundidade (Conductivity-Temperature-Depth - CTD), bóias flutuantes, bóias derivadoras, entre outros. Mais recentemente, o uso de satélites e sensores de alta tecnologia vem contribuindo para o registro contínuo de TSM, porém a série mais longa de TSM proveniente de satélite inicia-se na década de 80 e dados de climatologia provêm de meados de 1950 (CASEY et al., 2010; LOCARNINI et al., 2010).

TSM pretéritos podem ser obtidos a partir do uso de proxies, sendo esse o parâmetro mais comumente reconstituído. O termo proxy refere-se a medidas indiretas que descrevem variáveis desejadas, mas que não podem ser medidas diretamente, tais como temperatura, salinidade, concentração de nutrientes, concentração de oxigênio, dióxido de carbono, produtividade, entre outros. Este conceito presume a existência de um parâmetro alvo e dependendo da metodologia aplicada à determinação do parâmetro requer um algoritmo de transformação, que pode ser alcançado através de uma calibração (WEFER et al., 1999).

A calibração é executada expressando o parâmetro alvo em função de seu proxy, e a equação da transformação é obtida através da avaliação estatística de uma calibração referencial, consistindo geralmente de dois subconjuntos de dados, as variáveis proxies e o parâmetro alvo. Invariavelmente, a correlação entre o parâmetro alvo e a variável proxy não é totalmente perfeita, e diversos parâmetros independentes poderão ser utilizados para determinar o comportamento do proxy. Dessa maneira, pode existir mais de uma equação que utiliza uma mesma variável proxy, mas para parâmetros alvos diferentes (WEFER et al., 1999).

Os proxies podem ser classificados de acordo com propriedades do sedimento, propriedades físicas, geoquímicas, biológicas. Para estimativa da TSM, os proxies geralmente utilizados são baseados em associações de espécies de microfósseis, composição 
química de carapaças carbonáticas de foraminíferos bentônicos e planctônicos como $\delta^{18} \mathrm{O}$, $\delta^{13} \mathrm{C}, \mathrm{Mg} / \mathrm{Ca}, \mathrm{Sr} / \mathrm{Ca}, \delta^{44} \mathrm{Ca}$ ou ainda a partir de razões de moléculas orgânicas como alquenonas insaturadas produzidas biogenicamente (WEFER et al., 1999; HENDERSON, 2002).

A compreensão de variações paleoceanográficas na região da margem continental equatorial brasileira é de importância relevante uma vez que esta é caracterizada pela presença da Corrente Norte do Brasil (CNB), que contribui com transporte de massa e calor para o Atlântico Norte e compõe parte da circulação de revolvimento meridional do Atlântico, em inglês Atlantic Meridional Overtuning Circulation (AMOC). A CNB é uma corrente de superfície e seus padrões de intensidade e fluxo estão relacionadas a mudanças anual e interanual no regime de ventos e variabilidade da AMOC (JOHNS et al., 1998; ZHANG et al., 2011). Adicionalmente, Arz et al. (1998) indicaram que mudanças de curto período no padrão de fluxo e intensidade da CNB podem estar relacionadas às mudanças climáticas globais. Segundo esses autores, variações da CNB podem ter contribuído para variações no volume de gelo do hemisfério Norte.

O presente trabalho tem como proposta principal avaliar, através de análises sedimentológicas (granulometria, sortable silt) e geoquímicas (conteúdo de carbonato de cálcio, elementos inorgânicos em sedimento, razão $\mathrm{Mg} / \mathrm{Ca}$ e isótopos estáveis de oxigênio em foraminíferos planctônicos), possíveis variações das condições hidrodinâmicas do oceano da margem equatorial brasileira durante o Holoceno Médio e Tardio, procurando entender as relações do clima no continente e da região ao largo do rio Parnaíba, nos últimos 8100 anos cal A.P..

Na escala de tempo geológica, os últimos 8100 anos faz parte do Holoceno. O Holoceno é a unidade estratigráfica mais recente, que compreende os últimos 11700 anos antes do presente (A.P.) (WALKER et al., 2012). Registros estratigráficos pertencentes ao Holoceno geralmente são muito bem preservados, contínuos, o que permitem ser examinados em alta resolução temporal fornecendo evidências de mudanças climáticas, variações do nível do mar, processos hidrológicos e geomorfológicos, evolução de vegetação, entre outros (WALKER et al., 2012). Estudos paleoclimáticos em geral, costumam 
apresentar as dicussões do Holoceno em sub-períodos, classificados em três fases: Holoceno Inferior (Early Holocene) que compreende desde 11700 anos A.P até 8200 anos A.P., Holoceno Médio (Middle ou Mid- Holocene) entre 8200 anos A.P. a 4200 anos A.P. e o Holoceno Tardio (Late Holocene) de 4200 anos A.P até o presente (WALKER et al., 2012).

O limite entre o Holoceno Inferior e Holoceno Médio é marcado pelo evento 8.2 ka A.P., considerado o maior episódio de resfriamento de curta duração, constatados em diversos tipos de registros geológicos do hemisfério Norte, como por exemplo, testemunhos de gelo da Groelândia (WALKER et al., 2012). Este evento é associado a uma redução da formação da massa d'água denominada Água Profunda do Atlântico Norte (APAN) associado a um pulso de degelo do Atlântico Norte (ALLEY et al., 1997; WALKER et al., 2012).

Entre Holoceno Médio e Holoceno Tardio, o limite é marcado pelo evento 4.2 ka A.P., conhecido como um período de aridez em médias e baixas latitudes observado em diversos registros geológicos da América do Norte, Leste da China, África, parte da América do Sul e Antártica (MAYEWSKI et al., 2004). Segundo Walker et al. (2012), o mecanismo forçante deste evento não é tão claro como o caso do evento 8.2 ka A.P., por não existir nenhuma evidência, por exemplo, de liberação abrupta de um grande volume de água doce no Atlântico Norte. Mayewski et al. (2004) sugeriram, que um deslocamento na posição média geográfica da ZCIT em direção sul, poderia explicar a aridez em baixas latitudes, concomitante a um aumento do cisalhamento dos ventos de oeste sobre o Atlântico Norte, aumento de precipitação e avanço na formação de gelo na América do Norte ocidental. O estabelecimento de condições mais áridas também foi coincidente com um resfriamento de $1-2^{\circ} \mathrm{C}$ das águas superficiais do Atlântico Norte (Bond et al. (1997)), enquanto no Pacífico, um possível resfriamento das águas tropicais profundas teria ativado o regime atual do El Niño Oscilação Sul (ENOS), que se tornou mais acentuado após 4000 anos A.P. em regiões de médias latitudes (Walker et al, op cit.). 


\subsection{Foraminíferos plantônicos}

Foraminíferos planctônicos estão entre os mais importantes instrumentos da paleoceanografia. A excelente preservação nos registros sedimentares, ocorrência global, alta sensibilidade às condições ambientais, ciclo de vida curto com escalas semanais a mensais, além de grande abundância nos sedimentos marinhos, fazem deste grupo, uma ferramenta de grande aplicação na reconstituição histórica das águas de superfície dos oceanos (HALE e PFLAUMANN, 1999).

Os foraminíferos planctônicos são organismos unicelulares, eucariontes, heterotróficos marinhos pertencentes ao Reino Protista, Filo Granuloreticulosa, Classe Foraminifera (GUPTA, 2003). Ocorrem distribuídos verticalmente na coluna d'água e diversos estudos como Bé e Tolderlund (1971); Hemleben et al. (1989); Mulitza et al. (1997); Kucera (2007); Chiessi et al. (2007) indicam que as espécies destes organismos apresentam preferências por habitats, de acordo com temperatura, salinidade, níveis de profundidades, concentração de nutrientes, entre outros. O desenvolvimento destes organismos ocorre em equilíbrio com o ambiente circundante, o que permite pressupor que os sinais isotópicos e elementares da água do mar existente no local de sua calcificação ficam registrados em suas carapaças no momento da sua formação (ROHLING e COOKE, 2003).

Após a morte destes organismos as testas vazias decantam sobre os fundos dos oceanos e são preservadas no sedimento como registros das condições do seu habitat (PFLAUMANN et al., 1996).

A composição de espécies nas associações presentes em sedimentos marinhos é o resultado de uma complexa interação com o meio, pois estes reagem sensivelmente a fatores hidrográficos como oxigenação, concentração de nutrientes, condições de ressurgência e profundidade da termoclina. Apesar desta complexidade, supõe-se que todas as espécies contribuem com algum grau de informação sobre a temperatura da água em que vivem e se reproduzem (HALE e PFLAUMANN, 1999).

O uso das espécies de foraminíferos planctônicos em estudos paleoceanográficos pressupõe que cada morfoespécie representa uma espécie geneticamente contínua na qual preferências ecológicas e habitat, bem como equilíbrio químico da composição de suas 
testas (exemplo: razão $\mathrm{Mg} / \mathrm{Ca}, \delta^{13} \mathrm{C}$ ou $\delta^{18} \mathrm{O}$ ) se mantiveram constantes ao longo do tempo (KUCERA, 2007).

A espécie Globigerinoides ruber (G. ruber) é uma espécie característica de regiões tropical-subtropical, que vive em superfície na camada de mistura, preferencialmente nos primeiros $50 \mathrm{~m}$ de profundidade. Esta espécie ocorre geralmente em regiões com temperaturas médias no intervalo de $14^{\circ} \mathrm{C}$ a $30^{\circ} \mathrm{C}$, com pico de abundância em regiões com temperaturas entre $21^{\circ} \mathrm{C}$ e $29^{\circ} \mathrm{C}$ e salinidade de 34,5 a 36,0 (BÉ e TOLDERLUND, 1971; WANG, 2000).

Esta espécie apresenta variantes em duas cores, branca (Globigerinoides ruber white) e rosa (Globigerinoides ruber pink), sendo que a G. ruber white possui dois morfotipos que se diferem tanto em relação à forma das carapaças como também por apresentarem valores característicos de isótopos estáveis e assinatura da razão $\mathrm{Mg} / \mathrm{Ca}$ distintos (WANG, 2000; STEINKE et al., 2005).

No presente trabalho, seguiu-se o conceito de morfotipo proposto por Wang (2000), onde os morfotipos da G. ruber white são nomeadas G. ruber sensu strictu (s.s) e G. ruber sensu lato (s.l) (Figura 1). O morfotipo G. ruber s.s. são espécimes que apresentam câmaras esféricas dispostas simetricamente, caracterizada com grande abertura em arco, ocupando os primeiros $30 \mathrm{~m}$ da coluna d'água (Figura 1). As espécimes do morfotipo G. ruber s.l. apresentam testas com câmaras esféricas levemente achatadas ou ovais, distribuídas assimetricamente, com abertura semi-arqueada e menor em relação a G. ruber s.s., ocupando profundidades abaixo de $30 \mathrm{~m}$ (Figura 1). 


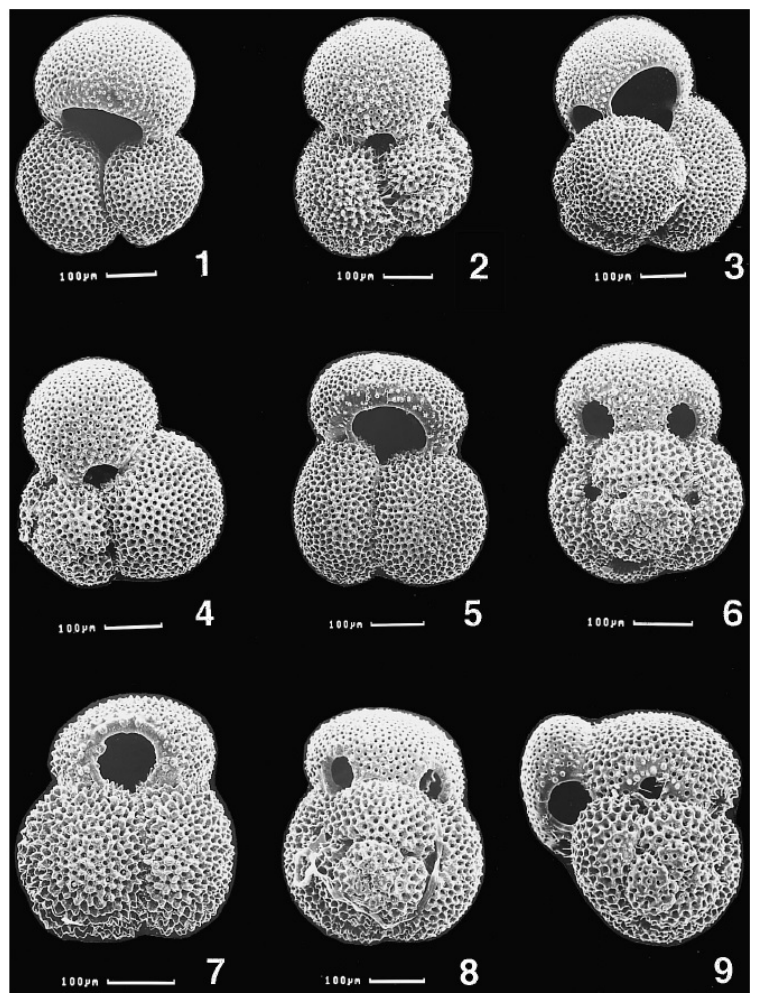

Figura 1: Foto ilustrativa dos dois morfotipos da espécie Globigerinoides ruber (white). 1-4: Globigerinoides ruber s.s.; e 5-9: Globigerinoides ruber s.1... Adaptado de Wang (2000).

A espécie G. ruber tem se tornado ferramenta padrão nos estudos de reconstituição de propriedades hidrográficas de superfície do mar (STEINKE et al., 2005). Dados de razão Magnésio/Cálcio $(\mathrm{Mg} / \mathrm{Ca})$ e isótopos estáveis de oxigênio $\left(\delta^{18} \mathrm{O}\right)$ obtidas em testas de espécimes destas espécie, por exemplo, são utilizados para estimativas de temperatura da superfície do mar (TSM) e salinidade de superfície do mar (SSM), em diversas escalas de tempo, nas regiões tropicais e subtropicais onde esta espécie é mais abundante (STEINKE et al., 2005; WELDEAB et al., 2006; NACE et al., 2014).

\subsection{Razão Mg/Ca em foraminíferos planctônicos}

A razão $\mathrm{Mg} / \mathrm{Ca}$ obtida na calcita de foraminíferos é basicamente dependente da temperatura da água em que os espécimes calcificam (ELDERFIELD e GANSSEN, 2000). O elemento $\mathrm{Mg}^{2+}$ é um dos divalentes que podem substituir o Ca durante a formação do carbonato de cálcio biogênico (BARKER et al., 2005). A incorporação deste elemento é diretamente influenciado pela temperatura da água em que o organismo 
cresce numa relação onde quanto maior a temperatura, maior a razão $\mathrm{Mg} / \mathrm{Ca}$ (BARKER et al., 2005).

Uma das vantagens da estimativa de paleotemperaturas a partir do $\mathrm{Mg} / \mathrm{Ca}$ é que o tempo de residência dos elementos $\mathrm{Ca}$ e $\mathrm{Mg}$ na água do mar, é relativamente longo, aproximadamente $10^{6}$ e $10^{7}$ anos respectivamente, o que permite considerá-la como constante em escalas de tempo glacial e interglacial (BARKER et al., 2005). Esta constante não ocorre por exemplo com $\delta^{18} \mathrm{O}$ da calcita do foraminífero, que além de ser sensível à temperatura também é fortemente influenciado por mudanças na composição isotópica da água do mar $\left(\delta_{w}\right)$. Considerando que o $\delta_{w}$ pode variar em função do volume global de gelo e diferenças de salinidade local, a interpretação de variação do $\delta^{18} \mathrm{O}$ da calcita torna-se mais complexo (BARKER et al., 2005). Outra vantagem da utilização da razão $\mathrm{Mg} / \mathrm{Ca}$ é que a temperatura estimada pode ser obtida na mesma porção ou amostras de foraminíferos em que poderão ser determinados os dados de isótopos de oxigênio, o que possibilita não apenas a estimativa de temperatura, mas também estimar o $\delta_{w}$ (ANAND et al., 2003).

Adicionalmente, considerando que as estimativas baseadas da razão $\mathrm{Mg} / \mathrm{Ca}$ são específicas de uma determinada espécie, é possível aplicá-lo para reconstituição de temperaturas de diferentes profundidades da coluna d'água uma vez que as espécies estão associadas ao seu habitat de preferência (BARKER et al., 2005).

Segundo Anand et al. (2003), a relação entre $\mathrm{Mg} / \mathrm{Ca}$ e temperatura é dada por uma exponencial expressa matematicamente por:

$$
M g / C a=B \exp (A T)
$$

onde $\mathrm{Mg} / \mathrm{Ca}$ corresponde aos resultados obtidos da razão $\mathrm{Mg} / \mathrm{Ca} ; A$ é a constante relacionada a componente sensível de temperatura característica para cada espécie e tamanho dos espécimes , $B$ é a constante exponencial relacionada à mudanças dos valores de $\mathrm{Mg} / \mathrm{Ca}$ para cada $1^{\circ} \mathrm{C}$ de temperatura e $T$ é a temperatura de calcificação. 


\subsection{Isótopos estáveis de oxigênio e carbono}

Ao longo das últimas décadas, registros de isótopos de oxigênio e de carbono obtidos em carapaças de foraminíferos tem sido amplamente utilizados em estudos paleoceanográficos e paleoclimáticos (RAVELO e HILLAIRE-MARCEL, 2007). Isto não seria possível se paralelamente não fossem compreendidos os processos vitais e ecológicos, como por exemplo, equilíbrio isotópico da calcificação de espécies de foraminíferos planctônicos e bentônicos (RAVELO e HILLAIRE-MARCEL, 2007).

Os isótopos estáveis de oxigênio aplicados nos estudos paleoceanográficos são ${ }^{16} \mathrm{O}$ e ${ }^{18} \mathrm{O}$, onde perfazem naturalmente $99,65 \%$ e $0,1995 \%$ respectivamente do oxigênio terrestre e isótopos de carbono, ${ }^{12} \mathrm{C} \mathrm{e}{ }^{13} \mathrm{C}$, com disponibilidade de $98,89 \%$ e $1,11 \%$ respectivamente do carbono global (RUDDIMAN, 2001; RAVELO e HILLAIRE-MARCEL, 2007).

A quantificação das baixas abundâncias dos isótopos ${ }^{18} \mathrm{O}$ e ${ }^{13} \mathrm{C}$ são determinados através do uso de razões com seus elementos mais abundantes, ${ }^{18} \mathrm{O} /{ }^{16} \mathrm{O}$ e ${ }^{13} \mathrm{C} /{ }^{12} \mathrm{C}$ da amostra, expressa em comparação com estas mesmas proporções de uma amostra padrão com valores conhecidos (RAVELO e HILLAIRE-MARCEL, 2007). A diferença da razão entre amostra e padrão são expressas como valor delta $(\delta)$ dado por:

$$
\begin{aligned}
& \delta^{18} O=\frac{\left(\frac{18 O}{16}\right)_{\text {amostra }}-\left(\frac{18 O}{16}\right)_{\text {padrao }}}{\left(\frac{18 O}{16}\right)} \cdot 1000 \\
& \delta^{13} C=\frac{\left(\frac{13 C}{12 C}\right)_{\text {amostrao }}-\left(\frac{13 C}{12 C}\right)_{\text {padrao }}}{\left(\frac{13 C}{12 C}\right)_{\text {padrao }}} \cdot 1000
\end{aligned}
$$

Os valores de $\delta^{18} \mathrm{O}$ e $\delta^{13} \mathrm{C}$ são expressos em unidade por mil (\%o) em relação ao padrão (RAVELO e HILLAIRE-MARCEL, 2007). Ou seja, um valor de $\delta^{18} \mathrm{O}$ igual a $1,0 \%$, significa que a amostra tem uma razão ${ }^{18} \mathrm{O} /{ }^{16} \mathrm{O}$ que é $0,1 \%$ maior que o padrão, ou um $\delta^{13} \mathrm{C}$ de $-25 \%$, uma amostra onde a razão ${ }^{13} \mathrm{C} /{ }^{12} \mathrm{C}$ é $2,5 \%$ menor que o padrão (RAVELO e HILLAIRE-MARCEL, 2007).

Os resultados de $\delta^{18} \mathrm{O}$ e $\delta^{13} \mathrm{C}$ em carbonatos são expressos em relação ao padrão Vienna Pee Dee Belemnite(VPDB) ou simplesmente PDB. Já valores de $\delta^{18} \mathrm{O}$ e $\delta^{13} \mathrm{C}$ para 
a água do mar, o padrão é o Vienna Standard-Mean-Ocean-Water (VSMOW) ou simplesmente SMOW (RUDDIMAN, 2001; RAVELO e HILLAIRE-MARCEL, 2007).

A razão de isótopos estáveis de oxigênio $\left(\delta^{18} \mathrm{O}\right)$ é uma das ferramentas mais importantes da paleocenografia e paleoclimatologia (MULITZA et al., 2003; RUDDIMAN, 2001). Devido a composição de isótopos de oxigênio registrada na calcita dos foraminífero responder à temperatura ambiente e à composição da água do mar, que circunda o organismo durante o processo de calcificação, faz deste parâmetro um importante indicador de condições ambientais do passado (WAELBROECK et al., 2005). Na paleoceanografia, este parâmetro tem sido utilizado para indicar por exemplo, temperatura, salinidade, condição de estratificação da coluna d'água, circulação dos oceanos entre outros (MULITZA et al., 1997; RUDDIMAN, 2001; MULITZA et al., 2003; WELDEAB et al., 2006).

A evolução dos isótopos de oxigênio está relacionada ao ciclo hidrológico e é controlada por processos associados a mudanças de fases que se iniciam basicamente na superfície do oceano, evaporação e condensação do vapor atmosférico (RUDDIMAN, 2001; RAVELO e HILLAIRE-MARCEL, 2007; LACHNIET, 2009). A existência dos isótopos de oxigênio $\left({ }^{18} \mathrm{O},{ }^{17} \mathrm{O},{ }^{16} \mathrm{O}\right)$ e isótopos de hidrogênio $\left({ }^{1} \mathrm{H} \mathrm{e}{ }^{2} \mathrm{H}\right)$ propiciam formação de moléculas de água com diferentes configurações isotópicas, como por exemplo, $\mathrm{H}_{2}^{16} \mathrm{O}$ e $\mathrm{H}_{2}^{18} \mathrm{O}$ (RUDDIMAN, 2001). O fracionamento isotópico ocorre em função do favorecimento de uma configuração isotópica de uma molécula em relação à outra durante a mudança de fase (RUDDIMAN, 2001; RAVELO e HILLAIRE-MARCEL, 2007; LACHNIET, 2009). Por exemplo, uma vez que a pressão de vapor da molécula $\mathrm{H}_{2}^{16} \mathrm{O}$ é maior do que a molécula $\mathrm{H}_{2}^{18} \mathrm{O}$, durante o processo de evaporação, o vapor de água formado é empobrecido em ${ }^{18} \mathrm{O}$ (e enriquecido em ${ }^{16} \mathrm{O}$ ), enquanto que a água remanescente se torna enriquecida em ${ }^{18} \mathrm{O}$ (RUDDIMAN, 2001). Dessa forma, estudos paleoceanográficos demonstram que durante períodos glaciais o isótopo ${ }^{16} \mathrm{O}$, por ser mais leve, é preferencialmente evaporado e no continente é aprisionado no gelo, portanto o oceano fica enriquecido com ${ }^{18} \mathrm{O}$ (altos valores de $\delta^{18} \mathrm{O}$ ). O inverso ocorre em períodos interglaciais, ou seja, baixos valores de $\delta^{18} \mathrm{O}$ são encontrados nas águas dos oceanos (RUDDIMAN, 2001). 
Localmente, os valores de $\delta^{18} \mathrm{O}$ da água do mar estão relacionados também com a salinidade que responde ao balanço entre precipitação e evaporação (RUDDIMAN, 2001; LACHNIET, 2009). Assim, regiões em que a evaporação é elevada, os valores de $\delta^{18} \mathrm{O}$ são tipicamente maiores; e regiões com elevadas taxas de precipitação, ou que sejam influenciadas por derretimento de camadas de gelo ou com elevadas descargas fluviais, os valores de $\delta^{18} \mathrm{O}$ são caracteristicamente menores (RAVELO e HILLAIRE-MARCEL, 2007; LACHNIET, 2009).

A salinidade tem um papel importante na circulação oceânica global e, portanto, no clima global. Assim, uma reconstituição paleoceanográfica deve incluir estimativas de temperatura e salinidade (TOLEDO et al., 2007). Diferente da temperatura, a paleossalinidade é estimada de forma indireta e é função da composição isotópica da água do mar (TOLEDO et al., 2007). A composição isotópica da água do mar é estimada pela combinação de valores de isótopos de oxigênio obtido na calcita em foraminífero com estimativa de temperatura determinado de forma independente como, por exemplo, através da razão Mg/Ca (TOLEDO et al., 2007). Segundo Toledo et al. (2007), a relação entre isótopo de oxigênio da água do mar e salinidade é linear e, entre as latitudes de $0^{\circ}$ a $45^{\circ} \mathrm{S}$, a cada aumento de $0,5 \%$ no $\delta^{18} \mathrm{O}_{w}$ a salinidade aumentaria em 0,93 .

\subsection{Carbonato de cálcio $\left(\mathrm{CaCO}_{3}\right)$}

Carbonato de cálcio $\left(\mathrm{CaCO}_{3}\right)$ é um dos principais componentes biogênicos dos sedimentos pelágicos marinhos (SCHNEIDER et al., 2006). Globalmente, 55\% dos sedimentos que recobrem o talude continental e mar profundo são constituídos por sedimentos considerados ricos em carbonato, com teores superiores a 30\% de $\mathrm{CaCO}_{3}(\mathrm{SCHNEIDER}$ et al., 2006).

$\mathrm{O} \mathrm{CaCO}_{3}$ presente nos sedimentos pelágicos são produzidos principalmente por organismos planctônicos como cocolitoforídeos, foraminíferos, pterópodos e organismos dinoflagelados calcários que são influenciados por variações de temperatura, luz, aporte de nutrientes (SCHNEIDER et al., 2006). Em regiões com maior produtividade ou aporte de matéria orgânica, parte do $\mathrm{CaCO}_{3}$ também pode ser proveniente de foraminíferos 
bentônicos e moluscos (SCHNEIDER et al., 2006).

Vários fatores podem influenciar a distribuição do conteúdo de $\mathrm{CaCO}_{3}$, como por exemplo, aportes fluviais, processos hidrotermais nos fundos marinhos e processos de troca e equilíbrio de $\mathrm{CO}_{2}$ na interface oceano-atmosfera (SCHNEIDER et al., 2006).

Dentre os principais processos que governam o conteúdo de $\mathrm{CaCO}_{3}$ nos sedimentos citam-se: variações na produtividade planctônica, dissolução da calcita durante e após o processo de deposição e diluição de $\mathrm{CaCO}_{3}$ pela presença de material não carbonático como por exemplo em condições de maior aporte de sedimentos terrígenos (SCHNEIDER et al., 2006).

\subsection{Elementos inorgânicos em sedimento}

Elementos como ferro $(\mathrm{Fe})$, titânio $(\mathrm{Ti})$ e cálcio $(\mathrm{Ca})$ podem indicar aporte de sedimento continental. O Ca é associado como componente da calcita e aragonita e reflete principalmente o conteúdo de carbonato de origem marinha presente no sedimento. Os elementos Ti e Fe, são relacionados a argilos minerais e componentes siliciclásticos geralmente proveniente de sedimentos de origem continental (ARZ et al., 1998). Desta forma, as razões Fe/Ca e Ti/Ca são consideradas como indicadores de aporte de material continental.

A determinação destes elementos podem ser realizadas através de técnicas como fluorescência de raio-X ou também digestão total.

Fluorescência de raio-X (XRF) é uma técnica não destrutiva que permite estimar a composição elementar de sedimentos, cujos resultados são qualitativos ou semiquantitativos, expressos usualmente por taxas de contagens, por exemplo, contagem por unidade de tempo por unidade de área, ou como razões de contagem, ou ainda por intensidade relativa dos elementos (RICHTER et al., 2006; WELTJE e TJALLINGII, 2008).

O princípio desta técnica é baseado na excitação de elétrons através da incidência de radiação de alta energia. A fluorescência de raios-X dos elementos presentes numa amostra ocorre através da incidência de raios provenientes de um tubo de raios-X. A incidência dos raios nos átomos da amostra faz com que elétrons sejam ejetados das cama- 
das próximas do núcleo formando vacâncias na camada energética. Estas vacâncias são imediatamente preenchidas por elétrons das camadas mais externas e simultaneamente há emissão de raios-X, fluorescentes ou secundários, cuja energia corresponde à diferença entre as energias dos níveis e sub-níveis das transições eletrônicas envolvidas. Cada transição entre sub-níveis específicos, possui uma energia característica onde cada tipo de átomo apresenta um espectro de raios-X. Logo, os comprimentos de onda de radiação emitida são característicos de cada elemento e a amplitude dos picos de cada espectro do XRF é proporcional à concentração dos elementos das amostras analisadas (RICHTER et al., 2006; WELTJE e TJALLINGII, 2008).

Citam-se como vantagens da técnica de XRF a obtenção das intensidades dos elementos provenientes diretamente da superfície do registro sedimentar, maior resolução espacial dos elementos com extração quase contínua dos elementos além de tratar-se de uma análise rápida, não destrutiva e de fácil preparação das amostras quando comparadas às análises geoquímicas convencionais. No entanto, efeitos decorrentes da heterogeneidade e rugosidade das amostras, que envolvem composição da amostra por diferentes tamanhos e geometrias de grãos, além de variações no conteúdo de água e possíveis interferências causadas por absorções de outros elementos presentes nas amostras, caracterizam resultados, provenientes da análise de XRF, como relativos e semi-quantitativos (RICHTER et al., 2006; WELTJE e TJALLINGII, 2008).

A digestão total é uma técnica analítica, destrutiva, que permite quantificar a composição elementar dos sedimentos. Através da acidificação controlada de uma massa conhecida de sedimento, é realizada a dissolução da matriz (amostra de sedimento). A partir da solução obtida após o processo de acidificação, multielementos, no caso Fe, Ti e Ca, podem ser determinados por espectrometria de emissão ótica por plasma indutivamente acoplado (ICP-OES).

O princípio da espectrometria de emissão ótica por plasma indutivamente acoplado segue o mesmo princípio da análise por XRF, por meio de excitação dos elétrons e emissão de energia absorvida através de energia luminosa. Entretanto, os átomos ou íons presentes nas amostras são excitados por um plasma e a intensidade da radiação 
resultantes da emissão espectral característico de cada elemento.

\subsection{Granulometria e sortable silt}

A principal aplicação da análise granulométrica em sedimentos de mar profundo na paleoceanografia é a de medir um parâmetro que pode ser relacionado à velocidade da corrente no momento da deposiação do sedimento (BIANCHI et al., 1999). O transporte e deposição de sedimentos, envolvem muitos ciclos de erosão e deposição através de fluxos presentes próximos ao fundo oceânico (MCCAVE, 2008). A atuação destes fluxos acabam proporcionando naturalmente uma separação ou um selecionamento dos tamanhos dos grãos de acordo com as propriedades do fluxo de transporte (MCCAVE, 2008).

Para que a reconstituição de paleocorrentes possa ser realizadas em alta resolução temporal faz se necessário uma contínua e elevada taxa de deposição de sedimentos. Devido à processos que possam interferir na preservação da sequencia natural de deposição, como por exemplo bioturbação, o conhecimento das frações granulométricas bem como tamanho médio dos grãos auxiliam na inferência relacionados à intensidade de corrente de fundo (MCCAVE, 2008).

McCave et al. (1995) propuseram o uso da média da fração de sedimentos com tamanhos entre $10 \mu \mathrm{m}$ e $63 \mu \mathrm{m}$, denominado por média do sortable silt, como indicador de intensidade da corrente de fundo nos oceanos. Segundo estes autores, sedimentos com tamanhos pertencentes à este intervalo são depositados em resposta à velocidade escalar do fluxo de transporte numa relação direta onde quanto maior o tamanho médio do sortable silt, maior a intensidade da corrente. Sedimentos mais finos, menores que $10 \mu \mathrm{m}$, não seriam apropriados como indicadores de correntes, pois geralmente estão agregados a matéria orgânica, que pode alterar propriedades relacionada à flutuabilidade da partícula a ser depositada (MCCAVE et al., 1995).

O tamanho da partícula de sedimento apresenta correlação significativa à velocidade do fluxo de deposição ou fluxo de erosão. Para sedimentos finos, Ledbetter's (1986, apud McCave, 2008) propuseram a partir de dados de granulometria e velocidade de corrente, uma equação empírica que relaciona estes dois parâmetros sendo: 


$$
U=183,4-30 \phi
$$

onde $U$ se refere a velocidade da corrente em $\mathrm{cm} . \mathrm{s}^{-1}$ e $\phi$ o tamanho da sedimento.

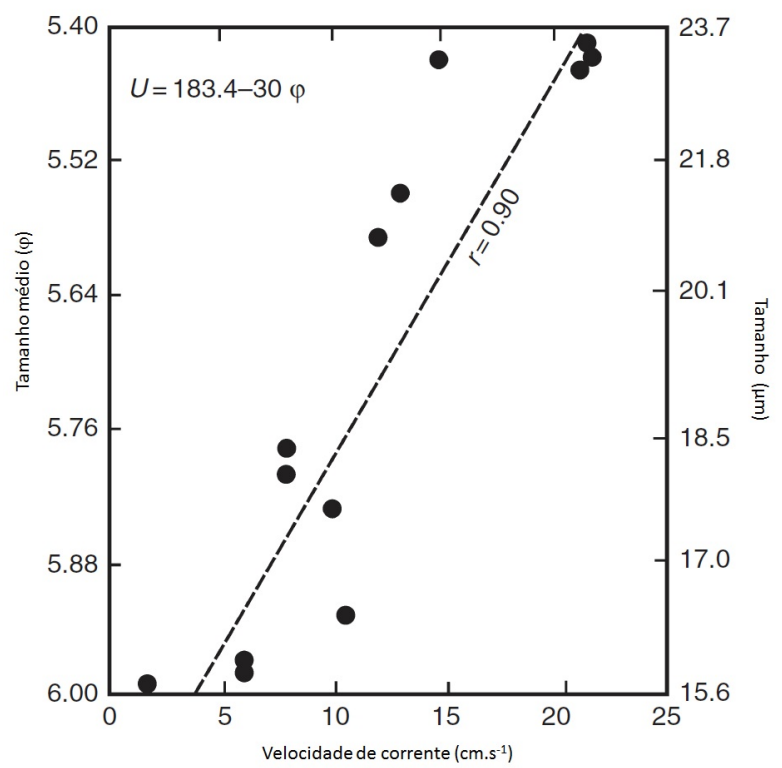

Figura 2: Relação entre tamanho de partícula de sedimentos finos com velocidade de corrente estabelecido por Ledbetter's (1986) apud McCave (2008) para Vema Channel no Atlântico Sul. Gráfico adaptado de McCave (2008). 


\section{Objetivos}

O presente trabalho tem como objetivo avaliar variações das condições hidrodinâmicas da margem continental equatorial brasileira durante os últimos 8100 anos, procurando entender suas relações com clima em continente.

Para alcançar o propósito principal deste projeto os seguintes objetivos específicos foram estabelecidos:

- estabelecimento de uma cronologia para o registro sedimentar;

- avaliação de variações da intensidade de corrente de fundo;

- avaliação de variações no aporte continental;

- reconstituir as condições hidrográficas de superfície, TSM e salinidade;

- relacionar e compreender as variações de aporte continental às mudanças climáticas e às condições hidrodinâmicas que ocorreram nos últimos 8100 anos A.P.. 


\section{3 Área de estudo}

A área de estudo faz parte da margem continental equatorial brasileira localizada a 1100 km ao sul do Rio Amazonas e 1200 km ao norte do rio São Francisco no nordeste da costa brasileira (Figura 3). Entre as latitudes de $2^{\circ} \mathrm{S}$ e $8^{\circ} \mathrm{S}$, a plataforma continental é caracterizada por uma largura de aproximadamente $80 \mathrm{~km}$, que se estreita em direção sul chegando a $40 \mathrm{~km}$ de largura em $8^{\circ} \mathrm{S}$ (CASTRO e MIRANDA, 1998). Nesta região, a quebra da plataforma continental localiza-se próximo à isóbata de 85 metros. O talude continental é considerado estreito entre $41^{\circ} \mathrm{W}$ e $47^{\circ} \mathrm{W}$ com declividade média entre $1: 7$ a 1:9 e base atingindo a profundidade de $3150 \mathrm{~m}$ de profundidade (CASTRO e MIRANDA, 1998; ZEMBRUSCKI, 1979).

\subsection{Condições oceanográficas atuais}

A margem continental equatorial brasileira faz parte da região tropical do Atlântico e corresponde a área de transição entre os dois giros oceânicos subtropicais delimitados aproximadamente entre as latidudes de $10^{\circ} \mathrm{N}$ e $10^{\circ} \mathrm{S}$. Nesta região, o sistema de circulação em superfície é aproximadamente zonal e inclui Corrente Sul Equatorial (CSE), Contracorrente Norte Equatorial (CCNE), Corrente Norte Equatorial (CNE) e Corrente Norte do Brasil(CNB) (Figura 3B). O transporte oceânico superficial é dominado pelas correntes geradas pelo vento e apresenta mudanças sazonais em resposta ao cisalhamento dos ventos alísios e posição da zona de convergência intertropical (STRAMMA e SCHOTT, 1999; SCHOTT et al., 2005; TALLEY et al., 2011).

A circulação tropical de superfície é delimitada ao sul pela CSE e ao norte pela CNE. Quando o ramo sul da CSE alcança a margem continental brasileira, entre as latitudes de $10^{\circ} \mathrm{S}$ e $15^{\circ} \mathrm{S}$, ela se bifurca contribuindo para a formação de um fluxo em direção sul denominada Corrente do Brasil e outro fluxo em direção norte conhecido como Subcorrente Norte do Brasil (SNB) e CNB (SILVEIRA et al., 1994; STRAMMA et al., 1995; JOHNS et al., 1998; SCHOTT et al., 2005; TALLEY et al., 2011; ZHANG et al., 2011).

Entre $11^{\circ} \mathrm{S}$ e $6^{\circ} \mathrm{S}$, a CNB é caracterizada como um forte fluxo que acompanha a 
costa brasileira em direção norte, ocupando os primeiros $1200 \mathrm{~m}$ de coluna d'água com um núcleo de velocidade em subsuperfície, em aproximadamente $200 \mathrm{~m}$, de profundidade que chega a alcançar velocidades máximas de $80 \mathrm{~cm} \cdot \mathrm{s}^{-1}$ (SCHOTT et al., 1998; SCHOTT et al., 2005; ZHANG et al., 2011). Schott et al. (2005), a partir de dados observacionais, provenientes de ADCP (acustic Doppler current profile), correntômetros e fundeios, obtiveram a partir de nove seções de velocidade, o transporte médio estimado de 26,5 $\pm 3,7 \mathrm{~Sv}$ $\left(\mathrm{Sv} \equiv 10^{6} \mathrm{~m}^{3} \cdot \mathrm{s}^{-1}\right)$ para a latitude de $5^{\circ} \mathrm{S} . \mathrm{Em} 11^{\circ} \mathrm{S}$, a partir de cinco seções de velocidade, o transporte médio estimado foi de 25,4 $\pm 7,4 \mathrm{~Sv}$, com variação sazonal de amplitude de 2.5 Sv, e valores máximos observados no mês Julho (SCHOTT et al., 2005).

Na latitude de $5^{\circ} \mathrm{S}$, próximo à região do Cabo de São Roque, o ramo central da CSE alcança a região, configurado praticamente na forma de um fluxo zonal, que flui em direção oeste e com núcleo de velocidade em superficie. O aporte deste ramo somado a uma complexa mistura de processos termodinâmicos, influenciados pelo vento e de efeitos equatoriais, contribui para que a SBN perca sua característica de subcorrente, tornando-se em um vigoroso fluxo que continua seguindo em direção noroeste ao largo da margem continental brasileira, conhecida como CNB (SILVEIRA et al., 1994; JOHNS et al., 1998; SCHOTT et al., 1998; GOES et al., 2005; ZHANG et al., 2011).

A CNB é a corrente de contorno oeste que flui em direção norte no Atlântico. Ela faz parte da circulação de superfície conhecida como giro equatorial, desempenha papel importante no sistema das contracorrentes zonais da região equatorial e atua como ligação entre os hemisférios Norte e Sul através do transporte de águas superficiais em direção norte (JOHNS et al., 1998; SCHOTT et al., 1998; ZHANG et al., 2011). Além disso, a CNB é também reconhecida como a maior componente do fluxo em superfície da célula de revolvimento meridional do Atlântico (AMOC), de fundamental importância nas trocas de calor e massa oceânicas inter-hemisféricas, e consequentemente, no clima global. (GOES et al., 2005; ZHANG et al., 2011)

Segundo Johns et al. (1998), o transporte da CNB nos primeiros $800 \mathrm{~m}$ de coluna d'água em $4^{\circ} \mathrm{N}$, apresenta uma média anual de $26 \mathrm{~Sv}$ com máximos alcançando $36 \mathrm{~Sv}$ entre Julho e Agosto e valores mínimos de 13 Sv entre Abril e Maio. Esta variabilidade 
do transporte em superfície coincide com resultados de modelos lineares de circulação, obtidos a partir da utilização de ventos como forçantes, o que indicaria a existência de uma relação de equilíbrio entre a variabilidade do transporte na superfície oceânica, associado à mudanças do cisalhamento do vento atuantes no Atlântico tropical e à migração sazonal da ZCIT.

(A)
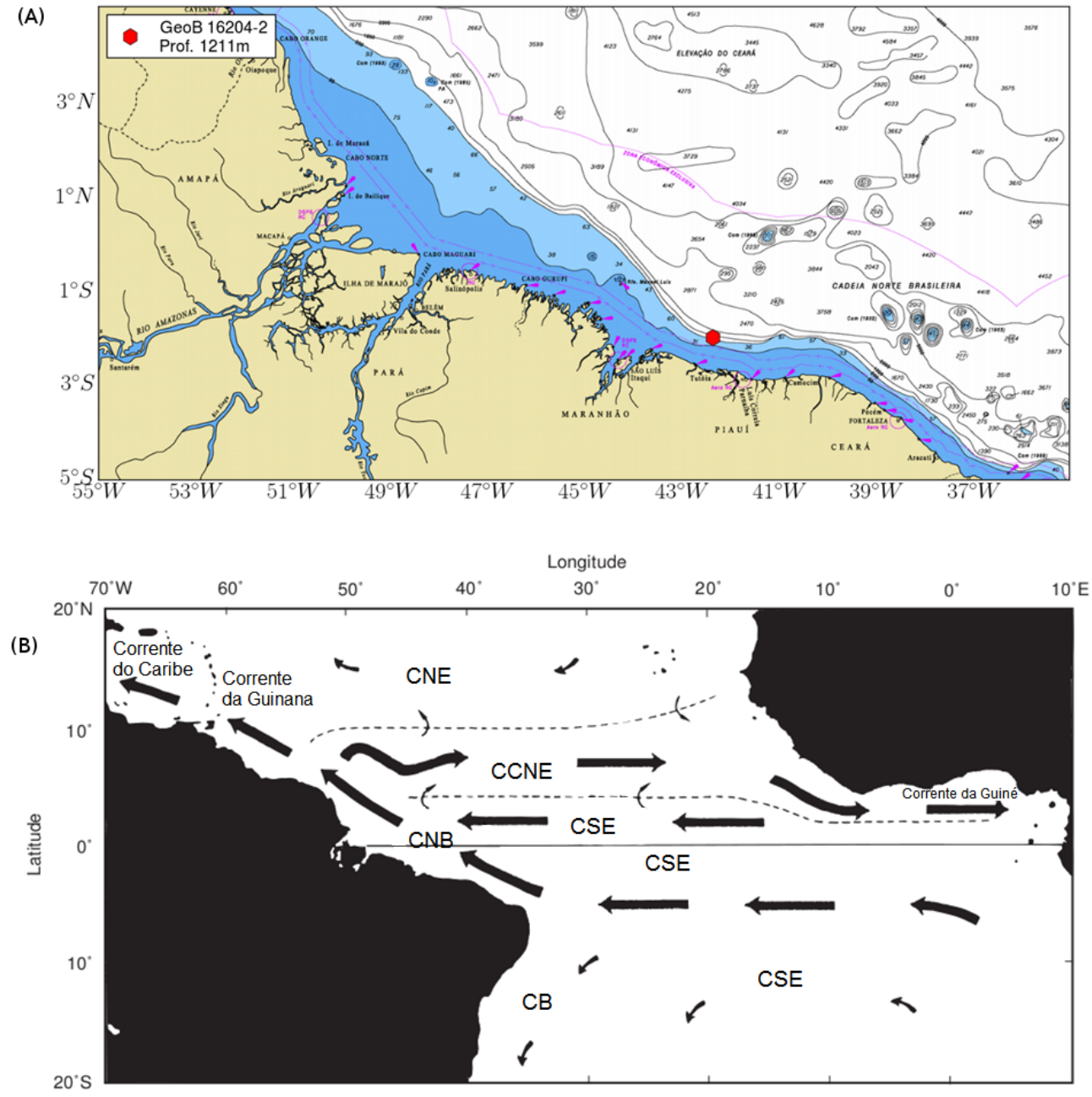

Figura 3: Área de estudo e posição geográfica do testemunho GeoB 16204-2. (A) Localização do testemunho GeoB $16204-2$ em vermelho $(\bullet)$, na latitude $1^{\circ} 59.75^{\prime} \mathrm{S}$ e longitude $42^{\circ} 20.30^{\prime} \mathrm{W}$. (B) Desenho esquemático das correntes de superfície da região tropical do Atlântico, configuração característica do período entre Julho e Setembro quando a Contracorrente Norte Equatorial (CCNE) flui em direção à leste. As demais correntes são: Corrente Sul Equatorial (CSE), Corrente do Brasil (CB), Corrente Norte do Brasil (CNB), Corrente Norte Equatorial (CNE). Figura adaptada de Philander (2001). 
Embora parte do transporte da CNB seja explicada pelo vento, o transporte médio da CNB é $15 \mathrm{~Sv}$ maior do que pode ser associado apenas à esta forçante. Assim, os valores estimados indicam que parte do transporte da CNB também está associada a uma forte componente termohalina explicada pela variação da AMOC (JOHNS et al., 1998). Além dos componentes citados, vento e variação da AMOC, o transporte da CNB também é associado a um fluxo muito fraco carregado através da termoclina tropical do Atlântico Sul. Com cerca de $4 \mathrm{~Sv}$ que segue em direção norte, este fluxo faz parte do ramo inferior da célula tropical-subtropical (CTS). No entanto, este ramo é balanceado pela corrente de deriva do vento com direção sul em superfície (SCHOTT et al., 2005; ZHANG et al., 2011).

Através de resultados estimados de transporte geostrófico da CNB obtidos através de uma série temporal de cinquenta anos de observações hidrográficas, Zhang et al. (2011) concluíram que a CNB apresenta variabilidade multidecadal, com reflexos em alguns anos de atraso, em relação à espessura da camada de água da região de convecção profunda do mar de Labrador, região de formação da massa de Água Profunda do Atlântico Norte (APAN) sugerindo a variabilidade do transporte da CNB como indicador da variabilidade da AMOC. Ainda segundo esses mesmos autores, a série temporal do transporte da CNB também mostrou comportamento que acompanha a Oscilação Multidecadal do Atlântico para a temperatura da superfície do mar que tem sido amplamente relacionada às flutuações da AMOC.

Nas profundidades entre 1000 e 1500 m, a circulação ainda é associada aos ventos através de processos de bombeamento de Ekman, incluindo movimentos de subducção e afloramento (TALLEY et al., 2011). Os sistemas de correntes associados ao vento estendem-se fracamente até o fundo e apresenta uma extensão lateral limitada. Fora do regime dos contornos de oeste forçados pelo vento, a circulação abaixo da picnoclina tropical e subtropical tem seu fluxo muitas vezes associado à força do empuxo, e seguem os contornos de topografia de fundo (TALLEY et al., 2011).

Abaixo da CNB, a Corrente de Contorno Oeste Profunda (CCP) carrega a APAN em direção sul em profundidades maiores que $1200 \mathrm{~m}$ e representa o ramo inferior da 
AMOC (SCHOTT et al., 2005; ZHANG et al., 2011).

A Figura 4 apresenta um diagrama T-S para posição próxima ao testemunho estudado, utilizando dados de média anual entre 1955 a 2012 para os primeiros $1500 \mathrm{~m}$ de profundidade. Esses dados são provenientes do World Ocean Database 2013 (WOA2013), disponível em http://odv.awi.de . A curva apresenta uma assinatura típica de massa d'água do Atlântico Sul composta pelas massas d'água: Água Tropical (AT), Água Central do Atlântico Sul (ACAS) e Água Intermediária Antártica (AIA) (SILVEIRA et al., 1994; STRAMMA e SCHOTT, 1999; SILVA et al., 2005). A ausência da APAN neste diagrama permite inferir que todo o fluxo da coluna d'água até $1250 \mathrm{~m}$ segue em direção noroeste.

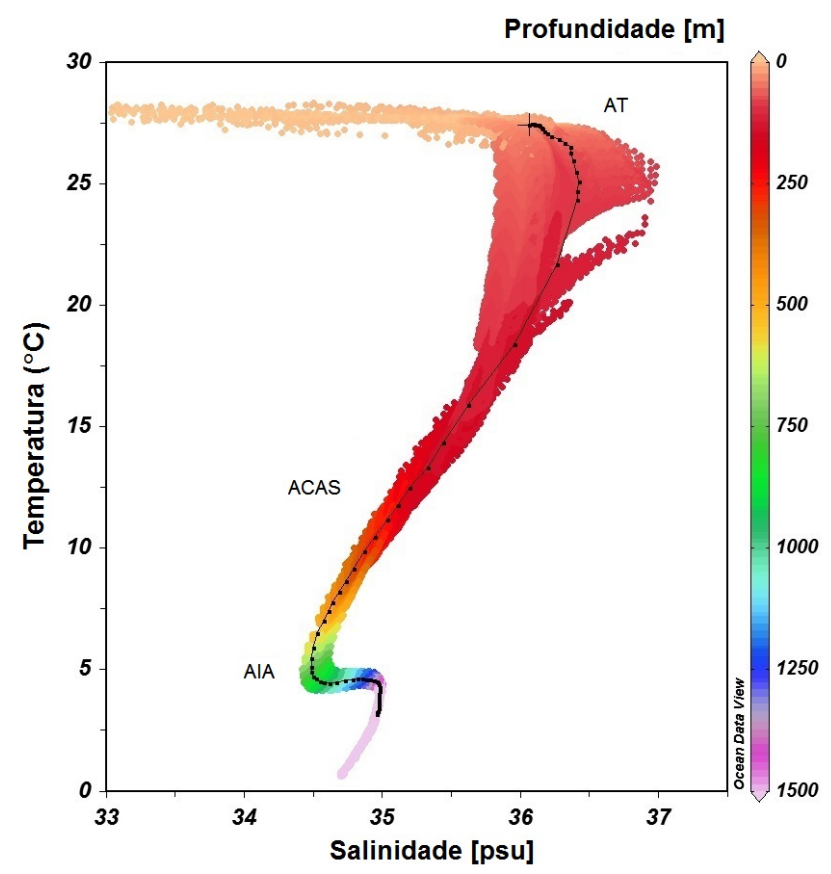

Figura 4: Diagrama T-S para a latitude $2.125^{\circ} \mathrm{S}$ e longitude $42.125^{\circ} \mathrm{W}$, dados provenientes do World Ocean Atlas 2013 (Levitus et al 2013). As massas d'água presentes nos primeiros $1500 \mathrm{~m}$ são: Água Tropical (AT), Água Central do Atlântico Sul (ACAS) e Água Intermediária Antártica (AIA).

Em relação às propriedades de superfície do mar, as médias anuais de temperatura e salinidade estão representadas na Figura 5. Esses dados também são provenientes do WOA2013 disponível em http://odv.awi.de. Durante os meses de Janeiro a Março, a temperatura média de superfície da região é de $28,07^{\circ} \mathrm{C}$ e salinidade de $36,090 \mathrm{psu}$. Entre Julho a Setembro, as médias apresentam pequena alteração sendo $26,58^{\circ} \mathrm{C}$ de tempera- 
tura e 36,289 de salinidade (LEVITUS et al., 2013; SCHLITZER, 2014). Próximo ao local de coleta do testemunho GeoB 16204-2, a região apresenta variações inferiores a $2^{\circ} \mathrm{C}$ de temperatura e menores que 0,5 psu de salinidade entre verão e inverno austral. Os perfis verticais de ambas variáveis, não apresentam mudanças significativas ao longo da coluna d'água indicando uma estrutura vertical de massa d'água estável, não ocorrendo alteração na estrutura vertical de massa d'água entre condições de verão e inverno austral, sem intrusão ou alteração de massa d'água na região.
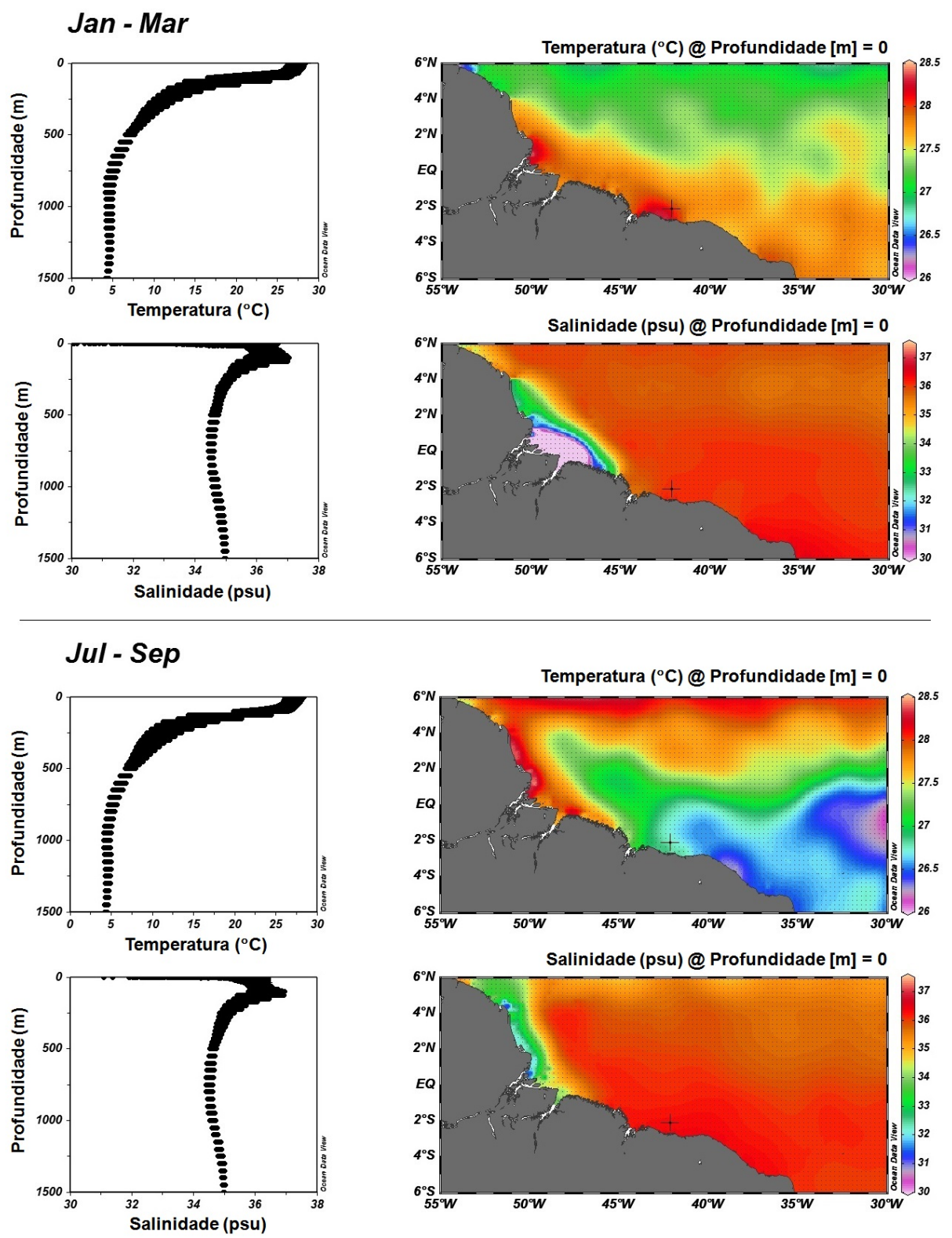

Figura 5: Média referente ao período de 1955 a 2012 de temperatura e salinidade da superfície do mar para os meses entre Janeiro a Março e Julho a Setembro provenientes do World Ocean Atlas 2013, Levitus et al. (2013). 


\subsection{Bacia de drenagem do rio Parnaíba}

O testemunho analisado, GeoB 16204-2, foi coletado ao largo da região nordeste brasileira, na região adjacente aos estados do Ceará, Piauí e Maranhão.

As principais fontes de sedimentos que alcançam esta região são provenientes principalmente do transporte da CNB e da descarga fluvial da região nordeste brasileira. Nesta região, o rio mais importante é o rio Parnaíba, que está inserido na região hidrográfica de mesmo nome, que estende-se entre as latitudes de $02^{\circ} 21^{\prime} \mathrm{S}$ a $11^{\circ} 06^{\prime} \mathrm{S}$ e longitude de $47^{\circ} 21^{\prime} \mathrm{W}$ a $39^{\circ} 44^{\prime} \mathrm{W}$, abrangendo parte dos estados de Piauí (75,3\%), Maranhão $(19,8 \%)$ e Ceará $(4,1 \%)$ (Figura 6). O rio Parnaíba estende-se por aproximadamente 1400 km, é perene e alcança o oceano Atlântico formando um delta, conhecido como delta do Parnaíba (MARQUES et al., 2004; CADERNO, 2006).

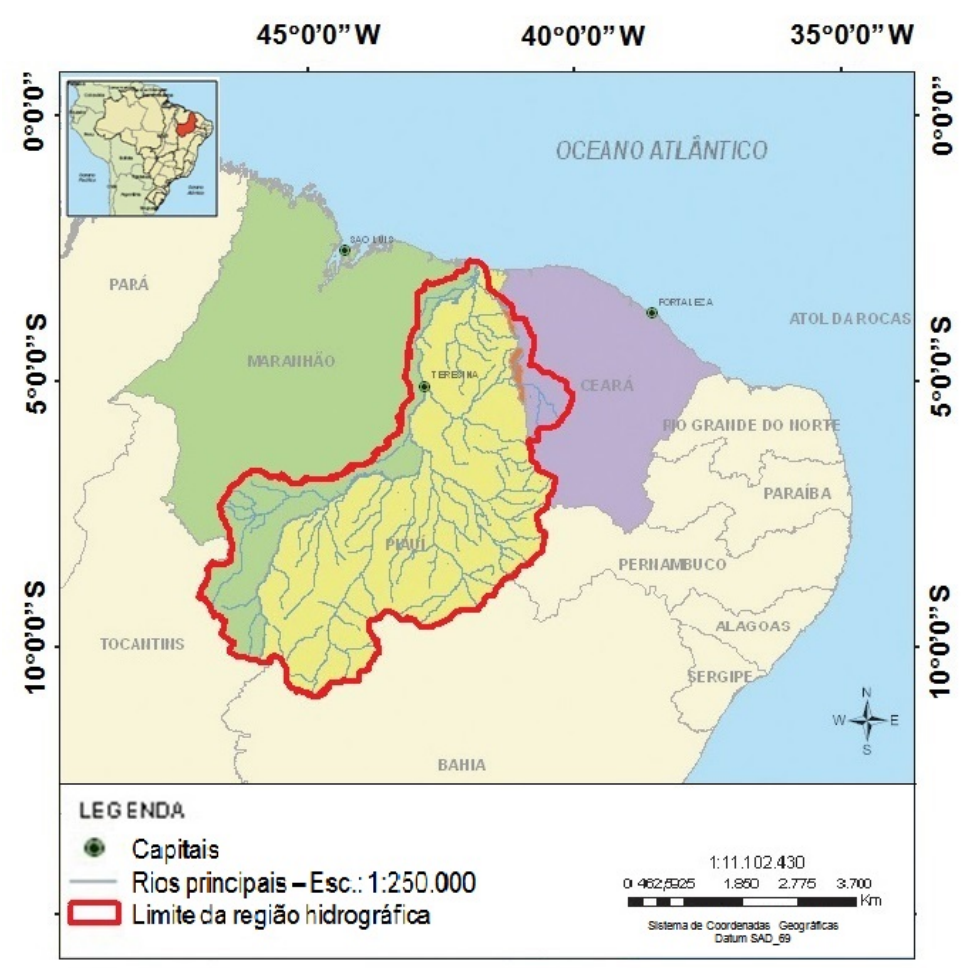

Figura 6: Localização da Bacia do Parnaíba, adaptado de Caderno da Região Hidrográfica do Parnaíba, Ministério do Meio Ambiente, Secretaria de Recursos Hídricos - Brasília: MMA (2006).

A região do delta do Parnaíba está sob influencia de uma maré semidiurna, com amplitude de aproximadamente 3,3 m durante maré de sizígia e 1,7 $\mathrm{m}$ em maré de qua- 
dratura (Figura 7). É uma região onde os ventos de nordeste são constantes ao longo do ano e atinge velocidades médias que variam de $2 \mathrm{~m} \cdot \mathrm{s}^{-1}$ a $6 \mathrm{~m} \cdot \mathrm{s}^{-1}$. A porção nordeste da região costeira do delta é dominada por ondas que vem de sudoeste, apresentando médias de altura de $1 \mathrm{~m}$ e período de 5 segundos. Esta combinação de configurações médias de vento e ondas favorecem o predomínio de correntes costeiras que vão de leste para oeste. Já a porção oeste do delta do Parnaíba é composta por um sistema de canais de maré e condições estuarinas lagunar, que se conectam ao rio Parnaíba através de um sistema de canais, que foi aberto artificialmente em 1960 (SILVA et al., 2015).

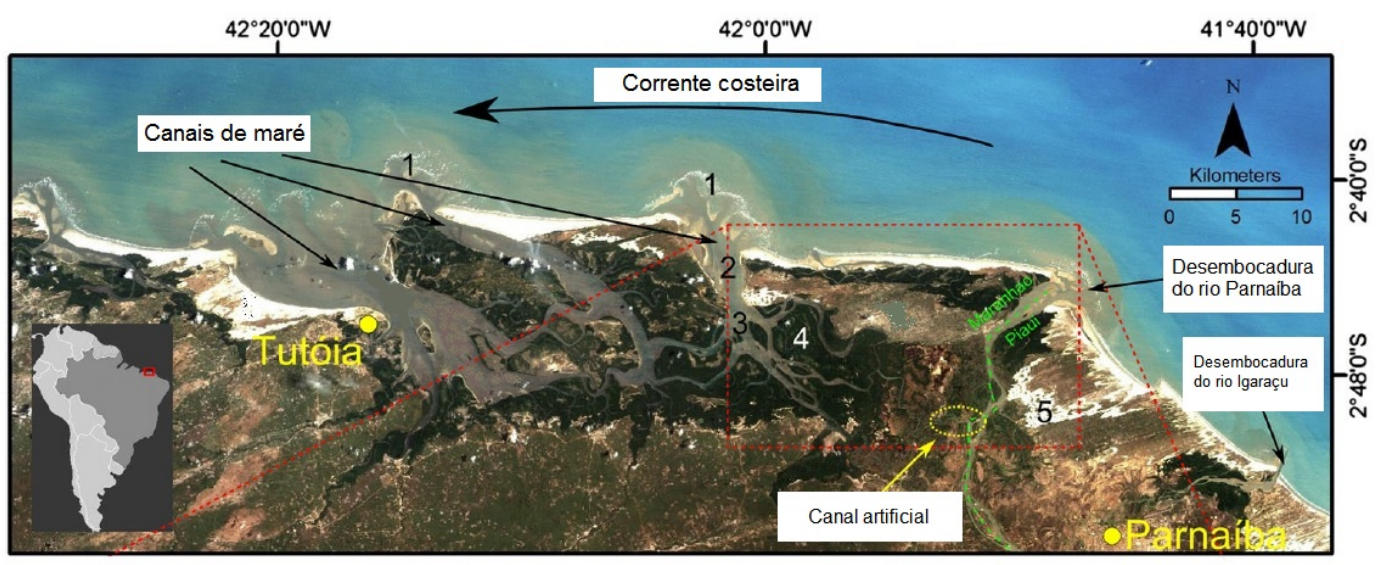

Figura 7: Imagem de satélite do delta do Parnaíba, adaptado de Szczygielski et al (2014)

O estado do Piauí, onde se situa grande parte da bacia hidrográfica do rio Parnaíba, localiza-se numa zona climática transicional entre região Amazônica, tipicamente quente e úmida, e região nordeste brasileira, semi-árida. Segundo a classificação climática de Köeppen, três tipos de climas dominam a região da bacia hidrográfica do Parnaíba: 1) o megatérmico chuvoso, variação (AW'), caracterizado como clima quente e úmido, com chuvas entre fevereiro e maio e temperaturas menores entre março e abril, característico da região litorânea e do baixo Parnaíba; 2) o semi-árido, variedade (BS), caracterizado por temperaturas elevadas e estáveis, superiores a $18^{\circ} \mathrm{C}$, e baixas precipitações médias anuais com distribuição irregular durante o ano, correspondendo às áreas de caatinga hiperxerófita; e 3) uma variedade do clima AW', o BSwh', caracterizado como clima semi-árido, que se caracteriza por curta estação chuvosa no verão influenciando princi- 
palmente a região sudeste da região hidrográfica (MARQUES et al., 2004; MMA, 2003; CADERNO, 2006).

Toda região hidrográfica do Parnaíba apresenta variações climáticas sazonais influenciadas pela posição da ZCIT e pela ocorrência e intensidade do fenômeno El Niño Oscilação Sul (ENOS). Garreaud et al. (2009), através da compilação de registros observacionais do século XX, apresentam os campos médios de precipitação, configuração média dos ventos em $925 \mathrm{hPa}$ (cerca de $1 \mathrm{Km}$ acima do nível do mar) e pressão atmosférica em 300 hPa para América do Sul nos meses de Janeiro e Julho (Figura 8).
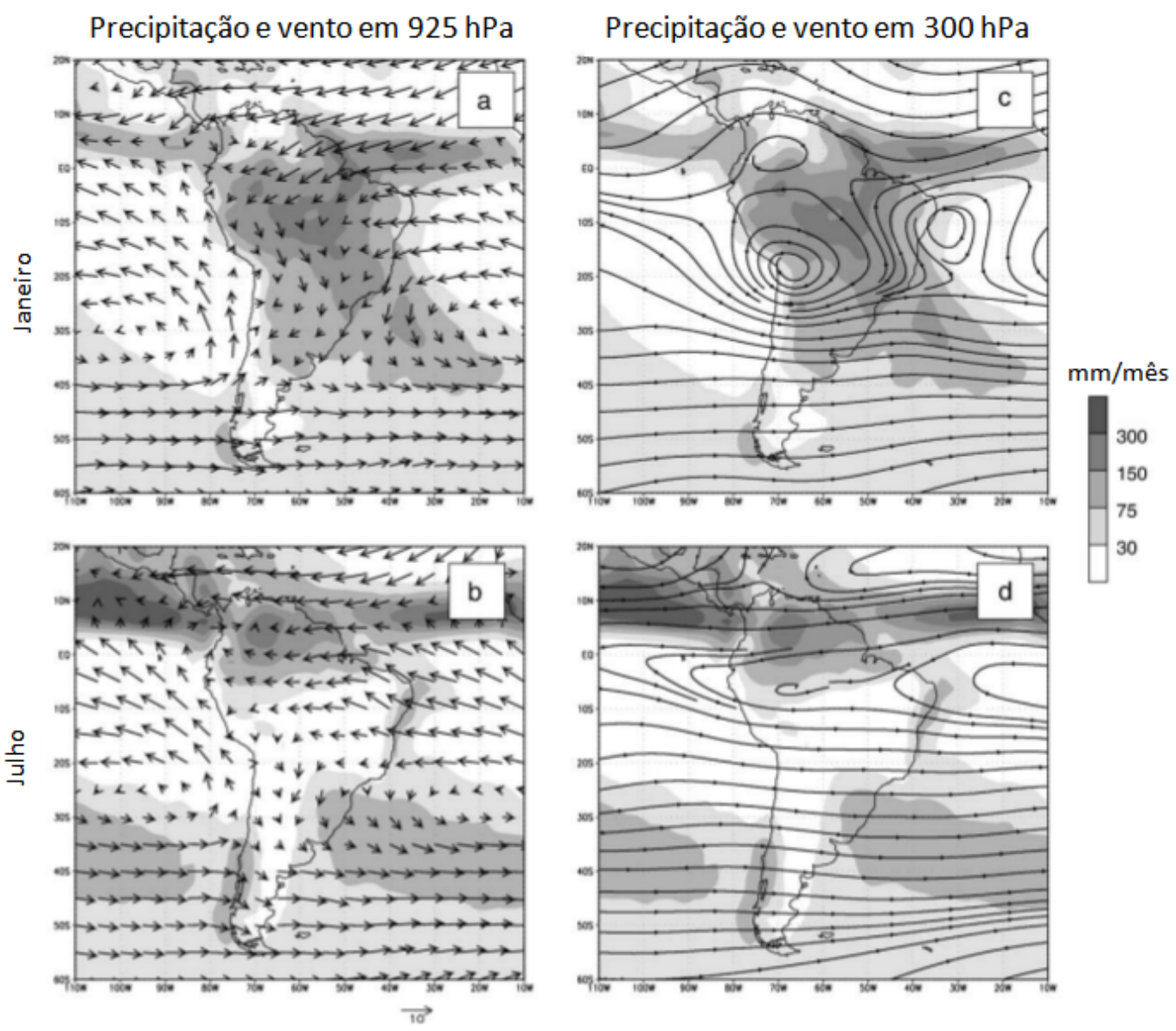

Figura 8: Painéis à esquerda: precipitação média de longo prazo em escala de cinza, valores extraídos de "Prediction Center de Prediction Center Merged Analysis of Precipitation" (CMAP) e vetores médios do campo de vento, em $925 \mathrm{hPa}$, para os períodos de (a) Janeiro e (b) Julho. Painéis à direita: precipitação média de longo prazo em escala de cinza e isolinhas do campo de pressão atmosférica em 300 hPa para (c) Janeiro e (d) Julho. Adaptado de Garreaud et al. (2009). 
Os dados de precipitação mostram a ocorrência de vários máximos: na região oceânica tropical configurado na forma de uma banda estreita orientada na direção lesteoeste, conhecida como ZCIT; sobre o continente, que se apresenta de forma ampla e bem desenvolvida durante o verão austral; e máximos na forma de bandas largas sobre os oceanos extratropicais (GARREAUD et al., 2009).

A ZCIT corresponde à uma feição meteorológica (ou cinturão) na região equatorial caracterizada por ser uma área de mínima pressão atmosférica, e intensa convergência dos ventos. Pelo fato da radiação solar ser intensa e uniforme na faixa equatorial, isto favorece condições de baixas pressões em superfície o que propicia a convergência dos ventos alísios de sudeste vindos do Hemisfério Sul (HS) e os ventos alísios de nordeste vindos do Hemisfério Norte (HN) em baixos níveis (Figura 9). A ascensão desses ventos provoca um resfriamento em níveis mais altos, com perda de umidade por condensação e precipitação. Desta forma, esta feição é considerada o mais importante sistema gerador de precipitação sobre a região equatorial do Atlântico, Pacífico e Índico (MELO et al., 2009).

No Atlântico Equatorial a ZCIT migra sazonalmente, em anos considerados normais, de sua posição mais norte, próximo a $14^{\circ} \mathrm{N}$, durante os meses de agosto-setembro, para sua posição mais ao sul, em torno de $2^{\circ} \mathrm{S}$, durante os meses de março-abril (Figura 11) (MELO et al., 2009). Durante o inverno austral, o máximo de precipitação continental localiza-se ao norte do equador, praticamente alinhado à posição da ZCIT oceânica, enquanto regiões continentais mais centrais, incluindo a porção sul da Amazonia, são caracterizadas por um período mais seco (Figura 8(b)). No final do mês de outubro, a ZCIT migra rapidamente em direção sul, propiciando durante o verão austral, uma extensa área de precipitação sobre o continente, que se estende da porção sul da Bacia Amazonica até a região norte da Argentina (Figura 8(a)). No outono austral, o máximo de precipitação retorna gradualmente à região norte da América do Sul. Esta migração tem levado alguns cientistas descreverem o clima da região central da América do Sul como clima de monção devido a alterações de direção dos ventos atuantes. Também durante o verão austral, o calor latente carregado por convecção sobre a Bacia Amazonica leva a formação de 
uma célula de alta pressão em altos níveis. Esta célula, conhecida como Alto da Bolívia, é uma feição que pode ser notada em até $200 \mathrm{hPa}$, cerca de $12 \mathrm{~km}$ acima do nível do mar (Figura 9) e é acompanhada por uma circulação ciclônica ligado à costa nordeste do Brasil (GARREAUD et al., 2009).

\section{Baixa Troposfera}

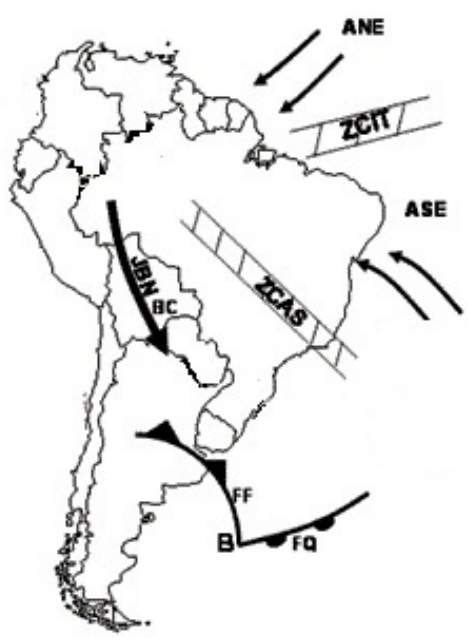

Alta Troposfera

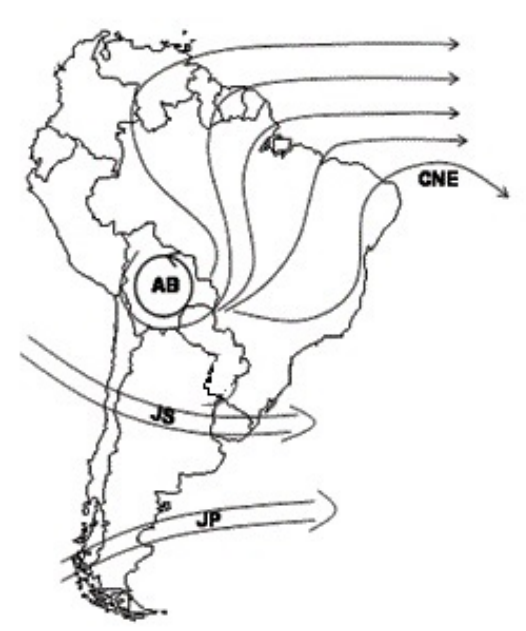

Figura 9: Circulação atmosférica esquemático em baixa e alta troposfera. ANE: alíseos de nordeste, ASE: alíseos de sudeste, ZCIT: Zona de Convergência Intertropical, ZCAS: Zona de Convergência do Atlântico Sul, JBN: jato de baixos níveis, FF: frente fria, FQ: frente quente, AB: Alto da Bolívia, CNE: cavado do nordeste, B: baixa pressão, BC: baixa do Chaco, JS: Jato subtropical e JP: jato polar. $\mathrm{AB}$ e o CNE são sistemas que se configuram no verão e desaparecem no inverno. Adaptado de Reboita et al. (2010).

A média anual de precipitação do nordeste brasileiro é apenas um terço dos valores médios em continentes de outras regiões de mesma latitude apresentando períodos de precipitação restritos ao outono austral, isto é, quando a ZCIT alcança a posição mais ao sul, apresentando variações da sua posição de ano-a-ano (NOBRE e SHUKLA, 1996). A aridez desta região parece ser resultado de uma intensificação local da célula de Hadley em conexão com regiões de forte convecção da região equatorial. Adicionalmente, outros estudos através do uso de modelos sugerem que o aquecimento da África está associada a um acentuado decréscimo da precipitação sobre o nordeste brasileiro devido aos baixos níveis de divergência de umidade e advecção de ar seco (COOK et al., 2004). 
Para a região hidrográfica do Parnaíba, anualmente as médias exibem temperatura do ar próxima de $27^{\circ} \mathrm{C}$, precipitação de $1.726 \mathrm{~mm} \cdot$ ano $^{-1}$ e evapotranspiração de 1.517 mm.ano ${ }^{-1}$ (MMA, 2003). Segundo dados climatológicos referentes ao período entre 1961 a 1990, provenientes do Instituto Nacional de Meterologia (INMET), e disponíveis em http://inmet.gov.br para as cidades de Parnaíba e Teresina, localizadas no estado do Piauí, a temperatura do ar, pressão atmosférica, evaporação e insolação apresentam menores valores entre janeiro e junho e maiores entre julho a dezembro. De forma oposta, a precipitação da cidade do Parnaíba exibe maiores valores entre janeiro a junho com máximos próximos a $400 \mathrm{~mm}$ em março e abril, e menores valores entre julho a dezembro, ocorrendo precipitação mínima inferior a $3 \mathrm{~mm}$ em agosto e setembro (Figura 10). Todas essas variações coincidem com a variação latitudinal da ZCIT (Figura 11).

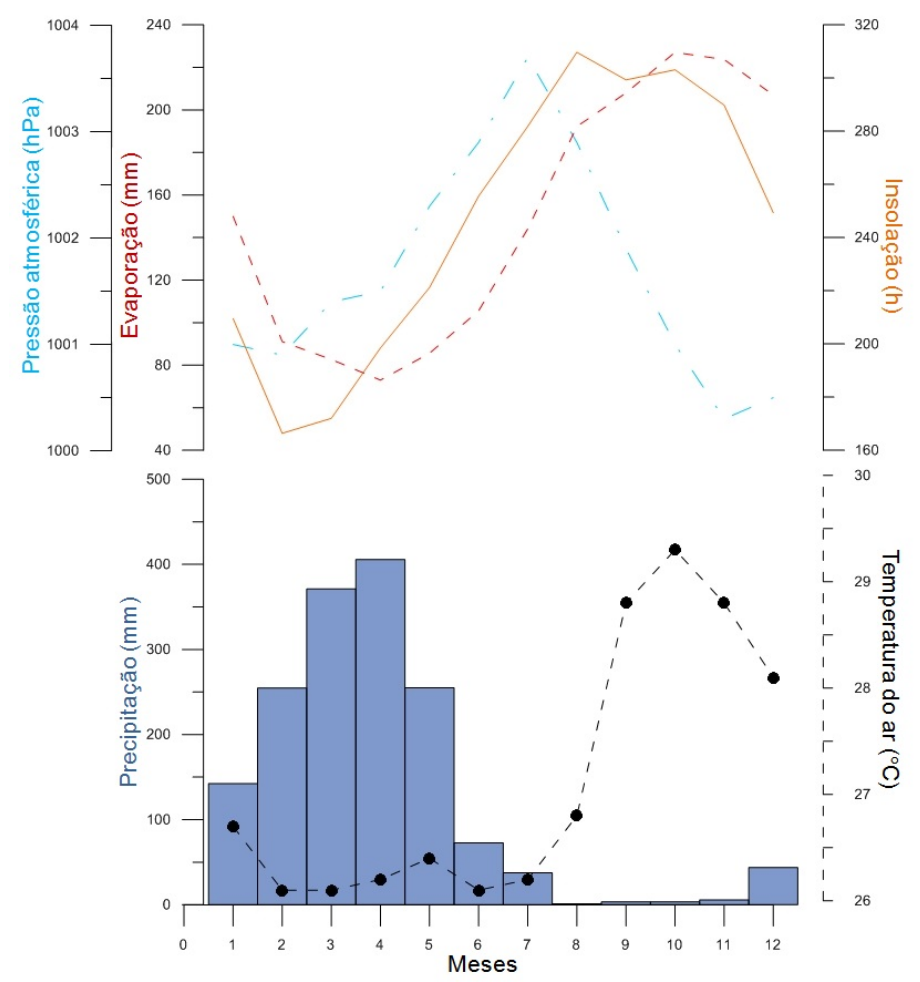

Figura 10: Médias climatológicas mensais normalizadas referente ao período de 1961 - 1990, provenientes do INMET. Os parâmetros climáticos apresentados são: temperatura do ar, pressão atmosférica, evaporação, insolação, precipitação para as cidades de Parnaíba e Teresina, estado do Piauí. 


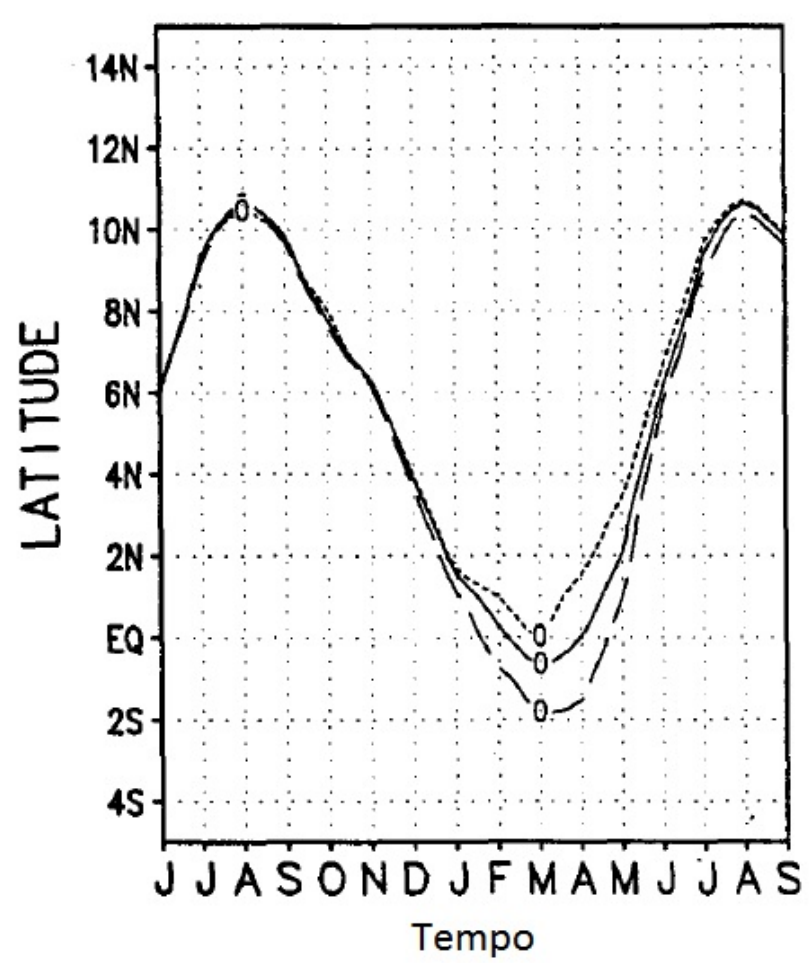

Figura 11: Deslocamento meridional da ZCIT sobre o oceano Atlântico, na longitude de 30W, adaptado de Nobre e Shukla (1996)

A precipitação na região nordeste brasileira também é influenciada pelo fenômeno El Ninõ Oscilação Sul (ENOS). O ENOS é um fenômeno natural de interação oceanoatmosfera, que afeta a circulação geral atmosférica, provocando remotamente variações na temperatura e precipitação de diversas regiões do globo. Este fenomeno é associado a alterações nos padrões normais da temperatura da superfície do mar e dos ventos alísios na região do Pacífico Equatorial, porém suas consequências para o Atlântico Sul ainda não são completamente conhecidas. Entretanto, estudos como Pezzi e Cavalcanti (2001) indicaram que em condições de dipolo positivo do Atlântico tropical, onde a TSM são anomalamente mais quentes no hemisfério norte e negativas no sul, associadas a condições de El Niño no Pacífico, indicaram um déficit de precipitação ou mesmo seca na região nordeste brasileira. Em condições de dipolo negativo do Atlântico, onde a TSM são anomalamente positivas no hemisfério Sul e negativas ao norte, verificou-se um aumento da precipitação na região norte do nordeste brasileiro. Em condições de La Ninã no Pacífico e dipolo negativo do Atlântico, obtiveram um aumento da precipitação por toda região nordeste brasileira (PEZZI e CAVALCANTI, 2001). Além da precipitação, 
aparentemente as variações na TSM causadas pelo ENOS afetam a variação do gradiente inter-hemisférico da TSM e tem impacto significativo na posição e intensidade da ZCIT, que acompanha o deslocamento das anomalias quentes da superficie do mar (NOBRE e SHUKLA, 1996).

\subsection{Clima da região nordeste brasileira durante o Holoceno}

Estudos paleoclimáticos na região de estudo, baseiam-se em interpretações provenientes de análises palinológicas, geoquímicas e isotópicas realizadas em registros sedimentares continentais, marinhos e espeleotemas. Alguns estudos em registros sedimentares continentais estão concentrados na região do lago de Caçó-MA e arredores (LEDRU et al., 2001; LEDRU et al., 2002; PESSENDA et al., 2005). Em sedimentos marinhos, Arz et al. (1998); Arz et al. (1999); Behling et al. (2000) realizaram estudos paleoceanográficos e paleoclimáticos, a partir de testemunhos coletados na margem continental ao largo dos estados da Paraíba, Rio Grande do Norte e Ceará. Além desses, estudos paleoclimáticos (e.g. Cruz et al. (2009)) foram realizados a partir de análises de espeleotemas, coletados no interior do Rio Grande do Norte. De forma genérica, a maioria dos trabalhos mencionados reconheceram condições climáticas de maior ou menor precipitação, associando essas mudanças de precipitação à posição média geográfica da ZCIT.

Segundo Cruz et al. (2009), os resultados isotópicos provenientes de espeleotemas do Rio Grande de Norte, indicaram que o período entre 13100 anos cal A.P. e 4200 anos cal A.P., as condições foram mais úmidas, enquanto que, o período de 4200 anos cal A.P. até o presente, foi menos chuvoso. Os autores também inferiram que a região nordeste brasileira estaria sob condições mais úmidas, ou de maior precipitação, durante condições de baixa insolação no verão e mais seco, ou menor precipitação, em condições de maior insolação. Já para a região continental sudeste brasileira as condições estariam em anti-fase às observadas na região nordeste. Entretanto, os resultados obtidos, a partir de análises de pólens e isótopos de carbono em sedimentos, indicaram que o período entre 9000 anos cal AP e 4000-3000 anos cal A.P., seria caracteristicamente mais seco devido a expansão de vegetação tipo savana e, posteriormente, de 3000 anos cal A.P. até o 
presente, teriam prevalecido condições mais úmidas na qual favoreceu o estabelecimento de uma vegetação mais densa (LEDRU et al., 2001; PESSENDA et al., 2005).

No ambiente marinho, Arz et al. (1998), através de resultados de isótopos estáveis em carapaças de foraminíferos planctônicos recuperados do talude superior ao largo da região do Rio Grande do Norte, reconstituíram as condições hidrográficas de superfície do mar. Os autores observaram a existência de uma periodicidade dos resultados em escalas milenares durante os últimos 85000 anos A.P. propondo que períodos quentes foram coincidentes com pulsos de sedimentos terrígenos indicados pelo conteúdo de titânio (Ti), ferro (Fe) e cálcio (Ca). Neste estudo, as variações de Ti e Fe foram utilizadas como indicadores de condições climáticas continentais úmidas, onde o aumento do conteúdo destes elementos no testemunho marinho estariam associados à elevação da taxa de pluviosidade sobre as bacias de drenagens de rios costeiros, associados a processos de erosão continental, vazão de rios e consequentemente no aporte de sedimentos terrígenos.

Complementando o trabalho de Arz et al. (1998), Behling et al. (2000) compararam os dados de Ti, Fe e $\delta^{18} O$ de G. sacculifer com dados de pólen do mesmo registro sedimentar marinho. Behling et al. (2000) identificaram períodos de alternâncias no tipo de vegetação da região ora composta por associações de espécies indicadoras de condições secas, ou semiáridas, e ora com períodos de elevada umidade e pluviosidade de forma concomitante às variação do aporte de sedimentos terrígenos ao longo do testemunho. Desta forma, os autores associaram tais variações a mudanças climáticas da região relacionado a alterações da configuração do campo de vento corroborando Arz et al. (1998). Além disso, também diagnosticaram que período, duração e intensidade dos eventos climáticos foram comparáveis a eventos, como por exemplo, Daansgaard-Oeschger e Bond sugerindo assim, a existência de uma teleconexão do sistema climático da área de estudo a regiões de altas latitudes do hemisfério Norte.

Prado et al. (2013), compilando um total de 120 conjuntos de paleodados multiproxies provenientes da América do Sul, através do uso de modelo computacional paleoclimático, sugeriram um cenário climático em 6000 anos cal A.P. no qual a região nordeste brasileira estaria sob condições mais úmidas, e posteriormente, em condições 
mais secas durante o Holoceno Tardio.

Em geral, a maioria dos resultados dos trabalhos realizados no nordeste brasileiro foi interpretada como variações de condições úmidas associados à mudança de posição geográfica da ZCIT. Além do padrão das variações da paleopluviosidade no continente sul-americano estarem condicionadas pela presença da ZCIT, um deslocamento em direção sul da posição média da ZCIT durante o Holoceno sustentariam mudanças nos padrões de configuração do oceano e atmosfera (HAUG et al., 2001; PETERSON e HAUG, 2006; SCHNEIDER et al., 2014).

\subsection{Flutuações do nível relativo do mar na região nordeste brasileira durante o Holoceno}

Flutuações do nível relativo do mar ao longo da costa brasileira durante o Holoceno ainda é uma questão muito discutida e não completamente compreendida. Suguio et al. (1985) apresentaram um dos primeiros trabalhos referente a curva de flutuação do nível relativo do mar durante o Holoceno para a costa brasileira, baseado em mais de 700 datações de radiocarbono, realizadas em indicadores biológicos como incrustrações de vermetídeos, além de outras conchas de moluscos e corais. A curva de flutuações do nível relativo do mar de Salvador, BA, é um dos exemplos pioneiros referente a região costeira nordestina brasileira proposta por estes autores. Os resultados deste trabalho indicaram que o nível do mar subiu rapidamente até atingir o nível do mar atual em aproximadamente 7100 anos A.P., e continuou subindo até alcançar o último máximo transgressivo holocênico ( $5 \mathrm{~m}$ acima do nível do mar atual) em aproximadamente 5100 anos A.P., idade posteriormente calibrada para 5660 anos cal A.P. (MARTIN et al., 2003). Ainda segundo Suguio et al. (1985), teria ocorrido regressão marinha, sendo que entre 4.200 anos A.P e 3900 anos A.P., o nível relativo do mar teria atingido um mínimo, situado provavelmente pouco abaixo do nível atual. Uma nova transgressão teria ocorrido entre 3900 - 3600 anos A.P., cujo máximo transgressivo teria sido próximo a 3,5 m acima do nível atual, que foi seguido por uma regressão lenta e regular até aproximadamente 2800 anos A.P., quando o nível do mar ficou abaixo do nível atual pela segunda vez. Para estes 
autores, entre 2700-2500 anos A.P., o nível do mar teria subido rapidamente até aproximadamente 2,5 m acima do nível atual. Após 2500 anos A.P. até o presente, o nível do mar foi caracterizado por uma descida regular até atingir a posição atual.

Bezerra et al. (2003), com base em datações de radiocarbono realizadas em conchas de moluscos, corais, incrustrados em beachrocks (arenitos de praia), sedimentos lagunares e turfas, apresentaram uma curva de flutuação do nível relativo do mar para a região costeira do Rio Grande do Norte. Estes autores observaram uma rápida subida do nível do mar entre 7100-5800 anos cal A.P. com a transgressão máxima holocênica ocorrendo em 5000 anos cal A.P., atingindo aproximadamente $4 \mathrm{~m}$ acima do nível do mar atual. Posteriormente, o nível relativo do mar começou a baixar progressivamente e apresentou duas oscilações ocorridas em 2100 anos cal A.P e 1100 anos cal A.P..

Mais recentemente, Caldas et al. (2006) também propuseram uma curva de flutuação do nível relativo do mar para a região do Rio Grande do Norte através de datação de radiocarbono em conchas de moluscos e material orgânico terrestres incrustrados em beachrocks e sedimentos lagunares. Entretanto, a curva proposta apresentou apenas um máximo seguido por uma descida constante do nível do mar. Para esses autores, em 7000 anos cal A.P o nível relativo do mar estaria a -3 m em relação ao nível atual. Ainda segundo essses autores, o nível relativo do mar foi subindo progressivamente até que em 6700 anos cal A.P. atingiu o nível relativo do mar atual e continuou subindo até alcançar o máximo de 1,3 m em 5.900 anos cal A.P., a partir do qual o nível do mar desceu progressivamente. 

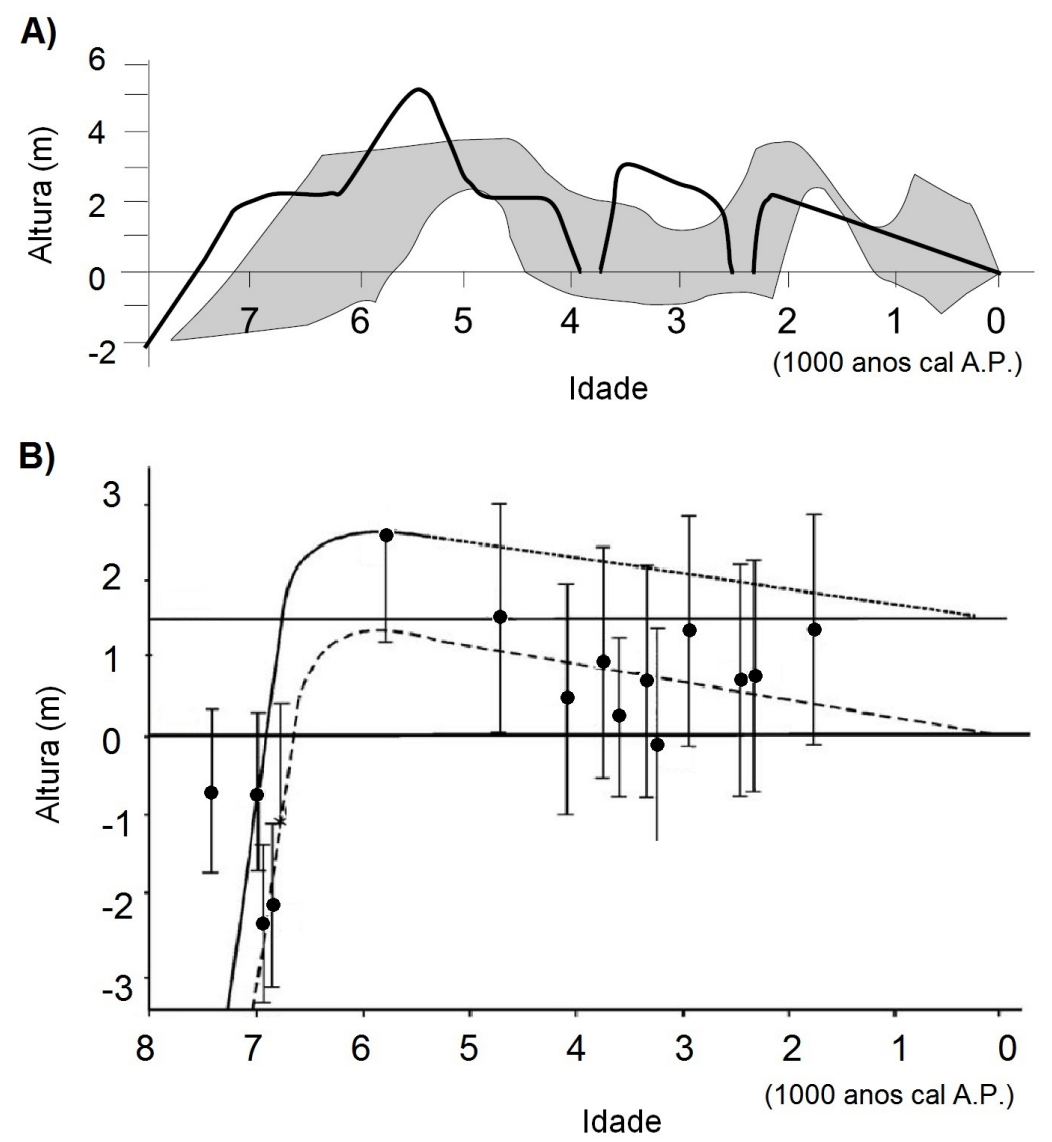

Figura 12: Curvas das flutuações do nível relativo do mar plotadas em idade calibrada e elevação em metros acima do nível do mar referente a região costeira do Rio Grande do Norte, nordeste brasileiro. A) Em linha continua, curva de variação do nível relativo do mar para o litoral de Salvador-BA proposto por Suguio et al.(1985) e, em cinza, curva proposta para o litoral do Rio Grande do Norte por Bezerra et al.(2003). B) Curva de variação do nível relativo do mar para o litoral do Rio Grande do Norte proposto por Caldas et al.(2006) 


\section{Materiais e Métodos}

Este trabalho é baseado na análise do registro sedimentar marinho GeoB 162042, coletado ao largo da desembocadura do rio Parnaíba, entre os estados de Piauí e Maranhão, na margem continental equatorial brasileira, latitude $01^{\circ} 59.75$ 'S, longitude $42^{\circ} 20.30^{\prime} \mathrm{W}$ e profundidade $1211 \mathrm{~m}$ (Figura 3). O testemunho GeoB 16204-2 foi coletado com um testemunhador a gravidade (gravity core), com recuperação total de 277 cm de comprimento. Entretanto, para o presente trabalho, apenas os primeiros $230 \mathrm{~cm}$ foram analisados. Este testemunho foi coletado no âmbito do projeto Response of Amazon Sedimentation to deforestation, land use and climate variability (AMADEUS), tendo sido coletado em Fevereiro de 2012 a bordo do N.Oc MARIA S. MERIAN, expedição MSM20/3, em parceria da Universidade de São Paulo e a Universidade de Bremen, Bremen, Alemanha.

Visando alcançar os objetivos propostos, foi estabelecida a cronologia do testemunho, além da realização de análises geoquímicas e sedimentológicas ao longo do registro sedimentar. Para as análises geoquímicas (conteúdo de carbonato de cálcio, elementos $\mathrm{Fe}, \mathrm{Ti}, \mathrm{Ca}$ ) e sedimentológicas (granulometria), o testemunho foi subamostrado em intervalos regulares de aproximadamente $2,5 \mathrm{~cm}$, perfazendo cerca de 90 subamostras. Para as análises geoquímicas em sedimento, as subamostras foram previamente congeladas e liofilizadas. As estimativas das propriedades hidrográficas da superfície do mar, temperatura e salinidade, foram baseadas na composição química (razão $\mathrm{Mg} / \mathrm{Ca}$, razão isotópica de ${ }^{18} \mathrm{O} /{ }^{16} \mathrm{O}$ ) de carapaças de foraminíferos planctônicos, sendo que para isso as subamostras foram peneiradas a úmido e secas em temperatura ambiente.

Nas subseções seguintes serão descritos os métodos empregados na obtenção dos resultados obtidos neste trabalho. 


\subsection{Cronologia}

A cronologia do GeoB 16204-2 foi baseada em oito datações radiométricas obtidas por espectrometria de massa em ${ }^{14} \mathrm{C}\left(\mathrm{AMS}{ }^{14} \mathrm{C}\right)$ realizadas em carapaças de foraminíferos planctônicos distribuídos ao longo dos primeiros $230 \mathrm{~cm}$. Cerca de $10 \mathrm{mg}$ de testas das espécies Globigerinoides ruber (G. ruber) (white and pink) e Globigerinoides sacculifer (G. sacculifer), com tamanho maior que $150 \mu \mathrm{m}$ foram selecionados e encaminhados para datação. Duas datações, obtidas nas profundidades de $06 \mathrm{~cm}$ e $200 \mathrm{~cm}$ no testemunho, foram realizadas no laboratório Poznan Radiocarbon Laboratory, Poznan, Polônia (Poz). As demais seis datações, obtidas nas profundidades de $50 \mathrm{~cm}, 106 \mathrm{~cm}$, $150 \mathrm{~cm}, 214 \mathrm{~cm}, 222 \mathrm{~cm}$ e $230 \mathrm{~cm}$ no testemunho, foram realizadas no laboratório Beta Analytics Inc., Miami, EUA (Beta) (Tabela 1).

As idades foram calibradas utilizando o software Calib 7.1, utilizando o Marine13 Calibration Dataset, disponível em http://calib.qub.ac.uk/calib/calib.html. Para a correção das idades calibradas, adotou-se como efeito reservatório a média global que é aproximadamente 400 anos, configurando o valor zero para correção marinha $(\triangle R=0)$ (STUIVER et al., 2005; REIMER et al., 2013). A relação idade-profundidade foi estabelecida através de interpolação linear simples entre as idades calibradas. O coeficiente angular, ou inclinação entre as idades e profundidades foram apresentados como taxa de sedimentação.

\subsection{Análise sedimentológica}

A análise granulométrica foi realizada em amostras previamente descarbonatadas utilizando o analisador a laser Malvern Mastersizer 2000 do Laboratório de Sedimentologia do IOUSP. A remoção do $\mathrm{CaCO}_{3}$ foi executada através da acidificação de aproximadamente $1 \mathrm{~g}$ de sedimento seco com $\mathrm{HCl}$ 10\%. Após a acidificação, as subamostras foram lavadas com água destilada e inseridas no analisador. Os resultados da distribuição granulométrica são apresentados em porcentagem (\%), em 53 intervalos utilizando notação phi $(\phi)$, onde $\phi$ é definido pela equação (5) 


$$
\phi=-\log _{2} d
$$

$d$ refere-se ao diâmetro do sedimento em mm e $\phi$ é adimensional.

A escala de $\phi$ varia entre $-1 \phi$ e $12 \phi$, com 53 subclasses de $0.25 \phi$. A classificação e o diâmetro médio foi obtida seguindo Folk e Ward (1957). O tamanho médio da fração silte, fração correspondente a 10 - $63 \mu \mathrm{m}$, foi denominado como sortable silte (SS) e aplicado como indicador de intensidade de corrente de fundo de acordo com McCave et al. (1995); Bianchi et al. (1999) and McCave (2008).

\subsection{Análises geoquímicas}

\subsubsection{Conteúdo de carbonato de cálcio $\left(\mathrm{CaCO}_{3}\right)$}

O conteúdo de $\mathrm{CaCO}_{3}$ foi obtido por diferença de pesos antes e depois da acidificação de aproximadamente $0,3 \mathrm{~g}$ de sedimento seco com $\mathrm{HCl} 10 \%$ e expresso em porcentagem (\%). Após a adição do ácido, as amostras foram aquecidas a temperatura de $50^{\circ} \mathrm{C}$ até que não se observasse a presença de bolhas. Para a certificação da total eliminação do $\mathrm{CaCO}_{3}$, adicionou-se 2 a 3 gotas de $\mathrm{HCl}$ concentrado. Em seguida, as amostras foram lavadas com água deionizada até que a solução sobrenatante apresentasse o pH igual da água deionizada fonte.

\subsubsection{Elementos inorgânicos no sedimento - Fe, Ti e Ca}

Elementos maiores constituintes do sedimento como Fe, Ti e Ca foram obtidos num intervalo regular de $2 \mathrm{~cm}$ ao longo de meia calha do testemunho através de um scanner de fluorescência de raio-X, Avaatech X-Ray Fluorescence operado a $10 \mathrm{kV}$ realizado em MARUM - Center of Marine Environmental Sciences, Universidade de Bremen, seguindo os procedimentos descritos por Richter et al. (2006). Os resultados dos elementos Fe, Ti e Ca provenientes do XRF são parâmetros relativos, semi-quantitativos, expressos em contagem por área por segundo, onde os resultados das razões dos elementos, $\mathrm{Fe} / \mathrm{Ca}$ e Ti/Ca, foram utilizadas como indicadores de aporte continental. 
Além da análise de XRF também foram determinados os teores dos elementos, Fe, Ti e Ca nos sedimentos. A determinação destes elementos foram realizadas em subamostras com intervalos de aproximadamente $2,5 \mathrm{~cm}$, submetidas a digestão total, isto é, destruição e solubilização através de um ataque ácido pelo método U.S.EPA 3052 (United States Environmental Protection Agency, de 1996), realizado no Laboratório de Química Inorgânica Marinha, LAQIMAR, no IOUSP. Aproximadamente 0,05 g de sedimento seco foram pesados em unidade digestora de teflon. Foram adicionados $5 \mathrm{~mL}$ de ácido nítrico concentrado $\left(\mathrm{HNO}_{3}\right), 2 \mathrm{~mL}$ de ácido fluorídrico $(\mathrm{HF})$ e $2 \mathrm{~mL}$ de peróxido de hidrogênio $\left(\mathrm{H}_{2} \mathrm{O}_{2}\right)$. Para cada etapa de adição, as amostras foram inseridas no sistema fechado de micro-ondas. A principal função dos ácidos é a liberação dos metais em sua totalidade, sendo o HF o agente responsável pela dissolução dos silicatos e o $\mathrm{H}_{2} \mathrm{O}_{2}$ responsável pela oxidação do material orgânico. A determinação dos teores de Fe, Ti e Ca foram realizadas por espectrometria de emissão ótica por plasma indutivamente acoplado (ICP-OES/Varian 710ES). Esta análise passou por um controle de qualidade no qual foram submetidas ao mesmo procedimento o material de referência, Estuarine Sediment SRM 1646a, intercalados a cada 20 amostras. Os resultados do controle de qualidade apresentaram bons resultados com precisão e acuracidade.

\subsubsection{Determinação da razão $\mathrm{Mg}$ /Ca e isótopos estáveis de oxigênio em foraminíferos planctônicos}

No presente trabalho as estimativas de paleotemperaturas e paleossalinidades foram baseadas nos dados de razão $\mathrm{Mg} / \mathrm{Ca}$ e isótopos estáveis de oxigênio determinadas nas carapaças de foraminíferos planctônicos da espécie Globigerionoides ruber (G. ruber) white, morfotipos sensu lato (s.l.) e sensu strictu (s.s.), seguindo Wang (2000). Cerca de $5 \mathrm{ml}$ de sedimento foram peneirados a úmido utilizando peneiras com abertura de malha de $0,250 \mathrm{~mm}$ e $0,350 \mathrm{~mm}$, em intervalos regulares de aproximadamente $2,5 \mathrm{~cm}$ ao longo do testemunho. Após o peneiramento úmido, as amostras foram secas em temperatura ambiente, temperaturas abaixo de $40^{\circ} \mathrm{C}$. Para cada amostra, cerca de 40 espécimes de G. ruber white de um único morfotipo foram separados, onde aproximadamente 30 
espécimes foram encaminhados para análise de $\mathrm{Mg} / \mathrm{Ca}$ e 5 a 10 espécimes para análise de isótopos estáveis de oxigênio $\left(\delta^{18} O\right)$. As amostras entre a base do testemunho, $230 \mathrm{~cm}$ até a profundidade de aproximadamente $170 \mathrm{~cm}$ foram selecionados o morfotipo s.s.; e de $170 \mathrm{~cm}$ ao topo, o morfotipo s.l. devido a não disponibilidade de um único morfotipo ao longo de todo o testemunho. Ambas as análises foram realizadas no Departamento de Geociências da Universidade de Bremen, Alemanha.

Para análise da razão Mg/Ca, seguiu-se essencialmente Barker et al. (2003), onde primeiramente as carapaças passaram por uma etapa de abertura e quebra, seguidas por um processo de limpeza e por último dissolução. O processo de abertura e quebra das carapaças teve como finalidade permitir e facilitar que sedimentos e detritos retidos na parte interna das câmaras dos foraminíferos pudessem se desprender da testa, além de aumentar a superfície de contato da calcita de forma a maximizar a eficiência do processo de limpeza. Para abertura e quebra das capaças foram utilizadas duas placas de vidro, os quais as carapaças foram sutilmente quebradas. Ressalta-se a importância do cuidado nesta etapa pois em caso de quebra excessiva das carapaças isto implica num possível aumento da probabilidade de perda de calcita durante o processo de limpeza (BARKER et al., 2003).

O processo de limpeza inclui etapas de descontaminação como (1) remoção de materiais argilosos, (2) remoção de matéria orgânica, (3) remoção de óxidos de Fe e Mn, (4) remoção de barita e por último (5) polimento final antes da dissolução. Após o processo de limpeza, as amostras foram dissolvidas em ácido nítrico $\left(\mathrm{HNO}_{3}\right)$ 0,0075M. A determinação dos teores dos elementos $\mathrm{Mg}$, $\mathrm{Ca}$ e $\mathrm{Al}$ foram executadas na solução final através do analisador Thermo Finnigan Element 2 com plasma indutivelmente acoplado ao espectrômetro de massa (ICP-MS) (BARKER et al., 2003). Além da razão $\mathrm{Mg} / \mathrm{Ca}$ obtida nas carapaças dos foraminíferos, foi utilizada a razão Al/Ca para identificar possíveis contaminações de argilo minerais residuais. Apenas 2 amostras apresentaram a razão $\mathrm{Al} / \mathrm{Ca}$ maior que $0,3 \mathrm{mmom} / \mathrm{mol}$ e foram consideradas contaminadas e descartadas. Durante o processo de determinação dos elementos, o equipamento passou previamente por um processo de calibração com uma solução branco e quatro soluções padrões com 
concentrações conhecidas de cada elemento para a determinação dos mesmos.

A análise de isótopos estáveis de oxigênio foi executada utilizando um espectrômetro de massa Finnigan MAT 251 acoplado a um sistema automático Kiel III, que se trata de um dispositivo automático para obtenção de $\mathrm{CO}_{2}$ do carbonato analisado. Os valores obtidos na análise de isótopos estáveis de oxigênio $\left(\delta^{18} O\right)$ estão expressos em unidades por mil (\%o), medidos em relação ao padrão Vienna Pee Dee Belemnite (VPDB), equação 6:

$$
\delta^{18} O=\frac{\left(\frac{18 O}{16 O}\right)_{\text {amostra }}-\left(\frac{18 O}{16 O}\right)_{\text {padrao }}}{\left(\frac{18 O}{16}\right)_{\text {padrao }}} \cdot 1000
$$

De acordo com o departamento de Geociências da Universidade de Bremen, o desvio padrão de longo termo do espectrômetro de massa utilizado na análise apresentou valores inferiores a $0,07 \%$ opara análise do $\delta^{18} \mathrm{O}$ e menores que $0,05 \%$ opara o $\delta^{13} \mathrm{C}$.

\subsubsection{Estimativa da temperatura (TSM) e salinidade da superfície do mar (SSM)}

As temperaturas de superfície do mar no presente trabalho foram estimadas a partir da combinação dos resultados da determinação da razão $\mathrm{Mg} / \mathrm{Ca}$ e a equação proposta por Anand et al. (2003), equação 7:

$$
M g / C a=0.449( \pm 0.006) e^{0.090 \cdot S S T}
$$

onde $\mathrm{Mg} / \mathrm{Ca}$ corresponde aos resultados obtidos da razão $\mathrm{Mg} / \mathrm{Ca} ; 0,449( \pm 0.006)$ a constante relacionada a temperatura para a espécie G. ruber white com tamanhos entre 250 $350 \mu \mathrm{m}$ e 0,090 a constante exponencial relacionada à mudanças dos valores de $\mathrm{Mg} / \mathrm{Ca}$ para cada $1^{\circ} \mathrm{C}$ de temperatura.

As estimativas de paleosalinidade foram determinadas indiretamente através da obtenção do isótopo oxigênio da água $\left(\delta^{18} O_{w}\right)$, através do uso de valores de SST obtidos na equação 7 e valores de isótopos estáveis de oxigênio obtidos nas carapaças $\left(\delta^{18} O_{\text {G.ruber }}\right)$. O $\delta^{18} O_{w}$ foi determinado seguindo a equação proposta por Mulitza et al. 


$$
T=-4.44 \cdot\left(\delta^{18} O_{\text {G.ruber }}-\delta^{18} O_{w}\right)+14.20
$$

onde $\mathrm{T}$ representa a temperatura durante a precipitação da calcita $\left({ }^{\circ} \mathrm{C}\right)$, proveniente da equação $7, \delta^{18} O_{\text {G.ruber }}$ representa os valores obtidos na análise de isótopos estáveis de oxigênio (\%o), e $\delta^{18} O_{w}(\% \circ)$ a composição isotópica da água do mar onde a calcita foi precipitada.

A estimativa da salinidade da superficie do mar (SSS) foi estimada a partir da equação proposta por Toledo et al. (2007) na qual:

$$
S S S=1.863 \cdot \delta^{18} O_{w}+34.95
$$

onde SSS refere-se a estimativa da salinidade da superfície do mar e $\delta^{18} O_{w}$ o valor da composição isotópica da água do mar obtido na equação 8. 


\section{Resultados}

Nesta seção serão apresentados todos os resultados obtidos das análises realizadas no registro sedimentar GeoB 16204-2. A apresentação seguirá a seguinte sequencia: cronologia, análise sedimentólogica e análises geoquímicas.

\subsection{Cronologia}

As datações obtidas no testemunho GeoB 16204-2 revelam que o registro sedimentar representa os último 8100 anos. Todos as datações obtidas estão apresentadas na Tabela 1, onde se verifica que a idade mais antiga, 8100 anos cal. A.P., ocorre na base do testemunho em $230 \mathrm{~cm}$ de profundidade e a idade mais recente, 400 anos cal. A.P., no topo do testemunho em $06 \mathrm{~cm}$ de profundidade. As idades referentes às profundidades intermediárias, entre base e topo do testemunho, apresentaram tendência linear decrescente contínua, conforme Figura 13. Graficamente, é possível verificar que a inclinação da reta que representa a relação idade-profundidade, neste estudo considerado como taxa de sedimentação, altera-se na profundidade de $214 \mathrm{~cm}$, próximo a 5200 anos cal. A.P.. Entre as idades estimadas das profundidades de $230 \mathrm{~cm}$ ( 8100 anos cal. A.P.) e $214 \mathrm{~cm}$ ( 5200 anos cal. A.P.), a inclinação observada é menor do que entre o intervalo de $214 \mathrm{~cm}$ (5200 anos cal. A.P.) e o topo. A inclinação no intervalo (8100 - 5200) anos cal. A.P. é de aproximadamente $5.5 \mathrm{~cm} \cdot \operatorname{kanos}^{-1}$, enquanto que entre (4900 - 417) anos cal. A.P., é $43.1 \mathrm{~cm} \cdot \operatorname{kanos}^{-1}$. Esta mudança da inclinação da reta em uma ordem de magnitude sugere que mudanças nas condições de sedimentação tenham ocorrido na área de estudo e proporcionado os valores observados. 
Tabela 1: Datações radiométricas e idades calibradas obtidas para o testemunho GeoB 16204-2.

\begin{tabular}{|c|c|c|c|c|c|c|}
\hline Prof. & Lab & Espécies & $\begin{array}{c}\text { Idade } \\
\text { radiométrica } \\
\text { convenc. } \\
\text { (anos A.P.) }\end{array}$ & $\begin{array}{c}+/-1 \sigma \\
\text { error } \\
\text { (anos A.P.) }\end{array}$ & $\begin{array}{c}\text { Idade } \\
\text { Radiométrica } \\
\text { ) } \\
\text { cal. (anos A.P.) }\end{array}$ & $\begin{array}{l}+/-1 \sigma \\
\text { error } \\
\text { (anos A.P.) }\end{array}$ \\
\hline 6 & Poz-49094 & & 770 & 30 & 417 & 80 \\
\hline 50 & Beta & G. ruber G. sacculifer & 2120 & 30 & 1705 & 100 \\
\hline 106 & Beta & G. ruber & 3110 & 30 & 2882 & 99 \\
\hline 150 & Beta & G. ruber G. sacculifer & 4030 & 40 & 4047 & 135 \\
\hline 200 & Poz-49095 & & 4695 & 35 & 4916 & 97 \\
\hline 214 & Beta & G. ruber & 4880 & 30 & 5205 & 114 \\
\hline 222 & Beta & G. ruber G. sacculifer & 5170 & 30 & 5534 & 66 \\
\hline 230 & & G. ruber & 7640 & 40 & 8095 & 98 \\
\hline
\end{tabular}

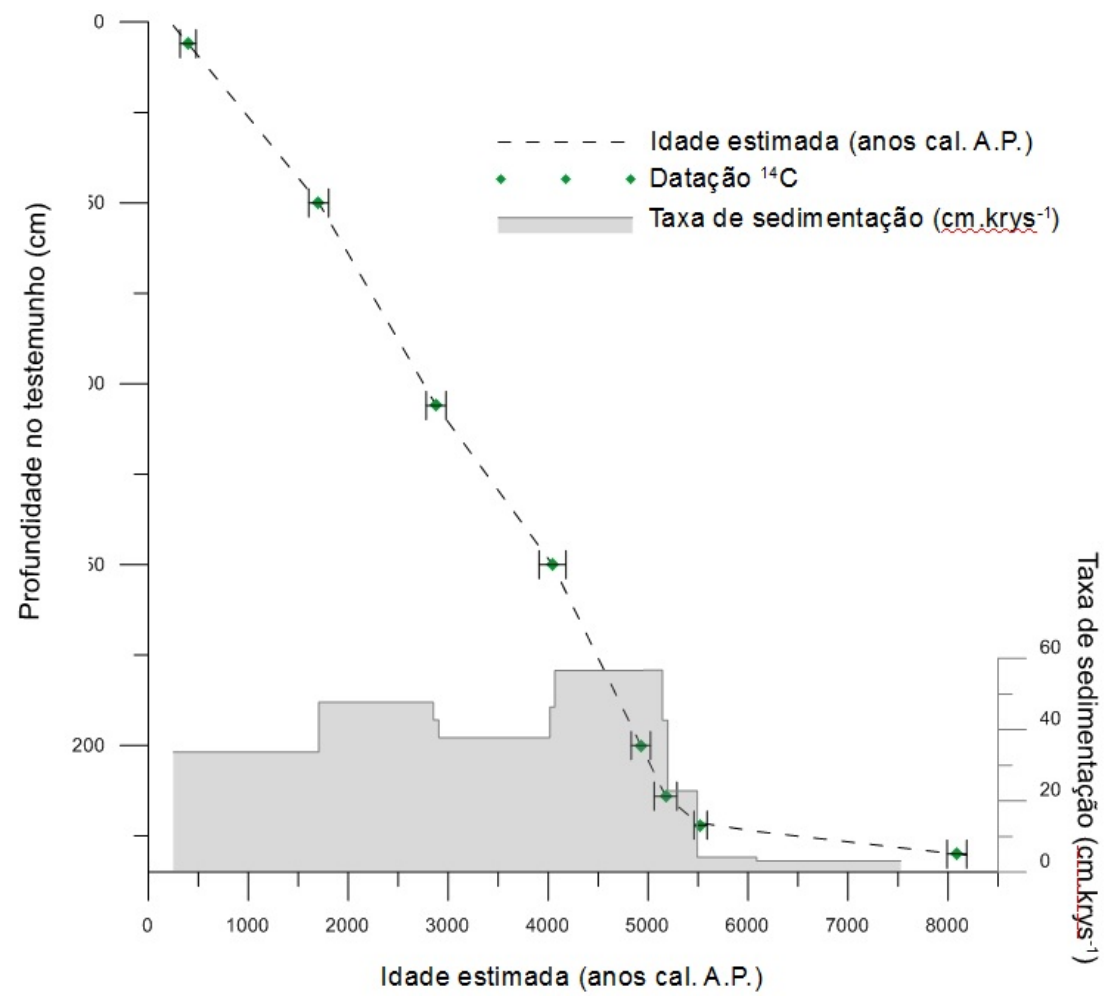

Figura 13: Cronologia do testemunho GeoB 16204-2: relação entre idade e profundidade baseado em 8 datações radiométricas distribuídas ao longo do testemunho. 


\subsection{Análise sedimentológica}

Os resultados da análise granulométrica estão apresentados na Figura 14 e revelam a predominância da fração fina ao longo de todo o testemunho. A fração dominante é a fração silte que apresenta valores entre $65 \%$ próximo a base e $85 \%$ próximo ao topo, com tendência crescente em direção ao topo. O conteúdo da fração argila está entre 7\% e $20 \%$, com os maiores valores inseridos no intervalo de 4500 anos cal A.P. a 2500 anos cal. A.P.. Já a fração areia apresentou valores entre $4 \%$ a 30\%, onde os maiores valores foram observados próximo a base, no intervalo entre 8100 anos cal. A.P. e 5000 anos cal. A.P. e menores valores próximo à região do topo do testemunho. De forma complementar à fração silte, a fração areia apresentou tendência decrescente em direção ao topo.

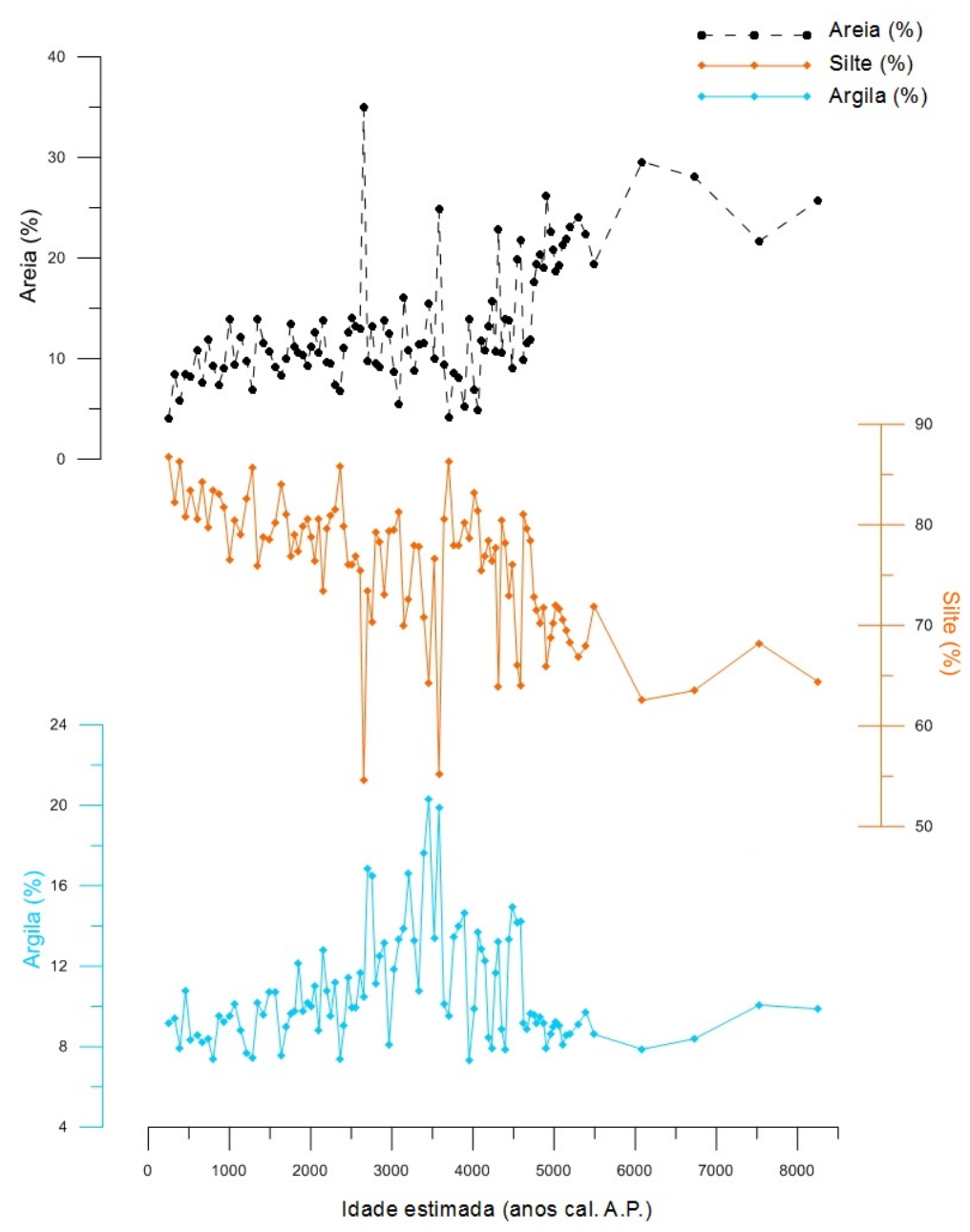

Figura 14: Distribuição das frações areia (\%), silte (\%) e argila (\%), nos últimos 8100 anos no testemunho GeoB 16204-2. 
A Figura 15 apresenta os dados de granulometria obtidos a cada $0,25 \phi$ interpoladas para um intervalo de 100 anos, distribuídos ao longo dos últimos 8100 anos cal A.P. Tendências semelhantes aos observadas na Figura 14 também ocorrem nesta representação em maior resolução. Maiores frequências para as classes próximo a $4 \phi$ ocorrem entre 8100 anos cal A.P. e 5000 anos cal A.P.. Entre 5000 anos cal A.P. e 2500 anos cal A.P. não se observa nenhuma moda definida para a distribuição das partículas, e entre 2500 anos cal A.P. e o presente, maiores frequências são observadas para $\phi$ próximo a 6.

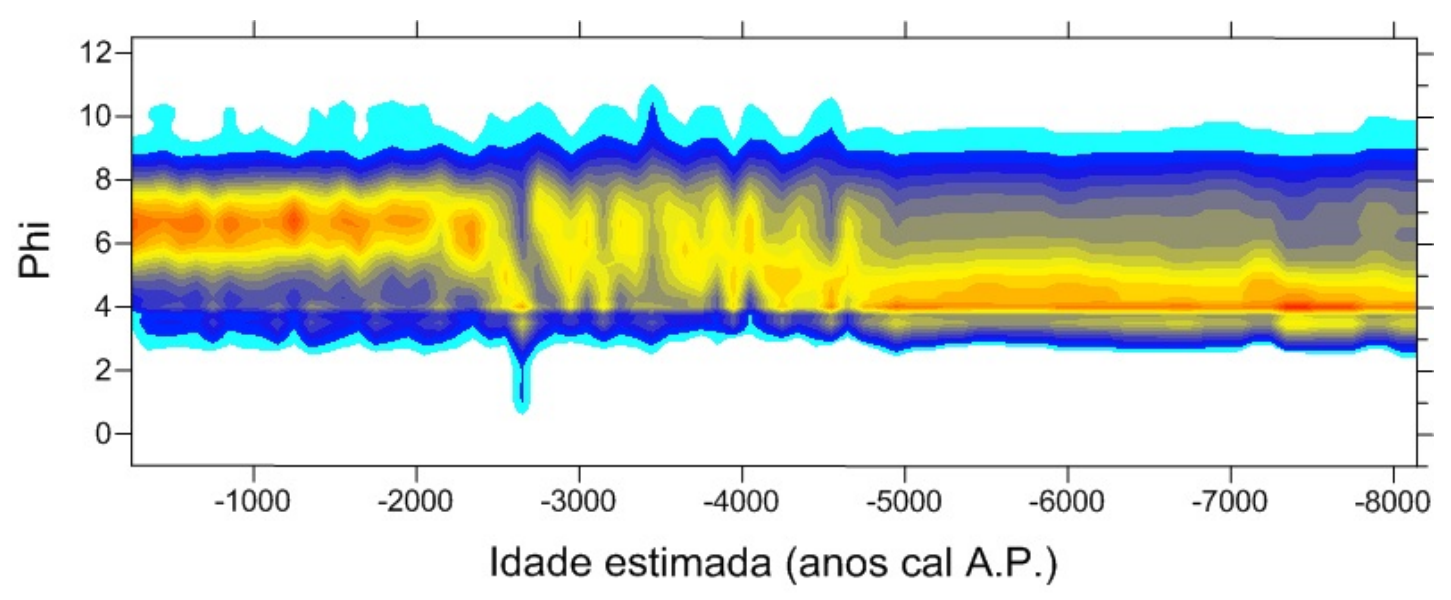

9.598 .587 .576 .565 .554 .543 .532 .521 .510 .50

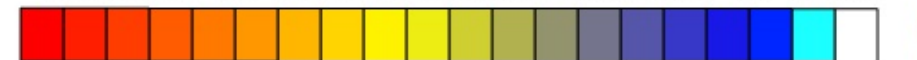

Figura 15: Distribuição dos tamanhos das partículas (Particle size distribution - PSD), frequência em \% para cada classe de $\phi$, nos últimos 8100 anos no testemunho GeoB 16204-2.

Na Figura 16, estão representados os resultados obtidos de sortable silt ao longo do testemunho. Observa-se que os valores da média do sortable silt apresenta tendência crescente em direção ao topo e variam entre $5.2 \phi$ e $5.7 \phi$. Três períodos distintos podem ser observados na distribuição dos valores de sortable silt ao longo do testemunho, onde o primeiro período, de 8100 anos cal A.P. a 5000 anos cal A.P., caracterizado pela ocorrência dos menores valores do sortable silt, em torno de $4.9 \phi$. O segundo período, de 5000 anos cal. A.P. até aproximadamente 2500 anos cal. A.P., onde se observa grande variabilidade nos valores, que oscilam de $5.2 \phi$ a $5.7 \phi$. Já no terceiro período, a partir de 2500 anos cal. A.P. até o presente, a variabilidade nos dados diminui, que ficam próximos 
a $5.7 \phi$.

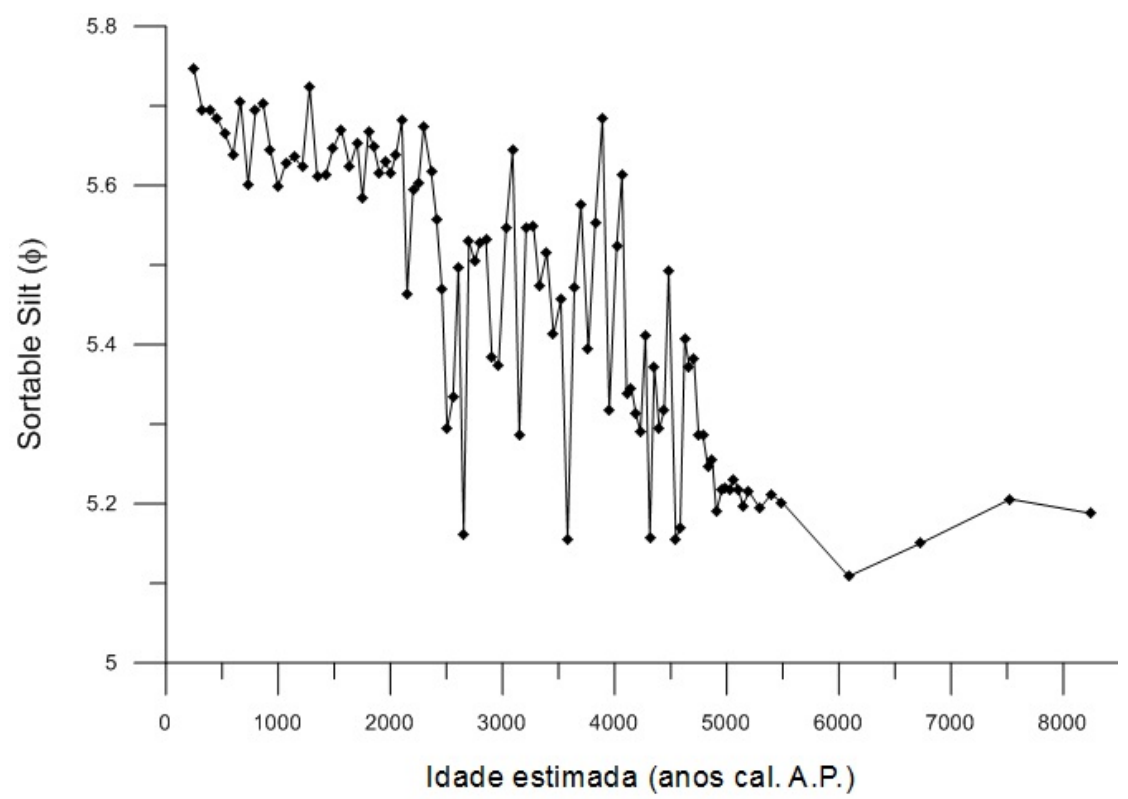

Figura 16: Distribuição dos valores de sortable silt $(\phi)$ para os para os últimos 8100 anos no testemunho GeoB 16204-2.

\subsection{Análises geoquímicas}

\subsubsection{Conteúdo de $\mathrm{CaCO}_{3}(\%)$}

Para a análise do conteúdo de $\mathrm{CaCO}_{3}$, os resultados apresentaram valores acima de $60 \%$ ao longo de todo o testemunho com tendência crescente em direção ao topo (Figura 17). No intervalo entre 8100 anos cal. A.P. e 5000 anos cal. A.P., verifica-se a ocorrência de menores valores, aproximadamente $68 \%$ enquanto entre 5000 anos cal. A.P. até o presente, os valores crescem gradativamente alcançando valores superiores a $80 \%$. 


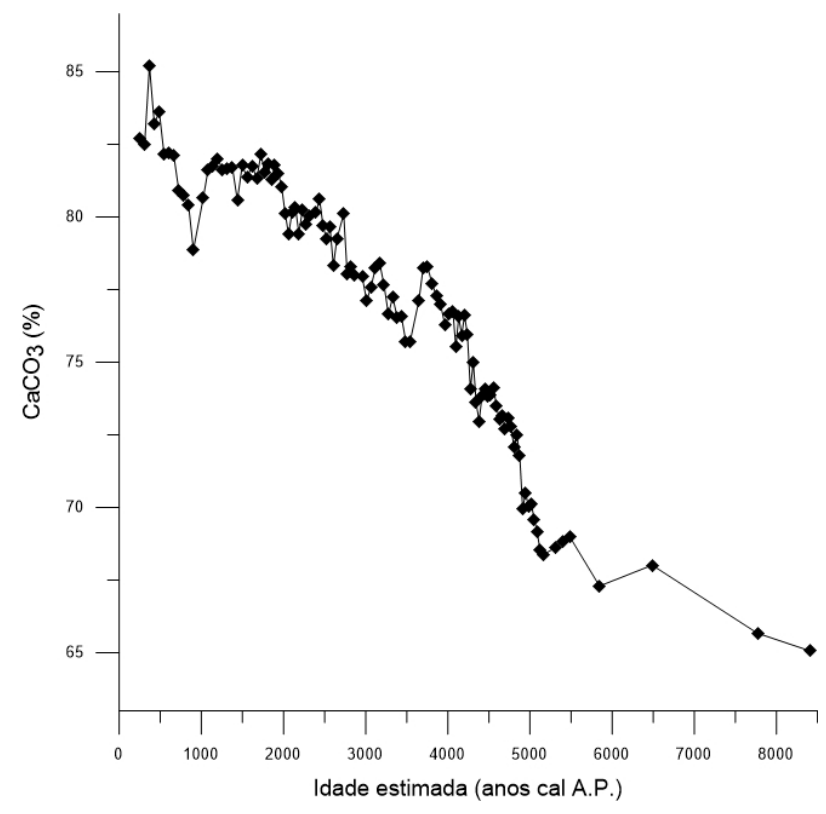

Figura 17: Distribuição dos valores de conteúdo de $\mathrm{CaCO}_{3}(\%)$ ao longo dos últimos 8100 anos no testemunho GeoB 16204-2.

\subsubsection{Elementos inorgânicos no sedimento - Ti, Fe e Ca}

Os resultados das razões $\mathrm{Fe} / \mathrm{Ca}$ e Ti/Ca obtidos por XRF e por digestão total estão apresentados na Figura 18. Os valores de ambas as razões apresentam progressiva diminuição em direção ao topo do testemunho. Entre 8100 anos cal. A.P. e 5000 anos cal. A.P. ocorrem os maiores valores, onde $\mathrm{Ti} / \mathrm{Ca}$ e $\mathrm{Fe} / \mathrm{Ca}$ alcançam valores próximos a 0,010 ppm e $0,10 \mathrm{ppm}$ respectivamente. Entre 5000 anos cal. A.P. até o presente, os valores das razões decrescem continuamente até atingirem valores inferiores a 0.004 para a razão Ti/Ca e 0,05 do Fe/Ca. É interessante notar que os valores obtidos para a razão Ti/Ca tanto por XRF e digestão total apresentaram valores similares, no intervalo entre 0,004 a 0,010. Entretanto, os resultados da razão Fe/Ca obtido por XRF variaram entre 0,03 a 0,09 , enquanto os valores obtidos por digestão total apresentaram variação entre 0,04 a 0,11 . 


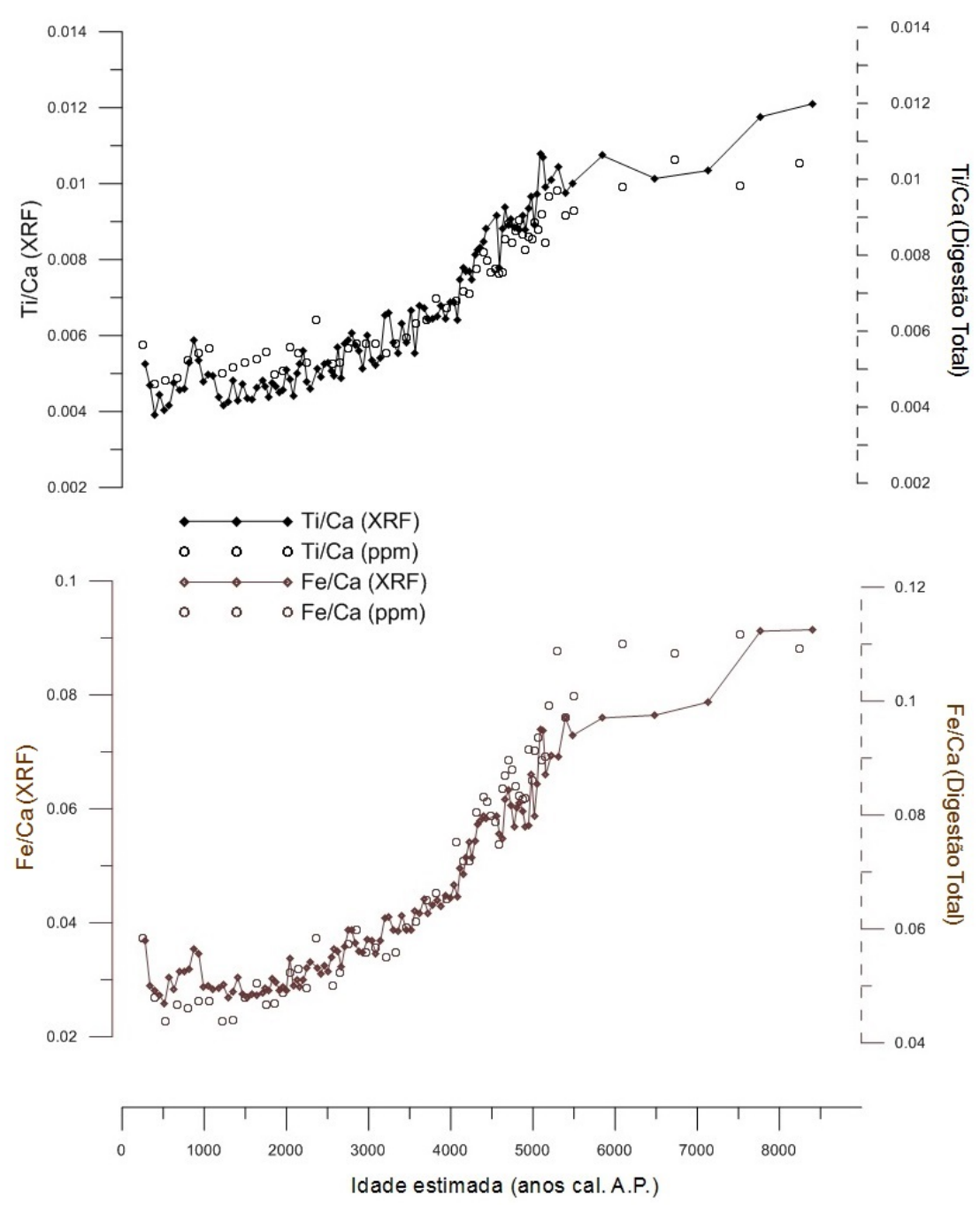

Figura 18: Distribuição dos valores das razões Ti/Ca e Fe/Ca ao longo dos últimos 8100 anos no testemunho GeoB 16204-2, obtidos pelos métodos de XRF e digestão total.

\subsubsection{Razão elementar Mg/Ca e Al/Ca em foraminíferos planctônicos}

Cerca de setenta valores de $\mathrm{Mg} / \mathrm{Ca}$ e $\mathrm{Al} / \mathrm{Ca}$ foram obtidos em testas de foraminíferos planctônicos da espécie G. ruber white do testemunho GeoB 16204-2. A baixa correlação obtida entre estas duas razões, apresentadas na Figura 19, atesta que o procedimento de limpeza realizada antes da dissolução das carapaças ocorreu de forma eficiente, e que os resultados de $\mathrm{Mg} / \mathrm{Ca}$ obtidos das testas dos foraminíferos não estão contaminados por sedimentos de origem não biogênica. 


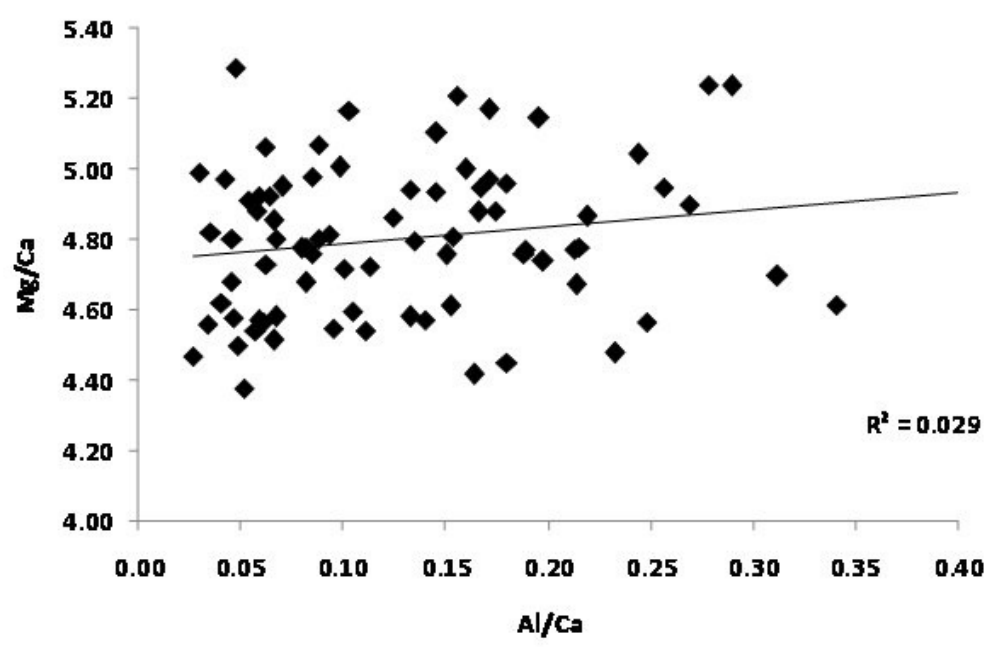

Figura 19: Dados obtidos de correlação simples entre as razões $\mathrm{Mg} / \mathrm{Ca}$ e $\mathrm{Al} / \mathrm{Ca}$ obtidas nas carapaças dos foraminíferos planctônicos do testemunho GeoB 16204-2

\subsubsection{Razão $\mathrm{Mg} / \mathrm{Ca}$, isótopos estáveis de oxigênio em foraminíferos planctônicos, TSM e SSM}

A Figura 20 apresenta os resultados obtidos de $\mathrm{Mg} / \mathrm{Ca}, \mathrm{TSM}, \delta^{18} \mathrm{O}_{\text {G.ruber }}, \delta^{18} \mathrm{O}_{\text {seawater }}$ e SSM para os últimos 5000 anos cal. A.P.. Observando a Figura 20 (I), constata-se que os valores de $\mathrm{Mg} / \mathrm{Ca}$ variaram entre 4,4 $\mathrm{mmol} \cdot \mathrm{mol}^{-1}$ a $5,3 \mathrm{mmol} \cdot \mathrm{mol}^{-1}$ e apresentaram média em torno de 4,8 $\mathrm{mmol} \cdot \mathrm{mol}^{-1}$ e desvio padrão de $0,22 \mathrm{mmol} \cdot \mathrm{mol}^{-1} \mathrm{sem}$ nenhuma tendência evidente (Figura 20). A distribuição dos valores de TSM segue o mesmo padrão de distribuição dos dados de $\mathrm{Mg} / \mathrm{Ca}$, entretanto, convertidos em valores de temperatura que variaram entre $25,5^{\circ} \mathrm{C}$ a $27,5^{\circ} \mathrm{C}$, média de $26,3^{\circ} \mathrm{C}$ e desvio padrão de $0,5^{\circ} \mathrm{C}$. Além disso, verifica-se que a amplitude de $\mathrm{Mg} / \mathrm{Ca}$ de aproximadamente 0,9 $m m o l \cdot m o l^{-1}$ equivale a amplitude em TSM de cerca de $2^{\circ} \mathrm{C}$.

Na Figura 20 (II) são exibidos os valores obtidos de $\delta^{18} \mathrm{O}_{\text {G.ruber }}$. Os valores de $\delta^{18} \mathrm{O}_{\text {G.ruber }}$ variaram entre $-2,3 \%$ a $-1,4 \%$, com média próximo a -1,9\%oe desvio padrão de 0,14\%o. Na Figura 20 (III), são apresentados os resultados de $\delta^{18} \mathrm{O}_{\text {seawater }}$ e SSM derivado da combinação dos resultados de TSM e $\delta^{18} \mathrm{O}_{\text {G.ruber }}$. O eixo do lado esquerdo do gráfico indica valores de $\delta^{18} \mathrm{O}_{\text {seawater }}$ expressos em \%ocujos valores variaram entre $0,3 \%$ oa $1,2 \%$, e apresentaram média próximo a $0,82 \%$ e desvio padrão de $0,2 \%$. De forma análoga, 
o eixo do lado direito representa os valores de $\delta^{18} \mathrm{O}_{\text {seawater }}$ convertidos em SSM com variação entre 35,5 a 37,2, média em torno de 36,5 e desvio padrão de 0,33 . Devido a problemas de transporte das amostras, cerca de 30 amostras não puderam ser analisadas. Assim, a região da base, intervalo entre 8100 anos cal A.P. e 5000 anos cal A.P., os valores de TSM e SSM não puderam ser reconstituídos.

(I)

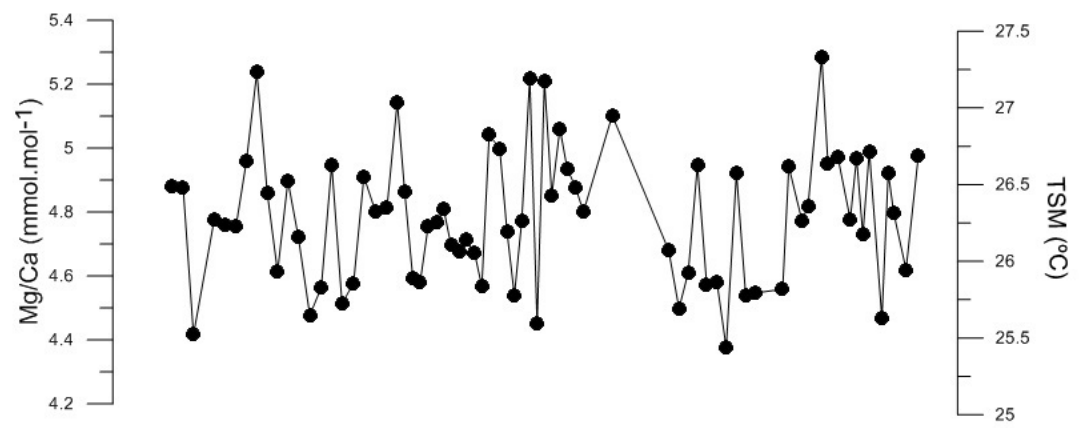

(II)

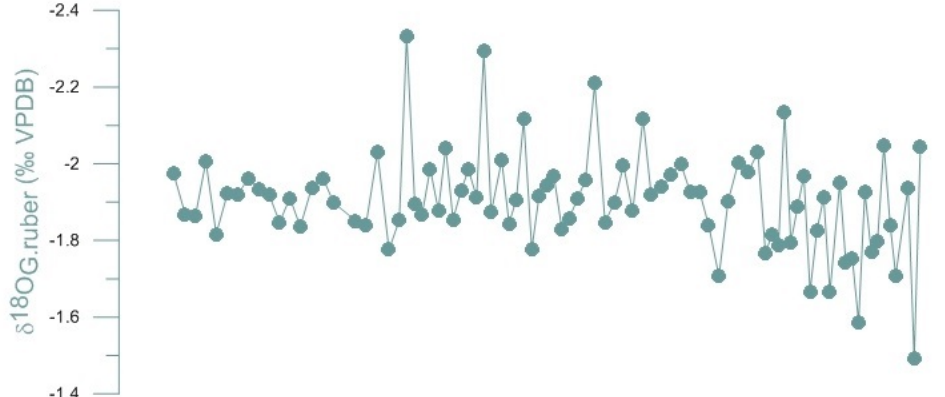

(III)

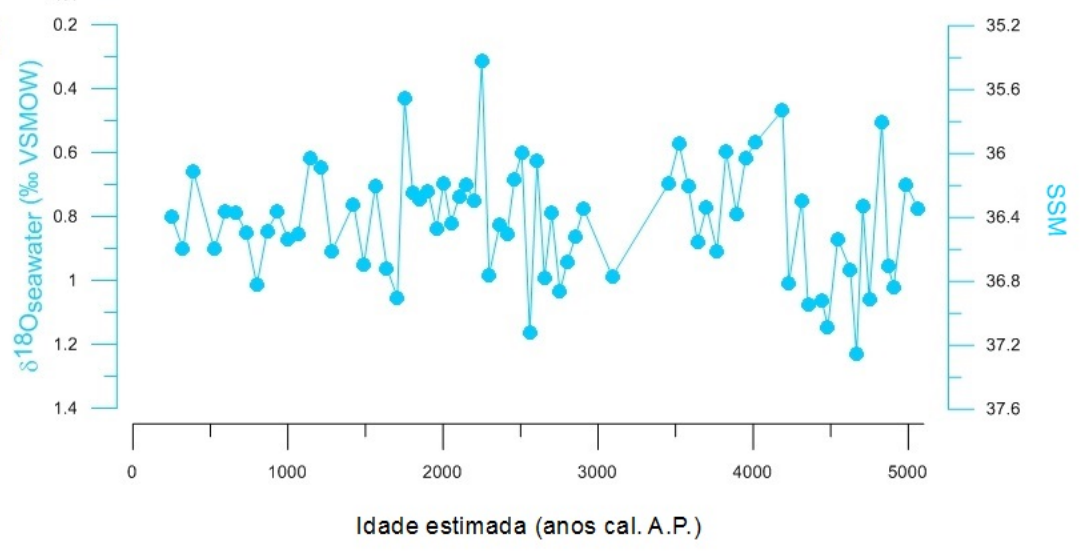

Figura 20: Resultados das análises geoquímicas obtidos em indivíduos de foraminíferos planctônicos da espécie G. ruber white para os últimos 5000 anos no testemunho GeoB 16204-2. (I) Resultados obtidos de Mg/Ca e TSM, (II) Resultados obtidos de $\delta^{18} \mathrm{O}_{\text {G.ruber }}$, (III) Resultados de $\delta^{18} \mathrm{O}_{\text {seawater }}$ e SSM. 


\subsection{5 $\delta^{18} \mathrm{O}$ e $\delta^{13} \mathrm{C}$ dos morfotipos Globigerinoides ruber (s.l.) e Globigerinoides ruber} (s.s.)

Para 15 amostras distribuídas aleatoriamente ao longo do testemunho GeoB 162042, foram obtidos valores de isótopos estáveis de oxigênio $\left(\delta^{18}\right)$ e isótopos estáveis de carbono $\left(\delta^{13} \mathrm{C}\right)$ para os morfotipos G. ruber (s.l.) e G. ruber (s.s.) (Tabela 2).

Tabela 2: Resultados dos isótopos estáveis para G. ruber (s.1.) e G. ruber (s.s).

\begin{tabular}{|l|cc|cc|}
\hline $\begin{array}{l}\text { Profundidade } \\
\text { testemunho } \\
(\mathrm{cm})\end{array}$ & $\begin{array}{c}\delta^{13} \mathrm{C} \\
\text { G. ruber } \text { s.l. } \\
(\%)\end{array}$ & $\begin{array}{c}\delta^{18} \mathrm{O} \text { ruber } \text { s.l. } \\
(\% \circ)\end{array}$ & $\begin{array}{c}\delta^{13} \mathrm{C} \\
\text { G. ruber s.s. } \\
(\%)\end{array}$ & $\begin{array}{c}\delta^{18} \mathrm{O} \\
\text { G. ruber } \text { s.s. } \\
(\% \circ)\end{array}$ \\
\hline 1.0 & 1.32 & -1.97 & 1.07 & -1.66 \\
19.5 & 1.19 & -1.94 & 1.15 & -1.72 \\
33.5 & 1.43 & -1.96 & 1.34 & -1.90 \\
40.5 & 1.26 & -1.85 & 1.42 & -1.67 \\
42.75 & 1.40 & -1.84 & 1.07 & -1.76 \\
66.5 & 1.14 & -1.85 & 1.46 & -1.85 \\
90.75 & 1.67 & -1.78 & 1.47 & -1.86 \\
114.0 & 1.41 & -1.90 & 1.56 & -1.99 \\
137.0 & 0.93 & -1.84 & 1.40 & -1.99 \\
151.25 & 1.50 & -1.77 & 1.55 & -1.93 \\
163.0 & 1.73 & -1.89 & 1.58 & -1.89 \\
165.25 & 1.43 & -1.76 & 1.63 & -1.97 \\
189.85 & 1.59 & -1.93 & 1.41 & -1.77 \\
214.5 & 1.55 & -1.76 & 1.48 & -1.79 \\
225.75 & 1.31 & -1.69 & 1.30 & -1.80 \\
\hline
\end{tabular}

Os resultados indicaram uma diferença média entre os morfotipos de $\delta^{18} \mathrm{O}$ de $0.012 \%$ e desvio padrão $0.15 \%$, e do $\delta^{13} \mathrm{C}$ de $-0.002 \%$ e desvio padrão de $0.22 \%$, onde as maiores diferenças para $\delta^{18} \mathrm{O}$ foram observadas nas primeiras amostras próximo ao topo do testemunho (Figura 21). A distribuição dos resultados de $\delta^{18} \mathrm{O}$ ao longo do testemunho não demonstra nenhuma tendência entre os morfotipos, ora apresentando valores de $\delta^{18} \mathrm{O}$ maiores para o morfotipo s.l. e ora o morfotipo com valores superiores aos s.s.. 


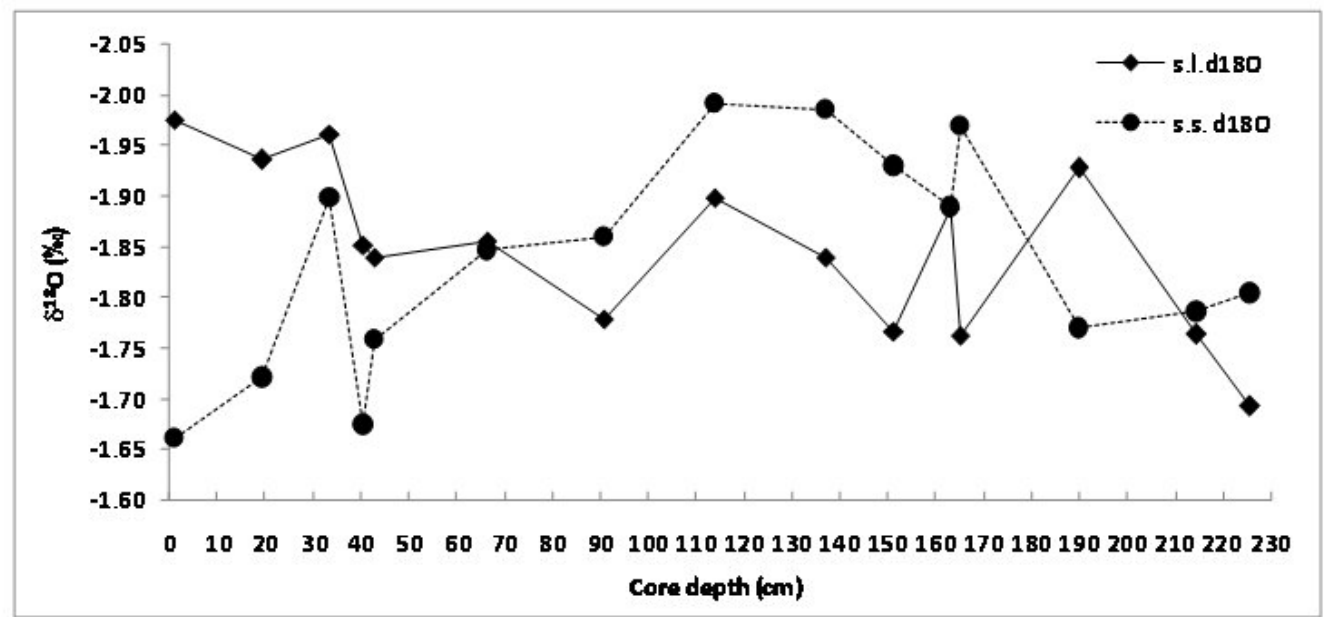

Figura 21: Distribuição do $\delta^{18}$ para os morfotipos G. ruber (s.l.) e G. ruber (s.s) ao longo do testemunho GeoB16204-2.

Através do gráfico cruzado entre os parâmetros $\delta^{13} \mathrm{C}$ no eixo da ordenada e $\delta^{18} \mathrm{O}$ na abcissa (Figura 22), verifica-se que os intervalos de variação dos parâmetros $\delta^{18} \mathrm{O}$ foi de $-1.99 \%$ a $-1.66 \%$ o do $\delta^{13} \mathrm{C}$ de $0.93 \%$ o $1.73 \%$. A partir deste gráfico é possível constatar que aparentemente os dois morfotipos não apresentam nenhuma preferência de distribuição.

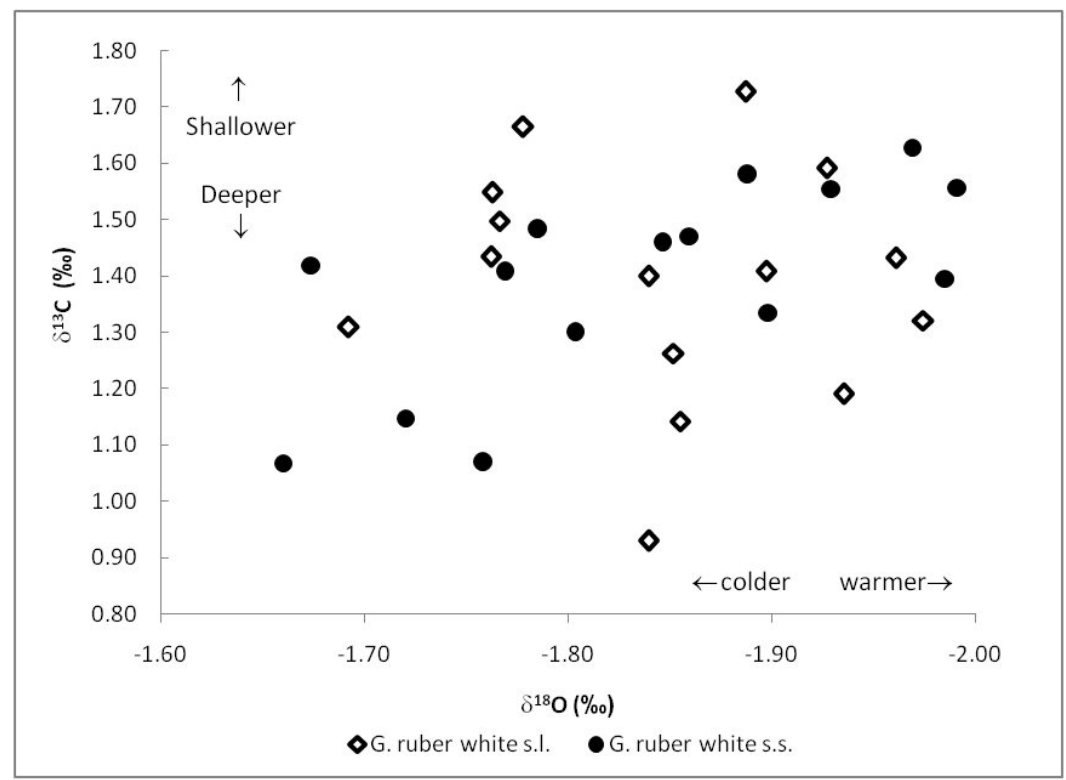

Figura 22: Relação entre $\delta^{18} \mathrm{O}$ e $\delta^{13} \mathrm{C}$ dos morfotipos G. ruber (s.l.) e G. ruber (s.s) do testemunho GeoB16204-2. 


\section{Discussão}

As análises sedimentológicas e geoquímicas do testemunho GeoB 16204-2 permitiram reconhecer variações paleoceanográficas e paleoclimáticas da margem continental equatorial brasileira nos últimos 8100 anos.

Alguns dos resultados das análises geoquímicas foram obtidos por métodos diferenciados, no qual permitiu fazer algumas considerações sobre os métodos. Antes de iniciar a discussão dos resultados num contexto paleoceanográfico e paleoclimático, primeiramente serão apresentados as considerações sobre os métodos de análise de XRF e digestão total, seguido por uma avaliação dos morfotipos G. ruber (s.1.) e G. ruber (s.s.).

\subsection{Comparação dos resultados de elementos químicos a partir de XRF e digestão total}

No presente trabalho, a utilização das razões elementares Ti/Ca e Fe/Ca obtidos através do método de XRF permitiu investigar a variação destes elementos ao longo do testemunho GeoB 16204-2. Entretanto, as variações obtidas destes elementos não poderiam ser comparados a outros testemunhos, uma vez que, seus resultados refletem a variação destes elementos apenas em relação ao próprio testemunho. Com intuito de possibilitar a comparação dos resultados das razões obtidas de Ti/Ca e Fe/Ca com outros testemunhos, realizou-se a análise de digestão total.

Embora os resultados destas análises, uma de natureza semi-quantitativa e outra quantitativa, permitiram verificar que ambos os resultados apresentaram tendências semelhantes para cada elemento analisado. Após a normalização dos elementos Fe e Ti pelo elemento $\mathrm{Ca}$, os resultados obtidos não só mantiveram suas tendências como também permitiram verificar que a amplitude ou escala de variação do Fe e Ti eram próximos, porém expressos em unidades diferentes. Os resultados de Ti/Ca apresentaram variações entre 0,004 a 0,012 para ambas as técnicas aplicadas e os valores de Fe/Ca apresentaram, no método XRF, variações entre $0,02 \mathrm{cps}$ a $0,09 \mathrm{cps}$ (contagem por segundos), e por digestão total, variações entre $0,04 \mathrm{ppm}$ a $0,11 \mathrm{ppm}$. Contudo, a amplitude de variação da razão 
$\mathrm{Fe} / \mathrm{Ca}$ foi de 0,07 para ambas as análises (Figura 18).

Deste modo, os resultados obtidos pelas razões $\mathrm{Fe} / \mathrm{Ca}$ e Ti/Ca provenientes da XRF, embora semi-quantitativos, indicam ser excelentes parâmetros para avaliação de tendências e inferências de condições paleoceanográficos e paleoclimáticos, onde numa comparação entre as técnicas, a digestão total, apresentaria desvantagem com maior demanda de tempo para obtenção dos resultados além de custos de insumos.

\subsection{Comparação entre sinais isotópicos dos morfotipos G. ruber (s.l.) e G. ruber (s.s.)}

Segundo Wang (2000), os morfotipos G. ruber (s.1.) e G. ruber (s.s.) apresentam valores característicos de $\delta^{18} \mathrm{O}$ e $\delta^{13} \mathrm{C}$ que indicam suas respectivas preferências de habitat. Estes autores propuseram que o morfotipo G. ruber (s.s.) apresentam preferências de habitat ocupando os primeiros $30 \mathrm{~m}$ de profundidade enquanto o morfotipo G. ruber (s.1.) habita profundidades inferiores a $30 \mathrm{~m}$.

Num contexto de análise de variabilidade intraespecífica, Waelbroeck et al. (2005), a partir de um gráfico cruzado entre $\delta^{18} \mathrm{O}$ e $\delta^{13} \mathrm{C}$, constataram sinais isotópicos diferentes dos espécimes da espécie G. ruber ao longo de um testemunho. Estes autores verificaram que amostras do topo do testemunho apresentaram menores valores de $\delta^{18} \mathrm{O}$ coincidindo com período mais quente e amostras em outras profundidades do testemunho com maiores valores de $\delta^{18} \mathrm{O}$ e períodos frios. Os autores, consideraram que os valores de $\delta^{13} \mathrm{C}$ indicariam a preferência de profundidade de habitat onde espécimes com preferência de habitat mais raso foram relacionados a maiores valores de $\delta^{13} \mathrm{C}$ e espécimes com preferência de habitat mais profundo com menores valores de $\delta^{13} \mathrm{C}$.

Adaptando esta análise de variabilidade intraespecífica apresentada Waelbroeck et al. (2005), observa-se que os resultados das 15 amostras analisadas ao longo do testemunho GeoB 16204-2 para os morfotipos G. ruber (s.1.) e G. ruber (s.s.) apresentaram distribuição generalizada, sem indicação de sinais isotópicos diferentes entre os morfotipos. Esta não diferenciação entre os sinais isotópicos pode indicar que possivelmente, as condições de superfície da região de estudo é verticalmente homogênea ao longo da 
camada de habitat da espécie G. ruber (white).

\subsection{Discussão no contexto Paleoceanográfico e Paleoclimático}

A linearidade da relação idade-profundidade obtida a partir das datações indica que o registro sedimentar, testemunho Geob 16204-2, não sofreu perturbações e nem apresentou hiatos ou períodos sem deposição, conferindo robustez e confiabilidade da cronologia estabelecida ao testemunho.

Próximo a 5200 anos cal A.P., é notável uma mudança na magnitude dos valores da taxa de sedimentação (Figura 13). Esta marcante mudança na taxa de sedimentação sugere que a região de estudo esteve sob influência de diferentes condições de sedimentação antes e depois desta idade. Entre 8100 anos cal A.P. e 5200 anos cal A.P., a região experimentou condições que propiciaram menores valores da taxa de sedimentação, inferiores a $6 \mathrm{~cm} \cdot \operatorname{kanos}^{-1}$, enquanto no período posterior, entre 5200 anos cal A.P. até o presente, as taxas de sedimentação são relativamente altas e constantes, apresentando valores superiores a $40 \mathrm{~cm} \cdot \mathrm{kanos}^{-1}$.

Sabe-se que diversos processos e fatores podem influenciar a taxa de sedimentação de uma região, como por exemplo, aporte sedimentar, configurações físicas e morfológicas do ambiente de deposição, processos químicos como precipitação, dissolução, processos biológicos como produtividade, aumento de matéria orgânica, entre outros, que podem ocorrer localmente ou também em regiões mais remotas. Um outro importante fator que influencia na taxa de sedimentação é o nível relativo do mar, que interfere diretamente no espaço de acomodação dos sedimentos (SUGUIO et al., 1985).

Curvas de variações do nível relativo do mar propostas para a região nordeste brasileira indicaram que nos últimos 7000 anos, as variações observadas foram inferiores a 7 m em regiões costeiras (Figura 12) (SUGUIO et al., 1985; BEZERRA et al., 2003; CALDAS et al., 2006). Além da amplitude de variação observada, as curvas propostas apontaram de forma genérica, uma tendência de queda progressiva do nível relativo do mar, sem oscilações, até atingir o nível atual durante os últimos 5000 anos. Contudo, considerando a distância em relação a costa, de aproximadamente $80 \mathrm{~km}$, e a profundidade 
da coluna d'água, de $1200 \mathrm{~m}$, em que o testemunho analisado foi recuperado, mudanças nas condições de sedimentação no local de recuperação do GeoB 16204-2 provavelmente não seriam decorrentes de variações do nível relativo do mar. Além disto, num cenário de diminuição progressivo do nível relativo do mar, esperaria-se observar uma possível diminuição no espaço de acomodação dos sedimentos, o que poderia acarretar em menor taxa de sedimentação, e avanço da linha de costa rumo ao oceano, propiciando condições ambientais progressivamente mais costeiras rumo ao topo do testemunho, situação oposta aos resultados observados do GeoB 16204-2. Os resultados do presente trabalho indicaram um aumento da taxa de sedimentação em direção ao presente, diminuição do aporte continental constatados pelos resultados das razões Fe/Ca e Ti/Ca e aumento da influência marinha sinalizados pelo conteúdo dos teores de $\mathrm{CaCO}_{3}$. Desta forma, acredita-se que mudanças no comportamento de dados sedimentológicos e geoquímicos observadas ao longo do testemunho, estão relacionadas às variações climáticas e de circulação oceânica que ocorreram nos últimos 8100 anos na margem continental equatorial brasileira.

Com base nos dados obtidos, três períodos distintos, em termos de condições climáticas e de circulação oceânica, podem ser reconhecidos para a região ao largo da desembocadura do rio Parnaíba durante os últimos 8.100 anos: o primeiro período fazendo parte do Holoceno Médio, entre 8100 anos cal. A.P e 5000 anos cal. A.P, o segundo período entre 5000 anos cal. A.P. e 2500 anos cal A.P. fazendo parte do Holoceno Médio e Holoceno Tardio e o terceiro de 2500 anos cal A.P. até o presente, Holoceno Tardio (Figura 23). 


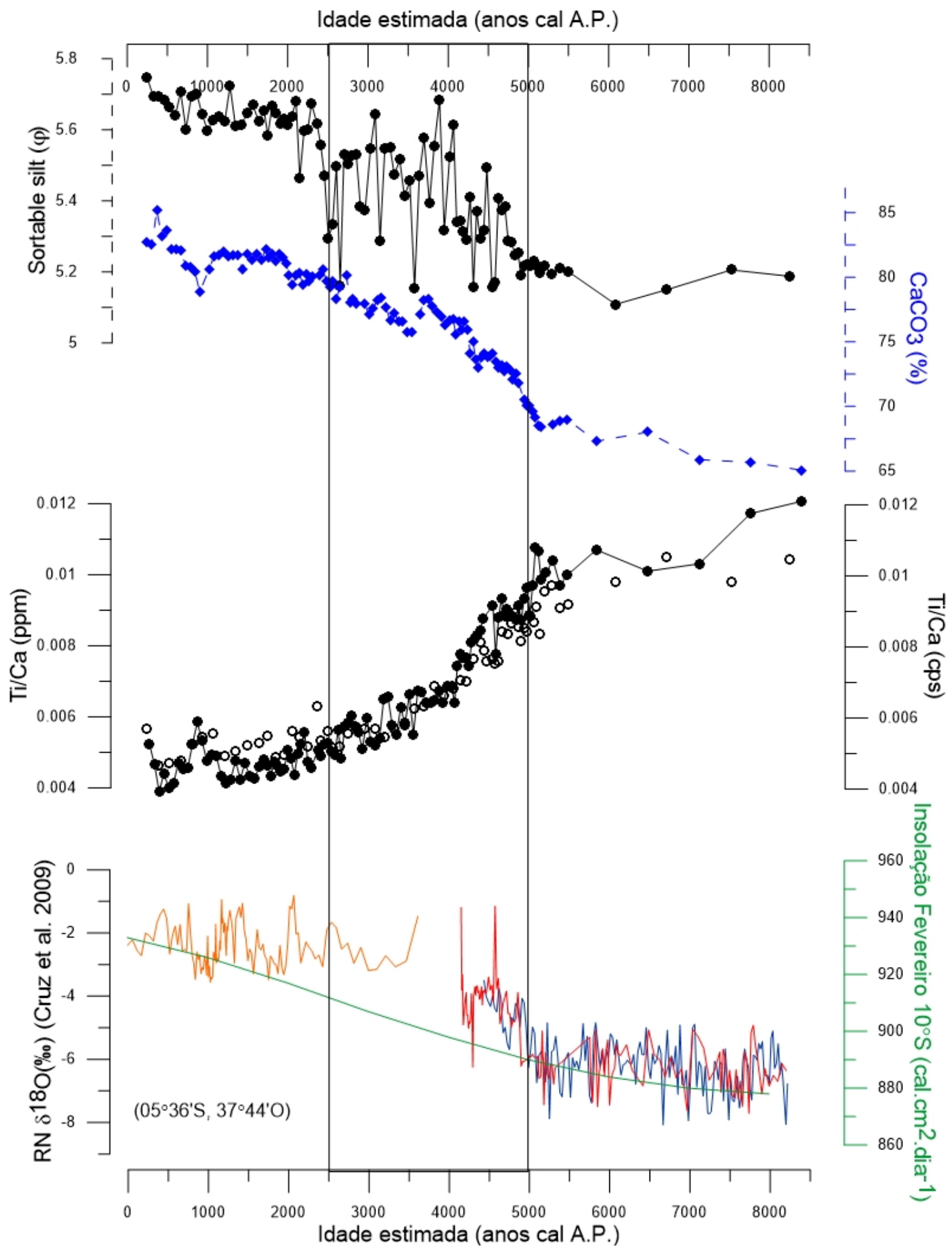

Figura 23: (a) Distribuição de sortable silt, (b) Distribuição do conteúdo de $\mathrm{CaCO}_{3}$, (c) Distribuição da razão Ti/Ca em ppm representados pelo símbolo "o", (d) Distribuição da razão Ti/Ca em cps representados por "•", (e) $\delta^{18} \mathrm{O}$ de espeleotemas do Rio Grande do Norte adaptado de Cruz et al. (2009), (f) Insolação de verão no mês de Fevereiro em $10^{\circ} \mathrm{S}$ adaptado de Cruz et al. (2009) 


\subsection{Holoceno Médio}

\subsubsection{Primeiro período ( $\sim 8100$ anos cal A.P. até 5000 anos cal. A.P.)}

O primeiro período, compreendido entre o intervalo de 8100 anos cal A.P e 5000 anos cal A.P., é aparentemente caraterizado por condições hidrodinâmicas mais intensas e condições climáticas mais úmidas.

As condições hidrodinâmicas mais intensas podem ser constatadas pela maior porcentagem da fração areia (Figura 14), maiores frequências para diâmetros com tamanhos próximos a $4 \phi$ (Figura 15) e menores valores do sortable silt (Figura 16). Conforme as configurações oceânicas atuais desta região, uma das possibilidades para o estabelecimento de condições de correntes mais intensas ocorre quando a ZCIT está em sua posição geográfica mais ao norte. O posicionamento mais ao norte da ZCIT propicia maior pista para atuação dos ventos alísios de sudeste, que nesta condição, favorece a intensificação das correntes em superfície e consequentemente o transporte oceânico na região de estudo (JOHNS et al., 1998). Esta configuração com posicionamento mais ao norte da ZCIT neste período corroboraria Haug et al. (2001) para este período.

Outra possível explicação para condições hidrodinâmicas mais intensas neste período, estaria associada à condição de CNB mais vigorosa refletindo condições de AMOC mais intensa. De acordo com Zhang et al. (2011), a CNB poderia ser utilizada como indicador da AMOC uma vez que o atual transporte observado da CNB não se explica apenas pela forçante vento e teria a AMOC como uma de suas principais componentes.

Num contexto de dinâmica de formação de massas d'águas no Atlântico Norte, Hoogakker et al. (2011) observaram, a partir da média do sortable silt, uma desintensificação no fluxo de formação da Água Profunda do Atlântico Nordeste (Northeast Atlantic Deep Water - NEADW), entre 8000 anos cal A.P. e 5200-4800 anos cal A.P. Segundo estes autores, a NEADW que é uma das componentes de formação da APAN, apresentou na sua formação, condições de fluxo mais intenso, em aproximadamente 8000 anos cal A.P., e tendência decrescente na intensidade de fluxo até 5.200-4.800 anos cal A.P. (Figura 24). Com base em isótopos estáveis de carbono $\left(\delta^{13} \mathrm{C}\right)$ obtidos em foraminíferos bentônicos, 
Oppo et al. (2003) também constataram condições semelhantes na formação da APAN, onde condições de fluxo mais intensas prevaleceram em aproximadamente 8000 anos cal A.P. com desintensificação gradual atingindo seu mínimo em aproximadamente 5000 anos cal A.P.

Embora os trabalhos de Hoogakker et al. (2011) e Oppo et al. (2003), retratem processos de regiões distantes da nossa área de estudo, eles reforçam a suposição de condições mais intensas da AMOC no período entre 8100 anos cal A.P. e 5000 anos cal A.P., uma vez que, possíveis mudanças na AMOC seriam refletidas globalmente em razão da continuidade de massa dos oceanos. Apesar da distribuição do sortable silt do GeoB 16204-2 exibir valores relativamente constantes e sem nenhuma tendência evidente entre 8100 anos cal A.P. e 5000 anos cal A.P., possíveis mudanças na intensidade dos fluxos de formação de massas d'água no hemisfério norte poderiam não ser sincrônicas às mudanças de fluxo que ocorreram no Atlântico tropical. Outro fato importante sobre estes dois trabalhos, Hoogakker et al. (2011) e Oppo et al. (2003), é que apesar de serem baseadas em proxies independentes e de natureza diferentes, ambos indicaram condições de configuração semelhantes da AMOC, com tendência de desintenstificação. 


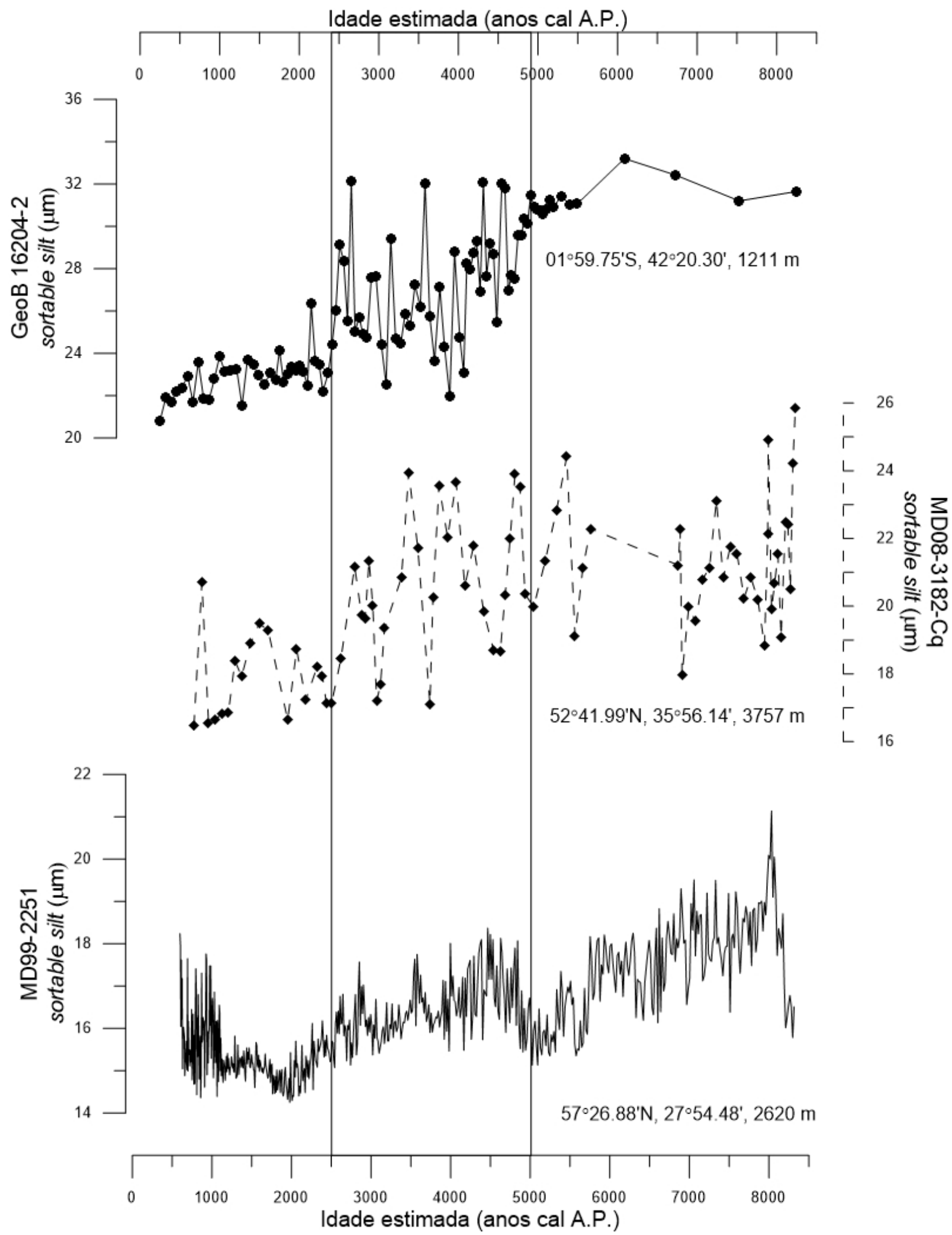

Figura 24: Distribuição da média do sortable silt nos testemunho (a) GeoB 16204-2 analisado no presente trabalho, Atlântico Sul, e testemunhos do Atlântico Norte:(b) MD08-3183Cq adaptado de Kissel et al. (2013), (c) MD99-2251 adaptado de Hoogakker et al. (2011).

A ocorrência de maiores valores de Ti/Ca e Fe/Ca (Figura 18 e 23) no período 
entre 8100 anos cal A.P. e 5000 anos cal A.P., pode ser um indicativo de aumento no aporte de sedimentos de origem continental, que por sua vez reflete condições climáticas mais úmidas neste período, entre 8100 anos cal A.P. e 5000 anos cal A.P . Segundo Arz et al. (1998), os elementos Ti e Fe seriam componentes de argilo minerais de origem terrígena e o $\mathrm{Ca}$ associado ao teor de carbonato de cálcio de origem marinha. Ainda de acordo com esses autores, o aumento nos valores das razões Ti/Ca e Fe/Ca reflete condições climáticas continentais mais úmidas, uma vez que estes elementos alcançariam o ambiente marinho principalmente por processos de drenagens das bacias hidrográficas e variações de vazões de rios costeiros respondendo principalmente ao regime de pluviosidade local.

Considerando que o regime de precipitação atual da região de estudo varia em função da presença da ZCIT, supõe-se que condições mais úmidas em continente implicaria na presença desta feição metereológica. Entretanto, esta condição não concordaria com Haug et al. (2001), que sugerem que neste período, entre 8100 anos cal A.P. e 5000 anos cal A.P., a ZCIT estaria localizado em sua posição média mais ao norte em relação à posição a atual. Uma outra observação constatada por Haug et al. (2001) foi que variações de Ti e Fe indicariam períodos de maior precipitação em função da presença da ZCIT numa relação anti-fásica meridional com a região Amazônica. Considerando que ambas as regiões, Bacia do Cariaco e região de estudo, apresentam variações de precipitação em função do posicionamento da ITCZ, esperaria-se observar tendências opostas aos indicadores de condições mais úmidas em continente devido a esta relação de anti-fase entre os hemisférios. No entanto, as mesma tendência decrescente de aporte continental foram observadas em ambas as regiões, sugerindo uma diminuição de condições úmidas em ambas as regiões (Figura 25).

Ao que tudo indica, o clima na região nordeste brasileira durante o Holoceno médio, foi mais úmido que o atual (Figura 23) (CRUZ et al., 2009; PRADO et al., 2013). Cruz et al. (2009) foram precursores na proposta de uma possível transição de condições mais úmidas durante o Holoceno Médio para condições mais secas no Holoceno Tardio na região nordeste brasileira. Segundo estes autores, a região nordeste brasileira apresentaria uma relação em anti-fase com a região oeste Amazônica, o qual períodos de 
maior precipitação no interior do continente seriam concomitantes a períodos secos na região nordeste. Esta relação anti-fásica teria sido intensificada com a migração da ZCIT em direção sul simultaneamente ao aumento de insolação no hemisfério sul resultando o estabelecimento de condições mais secas ou semi-áridas na região nordeste brasileira durante o Holoceno Tardio.

Prado et al. (2013), a partir do uso de modelo computacional paleoclimático e compilação de resultados multi proxies provenientes da América do Sul também chegaram a um cenário de condições mais úmidas que a atual para a região nordeste brasileira em 6000 anos cal A.P.. Esse cenário corrobora dados apresentados por Cruz et al. (2009).

Uma possível explicação para que o clima no nordeste brasileiro durante o Holoceno médio fosse mais úmido, poderia estar relacionada a variações nas forçantes orbitais relacionadas ao ciclo de precessão e posicionamento mais ao norte da ZCIT (HAUG et al., 2001), o Sistema de Monção da América do Sul (SMAS) e a configuração da circulação atmosférica em anti-fase zonalmente estariam enfraquecidos o que favoreceria condições mais úmidas no nordeste.

\subsection{Holoceno Médio - Tardio}

\subsubsection{Segundo período $(\sim 5000$ anos cal A.P. até 2500 anos cal. A.P.)}

O segundo período, compreendido entre 5000 anos cal A.P. e 2500 anos cal A.P., denota ser um intervalo de transição de regimes hidrodinâmicos marcado por um aumento da influência marinha, maiores variações da corrente de fundo e diminuição do aporte continental.

O aumento da influência marinha na região de estudo pode ser constatado pela tendência crescente dos teores de $\mathrm{CaCO}_{3}$ (Figura 17). Entretanto, este aumento poderia ser apenas aparente, uma vez que, as razões $\mathrm{Fe} / \mathrm{Ca}$ e $\mathrm{Ti} / \mathrm{Ca}$, indicadores do aporte de origem continental, apresentaram tendência decrescente neste período (Figura 18 e 23).

As variações da intensidade da corrente de fundo são associadas aos resultados do sortable silt (Figura 16, 23). Entre 5000 anos cal A.P. e 2500 anos cal A.P., as variações deste parâmetro alcançaram aproximadamente $0,5 \phi$, que representaria segundo a equação 
4, proposta empiricamente por Ledbetter's (1986, apud McCave, 2008), uma variação na velocidade da corrente de fundo de aproximadamente $15 \mathrm{~cm} \cdot \mathrm{s}^{-1}$. Este período com maiores variações poderia indicar que possivelmente este intervalo, seria um período de transição, onde as condições oceânicas ora eram dominadas por condições hidrodinâmicas mais intensas, indicados pelos menores valores em $\phi$ do sortable silt, e ora dominadas por condições hidrodinâmicas menos intensas, com maiores valores de $\phi$ (Figura 16), aumento da fração argila (Figura 14) e não apresentar uma moda definida na distribuição PSD (Figura 15).

Analogamente, Kissel et al. (2013), utilizando resultados de sortable silt, também observaram maiores variações em intervalo semelhantes (Figura 24). Neste trabalho, as variações observadas foram inferiores a $8 \mu \mathrm{m}$ e o período entre 6000 anos cal A.P e 2500 anos cal A.P.. Segundo Kissel et al. (2013), após 6000 anos cal A.P., as condições hidrológicas do Atlântico Norte sofreram uma reorganização em suas configurações onde um enfraquecimento da corrente de fundo foi observado até cerca de 2000 anos cal. A.P., quando atingiu seu estado atual. Nota-se que, as magnitudes das variações do sortable silt observadas por Kissel et al. (2013) foram semelhantes às do testemunho GeoB 162042, próximas a $10 \mu \mathrm{m}$, porém, não de forma sincrônica ou simultânea. No entanto, esse período de maior oscilação reforçaria a suposição de um período de instabilidade das configurações da AMOC em intervalo de tempo semelhante (Figura 24).

Embora Hoogakker et al. (2011) e Kissel et al. (2013) tenham apresentado resultados de sortable silt de testemunhos coletados em regiões próximas no Atlântico Norte, os resultados do testemunho MD99-2251 publicados em Hoogakker et al. (2011), não exibiram variações semelhantes neste mesmo intervalo, entre 5000 anos cal A.P. e 2500 anos cal A.P. (Figura 24). Entretanto, ambos sinalizaram enfraquecimento no fluxo de formação das massas d'água de fundo do Atlântico Norte refletindo uma possível desintensificação da AMOC.

A diminuição do aporte de material continental pode ser inferida pela tendência decrescente nos valores das razões Ti/Ca e Fe/Ca observados para o período entre 5000 anos cal A.P. e 2500 anos cal A.P. (Figura 18). O decréscimo nos valores das razões Ti/Ca 
e Fe/Ca foram coincidentes com o aumento das taxas de insolação no hemisfério sul e aumento dos valores de isótopos estáveis de oxigênio de espeleotemas observados por Cruz et al. (2009) (Figura 23).

Cruz et al. (2009), sugeriram que as variações nos valores destes parâmetros refletiram mudanças de condições climáticas mais úmidas entre 8000 anos cal A.P. e 5000 anos cal A.P. na região nordeste brasileira para condições progressivamente mais secas a partir de 5000 anos cal A.P.. Segundo estes autores, o estabelecimento de condições mais secas seriam associados ao deslocamento em direção sul da posição média da ZCIT que teria fortalecido o SMSA. Em consequência disto, o fortalecimento do SMSA associado ao aumento das taxas de insolação, teria contribuído para uma intensificação da circulação atmosférica zonal, em direção oeste-leste atuantes no mesmo hemisfério. Assim, a circulação atmosférica zonal intensificada teria acentuado a relação anti-fásica do regime de precipitação observada para a América do Sul. Ou seja, o deslocamento da ZCIT em direção sul teria proporcionado um aumento gradativo da precipitação nas região amazônica, região sul e sudeste brasileiro e Andes Centrais concomitantemente à diminuição da precipitação na região nordeste brasileira (CRUZ et al., 2009; BARRETO, 2010).

Registros marinhos corroboram as condições de aumento de precipitação na região sudeste brasileira durante o Holoceno Tardio (Figura 25) (PIVEL, 2009; GYLLENCREUTZ et al., 2010; PRADO et al., 2013). Um dos testemunhos analisados por Pivel (2009), testemunho (KF02), do talude inferior da Bacia de Santos, apresentou tendência crescente de razões $\mathrm{Ti} / \mathrm{Ca}$ e $\mathrm{Fe} / \mathrm{Ca}$ em direção ao recente. Estes autores relacionaram a tendência observada com um suposto aumento nos processos de drenagem da área continental adjacente e um possível aumento da influência do Rio da Prata. Adicionalmente, é notável que a distribuição de Ti/Ca e Fe/Ca dos testemunhos KF02 e GeoB 16204-2 exibam tendências opostas (Figura 25), os quais podem atestar a relação anti-fásica das variações de pluviosidade entre as regiões sudeste e nordeste brasileira sugeridas por Barreto (2010).

Segundo Gyllencreutz et al. (2010), a migração da posição da ZCIT em direção 
sul em conjunto com o modo de oscilação dos eventos ENOS teria propiciado o aumento da precipitação na região sudeste. Para estes autores, os sedimentos finos depositados próximos à desembocadura do Rio da Prata estariam associados a períodos de altas descargas, como por exemplo, durante eventos de El Niño, sendo possivelmente ressuspensos por fortes correntes geradas pelos ventos de S/SW durante eventos como La Niña, período o qual a pluma do Rio da Prata apresenta extensão máxima em direção norte.

Diferentemente do cenário proposto por Cruz et al. (2009), Barreto (2010) e Prado et al. (2013), Pessenda et al. (2005) analisando resultados de pólens e isótopos de carbono em sedimento da região do Maranhão, propuseram que entre 10000 anos A.P. e 5000 anos A.P., a região seria caracterizada por condições mais secas, com estabelecimento progressivo de condições mais úmidas após 4000 anos A.P.. Contudo, vale ressaltar que as idades apresentadas por Pessenda et al. (2005), não foram calibradas ou corrigidas, e foram obtidas por AMS ${ }^{14} \mathrm{C}$ em matéria orgânica no sedimento. Assim, os intervalos sugeridos em Pessenda et al. (2005) poderiam ser um pouco diferentes dos propostos pelos outros autores.

O período compreendido entre 5000 anos cal A.P. e 2500 anos cal A.P. parece ter sido um intervalo de transição de regimes climáticos onde o aumento de insolação de verão, em conjunto com o deslocamento da ZCIT em direção sul devem ter propiciado mudanças nas configurações de circulação, tanto no oceano como na atmosfera, que por sua vez foram refletidas nas variações da corrente de fundo e diminuição do aporte continental de forma contínua e gradual, sem evidências ou ocorrência de eventos climáticos abruptos. 


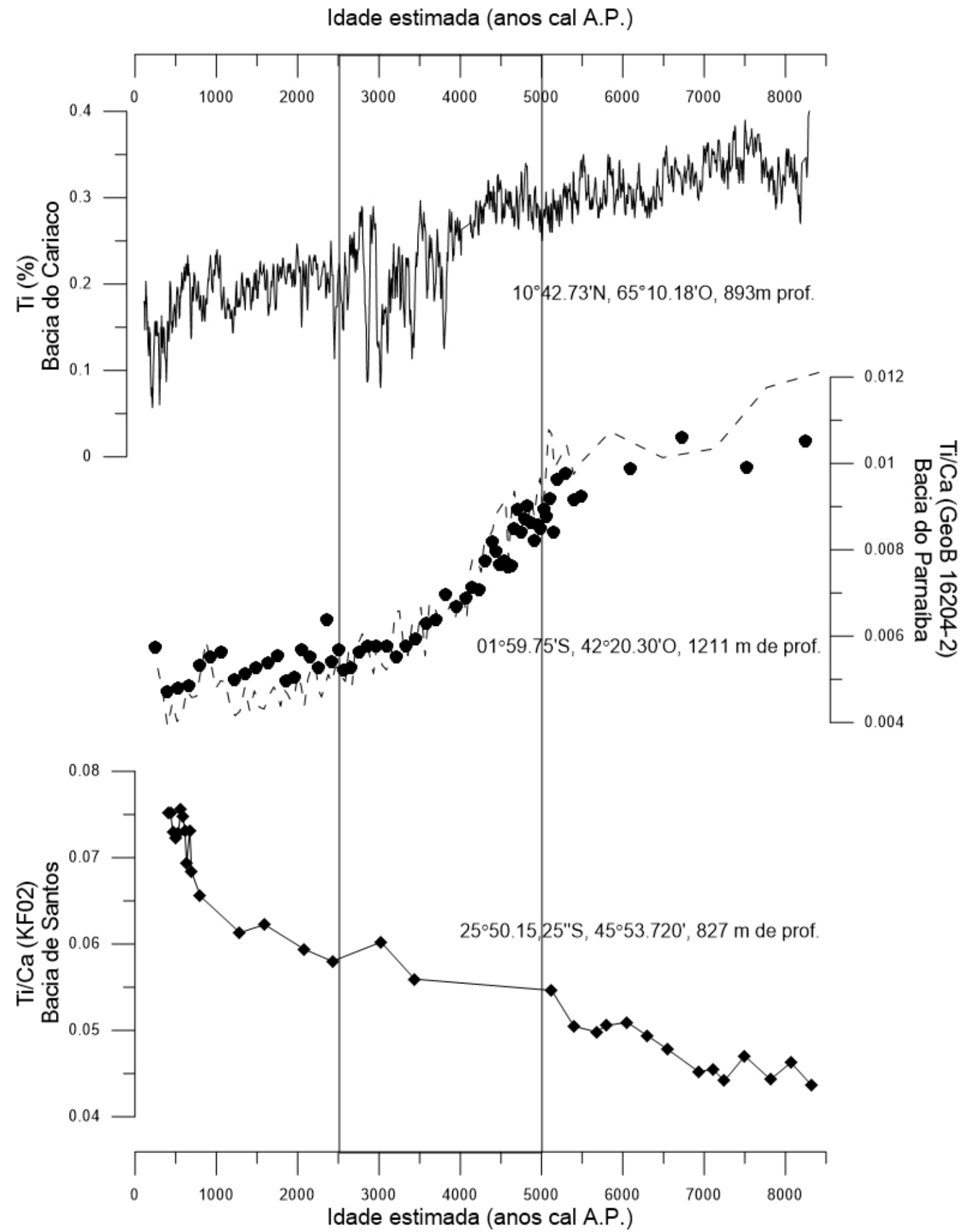

Figura 25: Comparação do aporte continental entre as Bacia do Cariaco, Bacia do Parnaíba e Bacia de Santos. (a) Ti (\%) da Bacia do Cariaco, Atlântico Norte adaptado de Haug et al. (2001), "•"se refere ao Ti/Ca obtido por digestão total e --"se refere ao Ti/Ca obtido por XRF, (b) Ti/Ca do testemunho GeoB 16204-2 analisado no presente trabalho, Atlântico Sul, (c) Ti/Ca da Bacia de Santos, Atlântico Sul, adaptado de Pivel (2010). 


\subsection{Holoceno Tardio}

\subsubsection{Terceiro período ( 2500 anos cal A.P. até o presente)}

O terceiro período compreende de 2500 anos cal A.P. até o presente e é marcado por elevada influência marinha na região de estudo, condições hidrodinâmicas menos intensas e relativamente estáveis e menor aporte de origem continental em comparação ao primeiro e segundo períodos descritos.

Os elevados teores de $\mathrm{CaCO}_{3}$, próximos a 80\% (Figura 17 e 23), indicam a predominância da influência marinha na região de estudo. Os resultados do sortable silt sugerem um cenário de condições hidrodinâmicas menos intensas no terceiro período quando comparado aos demais períodos identificados no presente trabalho (Figura 23). Os valores médios do sortable silt ocorreram próximos a 5,7 $\phi(22 \mu \mathrm{m})$ e não apresentaram grandes oscilações o que pode indicar condições oceanográficas mais estáveis (Figura 16, 23). Embora a distribuição do sortable silt não tenha exibido nenhuma tendência neste período, verifica-se que a fração silte apresenta tendência crescente em direção ao presente ao mesmo tempo que a fração areia diminui além de uma moda bem definida com maiores frequências próximo a $7 \phi$ (Figura 14, 15). Estas tendências do aumento da fração fina poderia refletir uma possível desintensificação ou enfraquecimento da corrente de fundo durante o período.

Num contexto global, esta desintensificação da corrente de fundo na região de estudo seria coincidente com enfraquecimento de fluxos de formação das massas d' águas profundas do Atlântico Norte constatados, por exemplo, por Oppo et al. (2003); Hoogakker et al. (2011) e Kissel et al. (2013), reforçando suposições relacionadas a desintensificação da AMOC neste mesmo intervalo (Figura 24). Contudo, estes cenários não são sustentados por estudos realizados na região do Atlântico Sul, como por exemplo, em Arz et al. (2001); Chiessi et al. (2014).

Arz et al. (2001) utilizaram a diferença de valores de isótopos estáveis de oxigênio $\left(\Delta \delta^{18} \mathrm{O}\right)$ entre duas espécies de foraminíferos planctônicos como indicadores da estratificação termal da coluna d'água, que nesta região, é fortemente influenciada pelos padrões de circulação atmosférica. Estes autores consideraram que baixos valores de 
$\Delta \delta^{18} \mathrm{O}$ indicariam menor gradiente vertical, numa relação onde a profundidade da camada de mistura estaria respondendo ao cisalhamento dos ventos. Ou seja, num cenário de ventos mais intensos, esperaria-se camada de mistura mais profunda e portanto, maior $\Delta \delta^{18}$ O. A distribuição dos $\Delta \delta^{18} \mathrm{O}$ obtidos por Arz et al. (2001), entre 2500 anos cal A.P. até o presente, exibiram uma tendência levemente crescente em direção ao presente. Esta tendência crescente indicaria condições de aumento gradual do cisalhamento dos ventos e provável intensificação da CNB, situação oposta ao indicado pelos resultados provenientes das análises sedimentológicas do GeoB 16204-2.

Analogamente, Chiessi et al. (2014) aplicando o mesmo princípio apresentado por Arz et al. (2001), inferiram a variabilidade da Corrente do Brasil nos últimos 5000 anos na margem oeste subtropical do Atlântico Sul. Chiessi et al. (2014) propuseram que mudanças na Corrente do Brasil seriam associados a alterações de configuração da AMOC, numa relação em que períodos mais intensos da Corrente do Brasil seriam coincidentes com fases enfraquecidas da AMOC e vice-versa. Além disso, os autores observaram que períodos de intensificação da Corrente do Brasil seriam sincrônicos com fases de enfraquecimento da CNB, anomalias negativas de TSM no Atlântico Norte em altas latitudes e anomalias positivas de precipitação no sudeste Sul Americano. Adicionalmente, os resultados apresentados por Chiessi et al. (2014) para o período entre 2500 anos cal A.P. até o presente, indicam tendência de enfraquecimento da Corrente do Brasil coincidindo com fortalecimento da $\mathrm{CNB}$, o que não atestariam os resultados sedimentológicos do presente trabalho.

A diminuição do aporte de origem continental pode ser constatada pela ocorrência de menores valores das razões $\mathrm{Ti} / \mathrm{Ca}$ e $\mathrm{Fe} / \mathrm{Ca}$ nos últimos 2.500 anos na área de estudo (Figura 18, 23 e 25). Esse decréscimo nos valores é coincidente com períodos de maior insolação de verão e condições mais secas no continente constatados por Cruz et al. (2009) (Figura 23). A progressiva diminuição das razões Ti/Ca e Fe/Ca refletiria a diminuição do aporte continental atestando o estabelecimento de um clima mais seco e árido no nordeste brasileiro durante o Holoceno Tardio conforme proposto por Cruz et al. (2009) (Figura 23 e 25). 


\subsection{Propriedades hidrográficas de superfície do mar: temperatura e salinidade, durante os últimos 5000 anos}

As estimativas de SST e SSM exibiram valores relativamente estáveis, constantes e sem nenhuma tendência ao longo dos últimos 5000 anos (Figura 20). Os valores estimados de TSM apresentaram valores médios próximos a $26,3^{\circ} \mathrm{C}$ e $\mathrm{SSM}$ de 36,5 , que são por sua vez, próximos aos valores climatológicos atuais, $27^{\circ} \mathrm{C}$ e 36,0 respectivamente. A diferença média de aproximadamente $-1{ }^{\circ} \mathrm{C}$ indica que o método aplicado para reconstituição das propriedades parece ser adequado para a região de estudo. Além disso, as variações observadas para as estimativas de TSM não ultrapassaram $2^{\circ} \mathrm{C}$ que são apoiadas pela climatologia atual onde as variações sazonais, diferença entre verão e inverno, apresentam esta mesma amplitude de TSM. A diferença observada de aproximadamente $-1^{\circ} \mathrm{C}$ dos valores estimados de TSM e ausência de tendência dos mesmos durante os últimos 5000 anos corroboram trabalhos como por exemplo Leduc et al. (2010) e Hessler et al. (2014), os quais apresentam uma compilação de dados de TSM baseado em $\mathrm{Mg} / \mathrm{Ca}$ provenientes de foraminíferos planctônicos na região tropical do Atlântico durante o Holoceno.

De forma semelhante aos resultados de TSM, os valores estimados de salinidade de superfície do mar (SSM) também apresentaram pequenas variações, denotando uma região de influência basicamente oceânica, onde provavelmente em superfície a pluma do rio Parnaíba teria pouca ou nenhuma influência. Considerando que variações de SSM sejam relacionadas principalmente ao balanço entre precipitação, evaporação e advecção lateral, a ausência de tendências ou alterações nos valores de SSM para os últimos 5000 anos indicam, que embora as taxas de insolação de verão tenha aumentado em direção ao presente e condições de precipitação tenha sofrido mudanças na região de estudo, estas não foram suficientes para alterar o balanço entre estes parâmetros na interface oceanoatmosfera exibindo valores de SSM relativamente constantes ao longo de todo o período reconstituído. 


\section{Conclusões}

Resultados de análises sedimentológicas e geoquímicas do testemunho GeoB 16204-2 permitiram a identificação e compreensão das variações paleoceanográficas e paleoclimáticas ao longo dos últimos 8100 anos cal A.P. para para a margem equatorial brasileira.

Três períodos, com diferentes condições hidrodinâmicas e climáticas, foram observadas nos últimos 8100 anos cal A.P.:

- Período entre 8100 e 5000 anos cal A.P.: condições hidrodinâmicas mais intensas caracterizadas por baixas taxas de sedimentação, menor influência marinha e maior aporte de origem continental constatados por menores valores médios de sortable silt, maior porcentagem da fração areia, menores teores de $\mathrm{CaCO}_{3}$ no sedimento e maiores valores das razões $\mathrm{Ti} / \mathrm{Ca}$ e Fe/Ca.

- Período entre 5000 e 2500 anos cal A.P.: período de transição de regimes caracterizado por maiores flutuações na intensidade das correntes de fundo indicadas pela grande variabilidade de valores de sortable silt no período, simultânea ao incremento da fração argila, aumento da influência marinha indicado pela tendência crescente dos teores de $\mathrm{CaCO}_{3}$ concomitantemente à diminuição do aporte continental indicados pelo decréscimo dos valores das razões Ti/Ca e Fe/Ca.

- Período entre 2500 anos cal A.P. até o presente: condições hidrodinâmicas relativamente estáveis e menos intensas evidenciadas por valores maiores e pouco variáveis de sortable silt, intervalo com pequena variação do sortable silt, incremento da fração silte simultaneamente à diminuição da fração areia, dominância da influência marinha apresentando maiores teores de $\mathrm{CaCO}_{3}$ e menor aporte continental com menores valores de Ti/Ca e Fe/Ca.

Ao longo dos últimos 8100 anos cal A.P., os dados sedimentológicos indicaram que condições hidrodinâmicas da região ao largo do rio Parnaíba, entre os estados de Piauí e Maranhão, nordeste brasileiro, foram ficando menos intensas, sendo observado um enfraquecimento da corrente de fundo. Esse possível enfraquecimento estaria associado tanto a uma desintensificação da AMOC e também à um deslocamento da posição média 
geográfica da ZCIT em direção sul.

Considerando que a AMOC responde por parte do transporte observado pela CNB, num contexto global, desintensificação do fluxo de formação de massas d'água profunda das regiões de altas latitudes do Atlântico Norte, indicados tanto por proxies sedimentológicos como geoquímicos, dão suporte às tendências observadas de enfraquecimento da corrente de fundo na região de estudo. Entretanto, esta mesma tendência não corrobora variabilidades de correntes observadas no Atlântico Sul, durante o Holoceno Tardio.

A migração da ZCIT em direção sul propiciaria mudanças nos padrões de circulação atmosféricas com consequente alteração de correntes oceânicas de superfície geradas pelo vento e mudanças nos padrões de precipitação em continente. A configuração da ZCIT numa posição mais ao sul proporcionaria menor cisalhamento dos ventos alísios de sudeste na região de estudo o que causaria uma diminuição de intensidade das correntes geradas pelo vento influenciando também o transporte oceânico. Em continente, o aumento da insolação de verão no hemisfério sul em conjunto com o deslocamento da ZCIT teria fortalecido o SMAS. O fortalecimento do SMAS favoreceria a intensificação da circulação zonal atmosférica que acentuou a relação em anti-fase do regime de precipitação observada para a América do Sul. Ou seja, a migração em direção sul da ZCIT promoveu um aumento gradual de precipitação na região amazônica, centro-sul e sudeste brasileira além dos Andes Centrais concomitantemente a uma diminuição de precipitação na região nordeste brasileiro. Adicionalmente, tendências opostas do aporte de sedimentos de origem continental indicados pelas razões Ti/Ca e Fe/Ca apresentados entre o testemunho GeoB 16204-2 e testemunhos marinhos localizados na margem sudeste brasileira corroboram a relação em anti-fase do regime de precipitação entre nordeste e sudeste.

A reconstituição das propriedades hidrográficas da superfície do mar, TSM e SSM, indicaram que nos últimos 5000 anos as condições de superfície eram aparentemente semelhantes à climatologia atual, apresentando média de TSM um pouco superior à $26^{\circ} \mathrm{C}$ e amplitude de variação inferior a $2^{\circ} \mathrm{C}$ e SSM de 36,5 e amplitude próximo a 2. A diferença média de TSM entre os valores obtidos na reconstituição e climatologia atual 
apresentaram variação de $-1{ }^{\circ} \mathrm{C}$ o que indica adequação do método aplicado além de corroborar compilações de TSM estimados a partir de $\mathrm{Mg} / \mathrm{Ca}$ de foraminíferos planctônicos da região tropical do Atlântico durante o Holoceno. Os dados de SSM reconstituídos indicaram que a região de estudo é influenciada por condições basicamente oceânica onde a pluma do rio Parnaíba teria pouca ou nenhuma relevância. Adicionalmente, a ausência de tendências e pequena variabilidades da SSM e TSM indicam que embora a região de estudo tenha sofrido um incremento das taxas de insolação de verão e sofrido com mudanças de precipitação e circulações atmosféricas, estas mudanças não foram suficiente para causar alterações no balanço dos processos entre oceano e atmosfera.

A comparação de dados de isótopos estáveis de oxigênio $\left(\delta^{18} \mathrm{O}\right)$ e isótopos estáveis de carbono $\left(\delta^{13} \mathrm{C}\right)$ permitiu concluir que os morfotipos não apresentaram diferenças significativas entre os resultados de $\delta^{18} \mathrm{O}$ e $\delta^{13} \mathrm{C}$, para a região de estudo. Tal fato poderia indicar que os morfotipos G. ruber (s.1.) e G. ruber (s.s.), embora possam apresentar preferências de profundidade na coluna d'água conforme a literatura, não demonstram nos sinais isotópicos essa provável diferença de habitat.

Em relação aos resultados obtidos pelos métodos de fluorescência de raio-X e digestão total pode-se concluir que embora a natureza dos métodos sejam um semiquantitativo e outro quantitativo, ao utilizar razões dos elementos maiores como Ti/Ca e $\mathrm{Fe} / \mathrm{Ca}$, ambos apresentaram o mesmo comportamento com tendências e amplitudes semelhantes. Esta constatação entre os resultados aponta que o método de XRF embora semi-quantitativo, apresenta resultados robustos e que seus resultados podem ser amplamente aplicados em estudos paleoceanográficos e paleoclimáticos com a vantagem de ser uma técnica de rápida obtenção de resultados além de não destrutiva. 


\section{Referências}

ALLEY, R. B. et al. Holocene climatic instability: A prominent, widespread event 8200 yr ago. Geology, Geological Society of America, v. 25, n. 6, p. 483-486, 1997.

ANAND, P.; ELDERFIELD, H.; CONTE, M. H. Calibration of mg/ca thermometry in planktonic foraminifera from a sediment trap time series. Paleoceanography, Wiley Online Library, v. 18, n. 2, 2003.

ARZ, H. W. et al. Millennial-scale changes of surface-and deep-water flow in the western tropical atlantic linked to northern hemisphere high-latitude climate during the holocene. Geology, Geological Society of America, v. 29, n. 3, p. 239-242, 2001.

ARZ, H. W.; PÄTZOLD, J.; WEFER, G. Correlated millennial-scale changes in surface hydrography and terrigenous sediment yield inferred from last-glacial marine deposits off northeastern brazil. Quaternary Research, Elsevier, v. 50, n. 2, p. 157-166, 1998.

ARZ, H. W.; PÄTZOLD, J.; WEFER, G. The deglacial history of the western tropical atlantic as inferred from high resolution stable isotope records off northeastern brazil. Earth and Planetary Science Letters, Elsevier, v. 167, n. 1, p. 105-117, 1999.

BARKER, S. et al. Planktonic foraminiferal $\mathrm{mg} / \mathrm{ca}$ as a proxy for past oceanic temperatures: a methodological overview and data compilation for the last glacial maximum. Quaternary Science Reviews, Elsevier, v. 24, n. 7, p. 821-834, 2005.

BARKER, S.; GREAVES, M.; ELDERFIELD, H. A study of cleaning procedures used for foraminiferal mg/ca paleothermometry. Geochemistry, Geophysics, Geosystems, Wiley Online Library, v. 4, n. 9, 2003.

BARRETO, E. A. de S. Reconstituição da pluviosidade da Chapada Diamantina (BA) durante o Quaternário Tardio através de registros isotópicos $(\mathrm{O}$ e C) em estalagmites. Tese (Doutorado) — INSTITUTO DE GEOCIÊNCIAS, 2010.

BARRON, E. J.; SEIDOV, D. Ocean currents of change: Introduction. Geophy- 
sical Monograph Series, American Geophysical Union, v. 126, p. 1-5, 2001.

BÉ, A.; TOLDERLUND, D. Distribution and ecology of living planktonic foraminifera in surface waters of the atlantic and indian oceans. The micropaleontology of oceans, p. 105-149, 1971.

BEHLING, H. et al. Late quaternary vegetational and climate dynamics in northeastern brazil, inferences from marine core geob 3104-1. Quaternary Science Reviews, Elsevier, v. 19, n. 10, p. 981-994, 2000.

BEZERRA, F. H.; BARRETO, A. M.; SUGUIO, K. Holocene sea-level history on the rio grande do norte state coast, brazil. Marine Geology, Elsevier, v. 196, n. 1, p. 73-89, 2003.

BIANCHI, G. et al. Measurement of the sortable silt current speed proxy using the sedigraph 5100 and coulter multisizer iie: Precision and accuracy. Sedimentology, Wiley Online Library, v. 46, n. 6, p. 1001-1014, 1999.

BOND, G. et al. A pervasive millennial-scale cycle in north atlantic holocene and glacial climates. science, American Association for the Advancement of Science, v. 278, n. 5341, p. 1257-1266, 1997.

BROWN, J. et al. Ocean Circulation. First edition. Oxford, U.K: Pergamon Press, 1989.

CADERNO, D. R. H. D. P. Ministério do meio ambiente, secretaria de recursos hídricos. Brasília: MMA, 2006.

CALDAS, L. H. d. O.; STATTEGGER, K.; VITAL, H. Holocene sea-level history: evidence from coastal sediments of the northern rio grande do norte coast, ne brazil. Marine Geology, Elsevier, v. 228, n. 1, p. 39-53, 2006.

CALVERT, S.; PEDERSEN, T. Elemental proxies for palaeoclimatic and palaeoceanographic variability in marine sediments: interpretation and application. Proxies in Late Cenozoic Paleoceanography, edited by: Hillaire-Marcel, C. and de Vernal, A., Elsevier, Amsterdam, Boston, Heidelberg, London, New York, Oxford, Paris, San Diego, San Francisco, Singapore, Sydney, Tokyo, p. 567-644, 2007. 
CASEY, K. et al. The past, present and future of the AVHRR pathfinder SST program. Oceanography from space: Revisited, Springer: New York, USA, 2010.

CASTRO, B. d.; MIRANDA, L. d. Physical oceanography of the western atlantic continental shelf located between $4 \mathrm{n}$ and 34 s. The sea, John Wiley \& Sons: New York, v. 11, n. 1, p. 209-251, 1998.

CHIESSI, C. M. et al. Variability of the brazil current during the late holocene. Palaeogeography, Palaeoclimatology, Palaeoecology, Elsevier, v. 415, p. 28-36, 2014.

CHIESSI, C. M. et al. Signature of the brazil-malvinas confluence (argentine basin) in the isotopic composition of planktonic foraminifera from surface sediments. Marine Micropaleontology, Elsevier, v. 64, n. 1, p. 52-66, 2007.

COOK, K.; HSIEH, J.; HAGOS, S. The africa-south america intercontinental teleconnection. Journal of climate, v. 17, n. 14, p. 2851-2865, 2004.

CRUZ, F. W. et al. Orbitally driven east-west antiphasing of south american precipitation. Nature Geoscience, Nature Publishing Group, v. 2, n. 3, p. 210-214, 2009.

ELDERFIELD, H.; GANSSEN, G. Past temperature and $\delta 180$ of surface ocean waters inferred from foraminiferal $\mathrm{mg} / \mathrm{ca}$ ratios. Nature, Nature Publishing Group, v. 405 , n. 6785 , p. $442-445,2000$.

FOLK, R. L.; WARD, W. C. Brazos river bar: a study in the significance of grain size parameters. Journal of Sedimentary Research, Society for Sedimentary Geology, v. 27 , n. $1,1957$.

GARREAUD, R. D. et al. Present-day south american climate. Palaeogeography, Palaeoclimatology, Palaeoecology, Elsevier, v. 281, n. 3, p. 180-195, 2009.

GODFREY, J. et al. The tropical ocean circulation. International Geophysics, Elsevier, v. 77, p. 215-246, 2001.

GOES, M. et al. Retroflections of the north brazil current during february 2002. Deep Sea Research Part I: Oceanographic Research Papers, Elsevier, v. 52, n. 4, p. 647-667, 2005. 
GUPTA, B. K. S. Introduction to modern foraminifera. In: Modern foraminifera. [S.1.]: Springer, 2003. p. 3-6.

GYLLENCREUTZ, R. et al. Mid-to late-holocene paleoceanographic changes on the southeastern brazilian shelf based on grain size records. The Holocene, Sage Publications, v. 20, n. 6, p. 863-875, 2010.

HALE, W.; PFLAUMANN, U. Sea-surface temperature estimations using a modern analog technique with foraminiferal assemblages from western atlantic quaternary sediments. In: Use of Proxies in Paleoceanography. [S.1.]: Springer, 1999. p. 69-90.

HAUG, G. H. et al. Southward migration of the intertropical convergence zone through the holocene. Science, American Association for the Advancement of Science, v. 293 , n. 5533, p. 1304-1308, 2001.

HEMLEBEN, C.; SPINDLER, M.; ERSON, O. Modern planktonic foraminifera. Springer, Berlin, 1989.

HENDERSON, G. M. New oceanic proxies for paleoclimate. Earth and Planetary Science Letters, Elsevier, v. 203, n. 1, p. 1-13, 2002.

HESSLER, I. et al. Implication of methodological uncertainties for midholocene sea surface temperature reconstructions. Copernicus Publications, 2014.

HIPPLER, D.; EISENHAUER, A.; NÄGLER, T. F. Tropical atlantic sst history inferred from ca isotope thermometry over the last 140ka. Geochimica et cosmochimica acta, Elsevier, v. 70, n. 1, p. 90-100, 2006.

HOOGAKKER, B. A. et al. Dynamics of north atlantic deep water masses during the holocene. Paleoceanography, Wiley Online Library, v. 26, n. 4, 2011.

JOHNS, W. et al. Annual cycle and variability of the north brazil current. Journal of Physical Oceanography, v. 28, n. 1, p. 103-128, 1998.

KISSEL, C. et al. Variations in the strength of the north atlantic bottom water during holocene. Earth and Planetary Science Letters, Elsevier, v. 369, p. 248-259, 2013. 
KUCERA, M. Chapter six planktonic foraminifera as tracers of past oceanic environments. Developments in Marine Geology, Elsevier, v. 1, p. 213-262, 2007.

LACHNIET, M. S. Climatic and environmental controls on speleothem oxygenisotope values. Quaternary Science Reviews, Elsevier, v. 28, n. 5, p. 412-432, 2009.

LEDRU, M.-P. et al. Late-glacial cooling in amazonia inferred from pollen at lagoa do caçó, northern brazil. Quaternary Research, Elsevier, v. 55, n. 1, p. 47-56, 2001.

LEDRU, M.-P. et al. Tropical climates in the game of two hemispheres revealed by abrupt climatic change. Geology, Geological Society of America, v. 30, n. 3, p. 275$278,2002$.

LEDUC, G. et al. Holocene and eemian sea surface temperature trends as revealed by alkenone and $\mathrm{mg} / \mathrm{ca}$ paleothermometry. Quaternary Science Reviews, Elsevier, v. 29, n. 7, p. 989-1004, 2010.

LEVITUS, S. et al. The world ocean database. Data Science Journal, CODATA, v. 12, n. 0, p. WDS229-WDS234, 2013.

LOCARNINI, R. A. et al. World Ocean Atlas 2010, Volume 1: Temperature. Ed: Sydney Levitus. [S.1.]: NOAA Atlas NESDIS 68, U.S. Government Printing Office, Washington, D.C., 2010. 184pp.

LU, R. Impact of atlantic sea surface temperatures on the warmest global surface air temperature of 1998. Journal of Geophysical Research: Atmospheres (1984-2012), Wiley Online Library, v. 110, n. D5, 2005.

MARQUES, M. et al. Water environments: anthropogenic pressures and ecosystem changes in the atlantic drainage basins of brazil. AMBIO: A Journal of the Human Environment, BioOne, v. 33, n. 1, p. 68-77, 2004.

MARTIN, L.; DOMINGUEZ, J. M.; BITTENCOURT, A. C. Fluctuating holocene sea levels in eastern and southeastern brazil: evidence from multiple fossil and geometric indicators. Journal of Coastal Research, JSTOR, p. 101-124, 2003. 
MAYEWSKI, P. A. et al. Holocene climate variability. Quaternary research, Elsevier, v. 62, n. 3, p. 243-255, 2004.

MCCAVE, I. Size sorting during transport and deposition of fine sediments: sortable silt and flow speed. Contourites. Developments in Sedimentology, v. 60, p. 121142, 2008.

MCCAVE, I.; MANIGHETTI, B.; ROBINSON, S. Sortable silt and fine sediment size/composition slicing: parameters for palaeocurrent speed and palaeoceanography. Paleoceanography, Wiley Online Library, v. 10, n. 3, p. 593-610, 1995.

MELO, A.; CAVALCANTI, I. d. A.; SOUZA, P. Zona de convergência intertropical do atlântico. Tempo e clima no Brasil. São Paulo: Oficina do Texto, p. 26-41, 2009.

MMA, . Ministério do meio ambiente, secretaria de recursos hídricos, plano nacional de recursos hídricos. Brasília: MMA, 2003.

MULITZA, S. et al. Temperature: $\delta_{i} \sup _{i} 18_{i} / \sup _{i}$ o relationships of planktonic foraminifera collected from surface waters. Palaeogeography, Palaeoclimatology, Palaeoecology, Elsevier, v. 202, n. 1, p. 143-152, 2003.

MULITZA, S. et al. Planktonic foraminifera as recorders of past surface-water stratification. Geology, Geological Society of America, v. 25, n. 4, p. 335-338, 1997.

NACE, T. E. et al. The role of north brazil current transport in the paleoclimate of the brazilian nordeste margin and paleoceanography of the western tropical atlantic during the late quaternary. Palaeogeography, Palaeoclimatology, Palaeoecology, Elsevier, v. 415, p. 3-13, 2014.

NOBRE, P.; SHUKLA, J. Variations of sea surface temperature, wind stress, and rainfall over the tropical atlantic and south america. Journal of Climate, v. 9, n. 10, p. 2464-2479, 1996.

OPPO, D. W.; MCMANUS, J. F.; CULLEN, J. L. Palaeo-oceanography: Deepwater variability in the holocene epoch. Nature, Nature Publishing Group, v. 422, n. 6929, p. $277-277,2003$. 
PESSENDA, L. et al. Holocene palaeoenvironmental reconstruction in norteastern brazi inferred from polen, charcoal and carboon isotope records. The Holocene, Sage Publications, v. 15, n. 6, p. 812-820, 2005.

PETERSON, L. C.; HAUG, G. H. Variability in the mean latitude of the atlantic intertropical convergence zone as recorded by riverine input of sediments to the cariaco basin (venezuela). Palaeogeography, Palaeoclimatology, Palaeoecology, v. 234, n. 1, p. 97 - 113, 2006. ISSN 0031-0182. Late Quaternary climates of tropical America and adjacent seas. Disponível em: $<$ http://www.sciencedirect.com/science/article/pii/S0031018205006115>.

PEZZI, L.; CAVALCANTI, I. The relative importance of enso and tropical atlantic sea surface temperature anomalies for seasonal precipitation over south america: a numerical study. Climate Dynamics, Springer, v. 17, n. 2-3, p. 205-212, 2001.

PFLAUMANN, U. et al. Simmax: A modern analog technique to deduce atlantic sea surface temperatures from planktonic foraminifera in deep-sea sediments. Paleoceanography, Wiley Online Library, v. 11, n. 1, p. 15-35, 1996.

PIVEL, M. A. G. Reconstrução da hidrografia superficial do Atlântico Sul Ocidental desde o Último Máximo Glacial a partir do estudo de foraminíferos planctônicos. Tese (Doutorado) — Universidade de São Paulo, 2009.

PRADO, L. et al. A mid-holocene climate reconstruction for eastern south america. Climate of the Past, Copernicus GmbH, v. 9, n. 5, p. 2117-2133, 2013.

RAVELO, A. C.; HILLAIRE-MARCEL, C. Chapter eighteen the use of oxygen and carbon isotopes of foraminifera in paleoceanography. Developments in Marine Geology, Elsevier, v. 1, p. 735-764, 2007.

REIMER, P. J. et al. Intcal13 and marine13 radiocarbon age calibration curves 0-50,000 years cal bp. Radiocarbon, v. 55, n. 4, p. 1869-1887, 2013.

RICHTER, T. O. et al. The avaatech xrf core scanner: technical description and applications to ne atlantic sediments. Geological Society, London, Special Publications, Geological Society of London, v. 267, n. 1, p. 39-50, 2006. 
ROHLING, E. J.; COOKE, S. Stable oxygen and carbon isotopes in foraminiferal carbonate shells. In: Modern foraminifera. [S.1.]: Springer, 2003. p. 239-258.

RUDDIMAN, W. F. Earth's Climate: past and future. [S.1.]: Macmillan, 2001.

SCHEFUSS, E. et al. African vegetation controlled by tropical sea surface temperatures in the mid-pleistocene period. Nature, Nature Publishing Group, v. 422, n. 6930, p. 418-421, 2003.

SCHLITZER, R. Ocean data view, h ttp. www.odv.de, 2014.

SCHNEIDER, R. R.; SCHULZ, H. D.; HENSEN, C. Marine carbonates: their formation and destruction. In: Marine geochemistry. [S.1.]: Springer, 2006. p. 311-337.

SCHNEIDER, T.; BISCHOFF, T.; HAUG, G. H. Migrations and dynamics of the intertropical convergence zone. Nature, Nature Publishing Group, v. 513, n. 7516, p. 45-53, 2014.

SCHOTT, F. A. et al. The shallow and deep western boundary circulation of the south atlantic at 5-11 s. Journal of Physical Oceanography, v. 35, n. 11, p. 2031-2053, 2005.

SCHOTT, F. A.; FISCHER, J.; STRAMMA, L. Transports and pathways of the upper-layer circulation in the western tropical atlantic. Journal of Physical Oceanography, v. 28, n. 10, p. 1904-1928, 1998.

SILVA, A. C. d.; ARAÚJO, M.; BOURLÈS, B. Variação sazonal da estrutura de massas de água na plataforma continental do amazonas e área oceânica adjacente. Revista Brasileira de Geofísica, SciELO Brasil, v. 23, n. 2, p. 145-157, 2005.

SILVA, A. G. Aquino da et al. The influence of climatic variations on river delta hydrodynamics and morphodynamics in the parnaíba delta, brazil. Journal of Coastal Research, The Coastal Education and Research Foundation, 2015.

SILVEIRA, I. C. da; MIRANDA, L. B.; BROWN, W. S. On the origins of the north brazil current. Journal of Geophysical Research: Oceans (1978-2012), Wiley Online Library, v. 99, n. C11, p. 22501-22512, 1994. 
STEINKE, S. et al. Mg/ca ratios of two globigerinoides ruber (white) morphotypes: implications for reconstructing past tropical/subtropical surface water conditions. Geochemistry, Geophysics, Geosystems, Wiley Online Library, v. 6, n. 11, 2005.

STRAMMA, L.; FISCHER, J.; REPPIN, J. The north brazil undercurrent. Deep Sea Research Part I: Oceanographic Research Papers, Elsevier, v. 42, n. 5, p. 773-795, 1995.

STRAMMA, L.; SCHOTT, F. The mean flow field of the tropical atlantic ocean. Deep Sea Research Part II: Topical Studies in Oceanography, Elsevier, v. 46, n. 1, p. 279-303, 1999.

STUIVER, M.; REIMER, P. J.; REIMER, R. CALIB 5.0. 2005.

SUGuiO, K.; MARTIN, L.; BITTENCOURT, A. C. d. S. P. Flutuações do nível relativo do mar durante o quaternário superior ao longo do litoral brasileiro e suas implicações na sedimentação costeira. 1985.

TALLEY, L. D. et al. Descriptive physical oceanography: an introduction. [S.1.]: Academic press, 2011.

TESSLER, M. G.; MAHIQUES, M. d. Processos oceânicos ea fisiografia dos fundos marinhos. Decifrando a Terra. São Paulo: Oficina de Textos, p. 262-284, 2000.

TOLEDO, F. A.; COSTA, K. B.; PIVEL, M. A. Salinity changes in the western tropical south atlantic during the last 30 kyr. Global and Planetary Change, Elsevier, v. 57, n. 3, p. 383-395, 2007.

WAELBROECK, C. et al. A global compilation of late holocene planktonic foraminiferal $\delta_{i} \sup _{i} 18_{i} / \sup _{i}$ o: relationship between surface water temperature and $\delta_{i}$

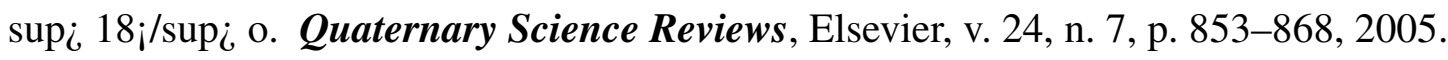

WALKER, M. et al. Formal subdivision of the holocene series/epoch: a discussion paper by a working group of intimate (integration of ice-core, marine and terrestrial records) and the subcommission on quaternary stratigraphy (international commission on stratigraphy). Journal of Quaternary Science, Wiley Online Library, v. 27, n. 7, p. 649_ 659, 2012. 
WANG, L. Isotopic signals in two morphotypes of $i_{i}$ globigerinoides ruber; $_{i} / i_{\mathcal{C}}$ (white) from the south china sea: implications for monsoon climate change during the last glacial cycle. Palaeogeography, Palaeoclimatology, Palaeoecology, Elsevier, v. 161, n. 3, p. 381-394, 2000.

WEFER, G. et al. Clues to ocean history: a brief overview of proxies. Use of proxies in paleoceanography. Examples from the South Atlantic, p. 1-68, 1999.

WELDEAB, S.; SCHNEIDER, R.; KÖLLING, M. Deglacial sea surface temperature and salinity increase in the western tropical atlantic in synchrony with high latitude climate instabilities. Earth and Planetary Science Letters, Elsevier, v. 241, n. 3, p. 699706, 2006.

WELTJE, G. J.; TJALLINGII, R. Calibration of xrf core scanners for quantitative geochemical logging of sediment cores: Theory and application. Earth and Planetary Science Letters, Elsevier, v. 274, n. 3, p. 423-438, 2008.

ZEMBRUSCKI, S. Geomorfologia da plataforma continental norte brasileira. Geomorfologia da margem continental brasileira e áreas oceânicas adjacentes. REMAC Project Series, Rio de Janeiro, Petrobras, v. 7, p. 25-88, 1979.

ZHANG, D. et al. Multidecadal variability of the north brazil current and its connection to the atlantic meridional overturning circulation. Journal of Geophysical Research: Oceans (1978-2012), Wiley Online Library, v. 116, n. C4, 2011. 